INSTITUTO DE PESQUISAS ENERGÉTICAS E NUCLEARES

Autarquia Associada à Universidade de São Paulo

\title{
COMPARAÇÃO DAS PROPRIEDADES DAS SUPERFÍCIES DA POLIAMIDA 6.6 TRATADA POR PLASMA E POR RADIAÇÃO IONIZANTE
}

ROSA MARIA DA SILVA IRINEU

Dissertação apresentada como parte dos requisitos para obtenção do Grau de Mestre em Ciências na Área de Tecnologia Nuclear - Aplicações

Orientador :

Prof. Dr. Leonardo Gondim de Andrade e Silva

SÃO PAULO 
A Deus,

Que sempre esteve presente na minha vida.

A minha filha Alice, Ao meu sobrinho Vinícius e Ao meu esposo Genésio,

Que sempre estiveram Ao meu lado.

(Dedico) 


\section{AGRADECIMENTOS}

Ao Prof. Dr. Leonardo Gondim de Andrade e Silva pela orientação deste trabalho.

À Prof ${ }^{a}$ Dra. Márcia de Almeida Rizzutto pela colaboração com este trabalho.

À equipe do Laboratório de Análise de Materiais por Feixes Iônicos do Instituto de Física da USP pelo incentivo e autorização na utilização do laboratório para as análises de PIXE, RBS e Ângulo de Contato.

Ao Prof. Dr. Reginaldo Muccillo pelas análises de AFM.

Aos engenheiros Carlos Gaia da Silveira e Elizabeth J. R. Somessari pela irradiação das amostras.

Ao Dr. José Eduado Manzoli pela ajuda na irradiação das amostras utilizando o dispositivo de enxertia.

À Sabó Ind. e Com. de Autopeças Ltda. pela oportunidade de realizar este trabalho.

Ao IPEN - CNEN/SP pela oportunidade de realizar este trabalho.

À minha família pelo apoio e dedicação constante.

À todos que contribuíram direta ou indiretamente para a realização deste trabalho. 


\title{
COMPARAÇÃO DAS PROPRIEDADES DAS SUPERFÍCIES DA POLIAMIDA 6.6 TRATADA POR PLASMA E POR RADIAÇÃO IONIZANTE
}

\author{
Rosa Maria da Silva Irineu
}

\author{
RESUMO
}

Este trabalho tem por objetivo a comparação das propriedades da superfície da poliamida 6.6 tratada por plasma e por radiação ionizante, assim como determinar qual a melhor técnica e condição para ativação da superfície, visando a adesão da mesma e borracha poliacrílica utilizada na fabricação de retentores automotivos. O tratamento da poliamida 6.6 por plasma foi realizado utilizando um equipamento "Electronic DIENER Plasma - Surface- Technology LFG40", com gás nitrogênio à pressão de $1,40 \mathrm{~kg} / \mathrm{cm}^{2}$. As amostras de poliamida 6.6 também foram tratadas por radiação ionizante, à pressão atmosférica e em vácuo, utilizando um acelerador industrial de elétrons, Dynamitron JOB 188, com dose de radiação de 5, 10, 20, 40, 50, 100, 200, 300, 400 e 500kGy com taxa de dose de 11,22 kGy/s para todas as doses e taxa de 11,22 kGy/s e 22,38 kGy/s para a dose de 20kGy. Após os processos de modificação da superfície da poliamida 6.6, parte das amostras não tratadas, tratadas por plasma e por radiação ionizante foram incorporadas à borracha poliacrílica, e outra parte foi destinada a caracterização da superfície utilizando as técnicas de MEV/EDS, FT-IR, PIXE/RBS, AFM e ângulo de contato. As amostras não tratadas e as amostras irradiadas não aderiram à borracha poliacrílica. As amostras tratadas por plasma aderiram à borracha poliacrílica com eficiência e apresentaram diferenças de rugosidade, nas análises de MEV e AFM, e aumento no ângulo de contato quando comparado com as amostras não tratadas. As amostras irradiadas não apresentaram diferenças significativas de propriedades nas análises utilizadas neste trabalho, quando comparadas com as amostras não tratadas. A radiação ionizante não foi eficiente na modificação da superfície da poliamida 6.6 para aderência à borracha poliacrílica. 


\title{
COMPARISON OF THE PROPERTIES POLYAMIDE 6.6 SURFACES TREATED BY PLASMA AND BY IONIZING RADIATION
}

\author{
Rosa Maria da Silva Ireneu
}

\begin{abstract}
This study aims to compare the surface properties of polyamide 6.6 plasma treatment and ionizing radiation, as well as determine the best technique and condition of the surface activation, adhesion of the same order and polyacrylic rubber used in manufacturing of automotive retainers. Treatment of polyamide 6.6 plasma was performed using an equipment "Electronic Diener - Plasma - Surface-Technology LFG40" with nitrogen gas at a pressure of $1.40 \mathrm{~kg} / \mathrm{cm}^{2}$. Samples of polyamide 6.6 were also treated with ionizing radiation, atmospheric pressure and in vacuum, using an industrial electron accelerator, Dynamitron JOB 188 with radiation dose of 5, 10, 20, 40, 50, 100, 200, 300, 400 and $500 \mathrm{kGy}$ with a dose rate of $11.22 \mathrm{kGy} / \mathrm{s}$ for all doses and rate of $11.22 \mathrm{kGy} / \mathrm{s}$ and $22.38 \mathrm{kGy} / \mathrm{s}$ for a dose of $20 \mathrm{kGy}$. After the processes of surface modification of polyamide 6.6, part of the untreated samples, treated by plasma and by ionizing radiation were incorporated into the polyacrylic rubber, and another part was designed to characterize the surface using the techniques of SEM / EDS, FT- IR, PIXE / RBS, AFM and contact angle. Untreated samples and the irradiated samples did not join the polyacrylic rubber. The samples treated by plasma joined the polyacrylic rubber efficiently and showed differences in roughness in SEM and AFM, and an increase in contact angle when compared with untreated samples. The irradiated samples showed no significant differences in the analysis of properties used in this study when compared with untreated samples. Ionizing radiation was not effective in surface modification of polyamide 6.6 for adherence with polyacrylic rubber.
\end{abstract}




\section{SUMARIO}

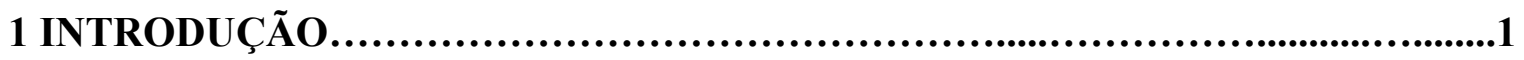

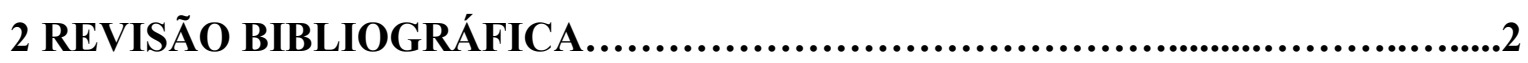

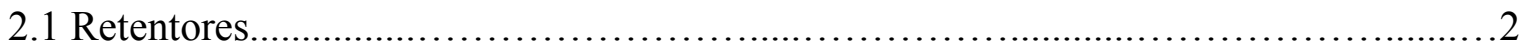

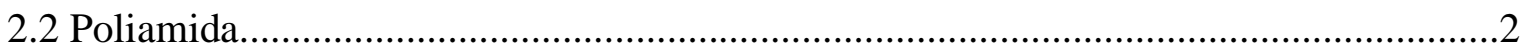

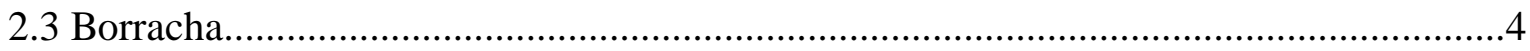

2.4 Tratamentos de superfícies..................................................................................

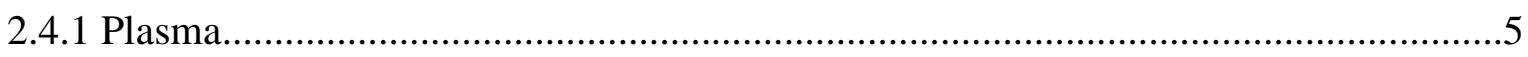

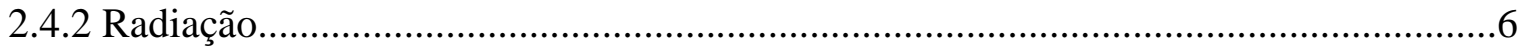

2.4.2.1 Acelerador de elétrons................................................................................

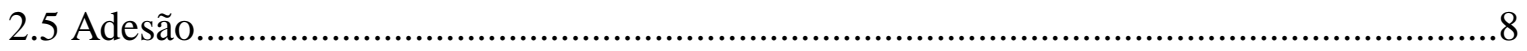

2.5.1 Procedimento de análise.................................................................................

2.6 Técnicas de caracterização de superfícies....................................................................

2.6.1 Microscopia eletrônica de varredura e espectroscopia de dispersão de

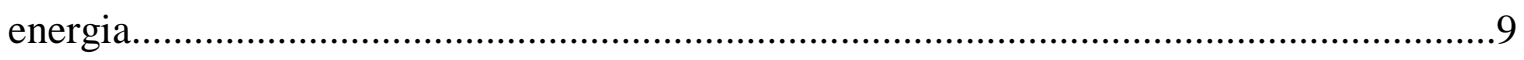

2.6.1.1 Princípio de funcionamento...........................................................................11

2.7 Espectroscopia na região do infravermelho por transformada de Fourier (FT-IR).......13

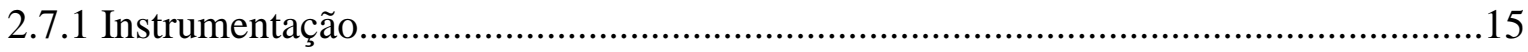

2.7.2 Interpretação dos espectros....................................................................................16

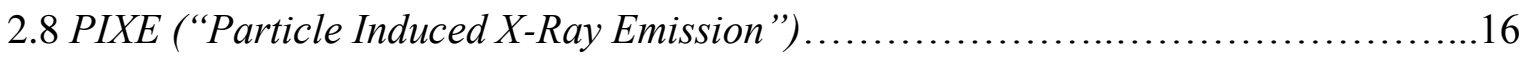

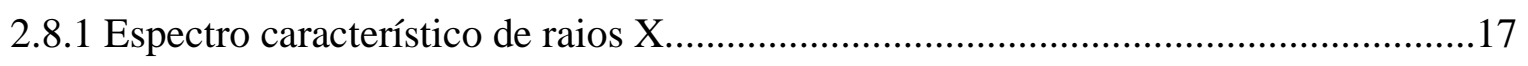

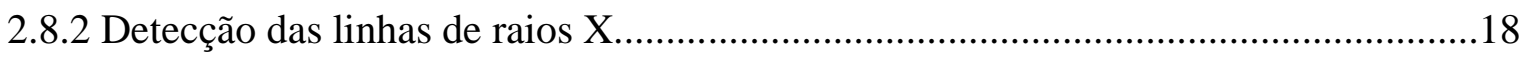

2.9 RBS ("Rutherford Backscattering Spectrometry") .....................................................18

2.9.1 Interpretação e processamento de um espectro de RBS...............................................19

2.9.2 Altura de picos e patamares..................................................................................20

2.10 MFA (microscopia de força atômica)...............................................................................20

2.11 Ângulo de contato.........................................................................................................21

3 OBJETIVO.........................................................................................................................24

4 MATERIAIS E MÉTODOS........................................................................................25

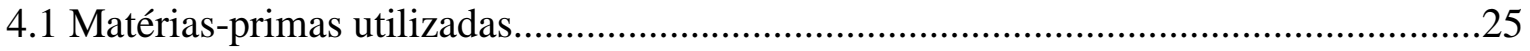

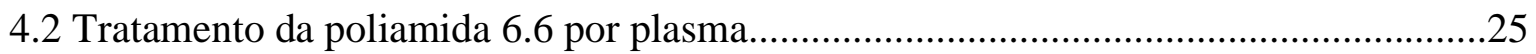


4.3 Tratamento da poliamida 6.6 por radiação ionizante. .27

4.4 Incorporação da poliamida 6.6 à borracha poliacrílica. .29

4.5 Ensaios de adesão da poliamida 6.6 com a borracha poliacrílica...................................31

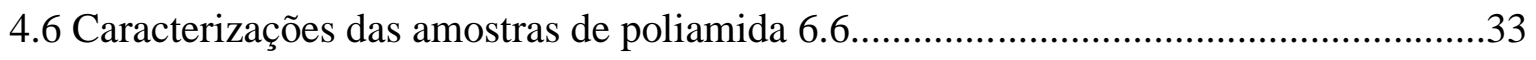

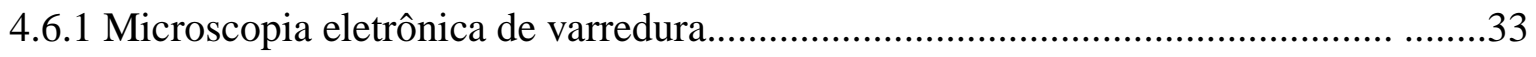

4.6.2 Espectroscopia na região do infravermelho por transformada de Fourier.(FTIR)...... .34

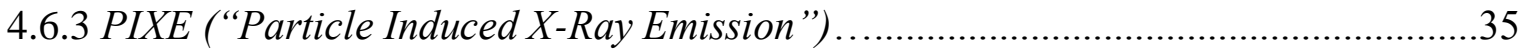

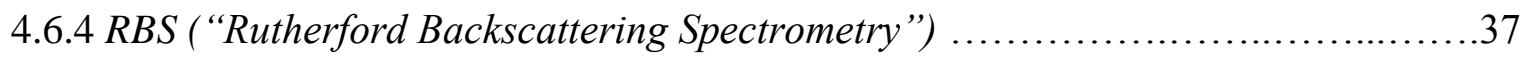

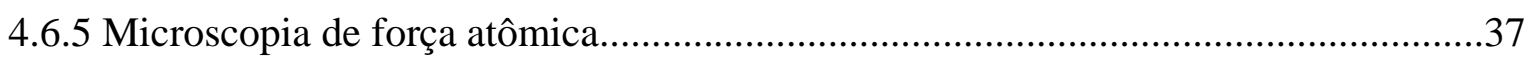

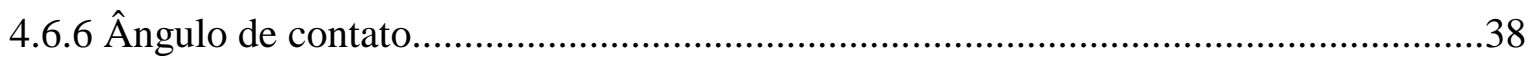

5 DISCUSSÃO DOS RESULTADOS.....................................................................39

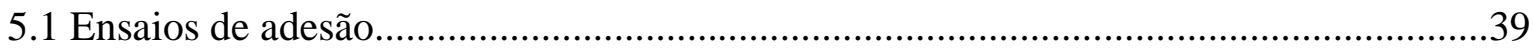

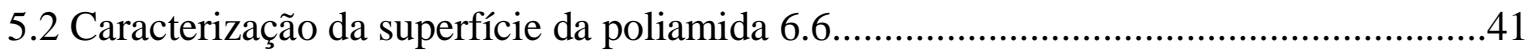

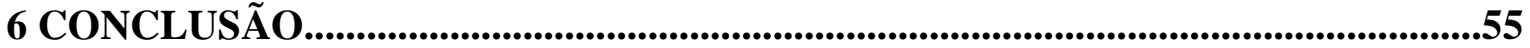

REFERÊNCIAS BIBLIOGRÁFICAS...........................................................................57 


\section{LISTA DE TABELAS}

TABELA 1 Resultados dos ensaios de adesão $(\mathrm{N} / \mathrm{mm})$ entre a poliamida 6.6 e a borracha poliacrílica para amostras sem tratamento e após 8 horas do tratamento. .39

TABELA 2 Resultados dos ensaios de adesão $(\mathrm{N} / \mathrm{mm})$ entre a poliamida 6.6 e a borracha poliacrílica para amostras sem tratamento e após 72 e 168 horas do tratamento. .40

TABELA 3 Resultados dos ensaios de adesão $(\mathrm{N} / \mathrm{mm})$ entre a poliamida 6.6 e a borracha poliacrílica para amostras sem tratamento e após 504 e 1008 horas do tratamento. . .40

TABELA 4 Análise de composição da amostra de PA 6.6 sem tratamento .42

TABELA 5 Análise de composição da amostra de PA 6.6 após tratamento por plasma. 


\section{LISTA DE FIGURAS}

FIGURA 1 Desenho esquemático da coluna de alto vácuo do MEV

FIGURA 2 Esquema representativo do volume da interação dos elétrons com a amostra

FIGURA 3 Esquema representativo da emissão de raios $X$ induzidos por partículas .17

FIGURA 4 Esquema representativo da espectrometria por retroespalhamento de Rutherford .18

FIGURA 5 Desenho esquemático da interação entre uma superfície e um determinado líquido.

FIGURA 6 Fotografia do equipamento de plasma "Electronic DIENER - Plasma Surface- Technology LFG40". .26

FIGURA 7 Fotografia das amostras de PA 6.6 incorporadas à borracha poliacrílica, após tratamento por plasma.

FIGURA 8 Fotografia do acelerador industrial de elétrons Dynamitron II, modelo DC 1500 JOB 188.

FIGURA 9 Fotografia das amostras de PA 6.6 irradiadas e incorporadas à borracha poliacríllica.

FIGURA 10 Fotografia da prensa hidráulica para a incorporação da poliamida 6.6 à borracha poliacríllica.

FIGURA 11 Fotografia do molde utilizado para a incorporação da poliamida 6.6 à borracha poliacrílica.

FIGURA 12 Fotografia das amostras de PA 6.6 incorporadas a borracha polliacrílica

FIGURA 13 Fotografia da máquina universal de ensaio Emic dl2000, com célula de carga de carga de 50kgf..

FIGURA 14 Fotografia do instrumento utilizado para realizar o ensaio de aderência da PA 6.6/borracha poliacrílica

FIGURA 15 Microscópio Eletrônico de Varredura modelo 6460LV da marca Jeol. 
FIGURA 16 Fotografia do espectrômetro Perkin Elmer, modelo Spectrun One, acoplado com dispositivo Universal ATR ("Sampling Acessory”).

FIGURA 17 Fotografia do acelerador do tipo Pelletron-Tandem com stripper gasoso

$\left(\mathrm{N}_{2}\right)$, modelo 5SDH, construído pela NEC ("National Eletrostatic Corporation")..... .36

FIGURA 18 Fotografia da estação de análises PIXE com dois detectores de $\mathrm{Si}(\mathrm{Li})$ .36

FIGURA 19 Fotografia da câmara multiuso para análises RBS. .37

FIGURA 20 - Fotografia do equipamento de microscopia de força atômica... .38

FIGURA 21 - Fotografia do equipamento de medição de ângulo de contato. 38

FIGURA 22 Imagem topográfica da amostra de PA 6.6 sem tratamento, magnitude 1000X e $30 \mathrm{kV}$.

FIGURA 23 Imagem topográfica da amostra de PA 6.6 após tratamento por plasma, magnitude $1000 \mathrm{X}$ e $10 \mathrm{kV}$

FIGURA 24 Curva de composição da amostra de PA 6.6 sem tratamento. .43

FIGURA 25 Curva de composição da amostra de PA 6.6 após tratamento por plasma.

FIGURA 26 Espectro de transmissão de IR de uma amostra não tratada e uma tratada por plasma na região de 500 a $4000 \mathrm{~cm}^{-1}$.

FIGURA 27 Espectro de transmissão de IR de uma amostra não tratada e uma tratada por plasma na região de 4000 a $8000 \mathrm{~cm}^{-1}$

FIGURA 28 Curvas dos espectros de infravermelho ATR das amostras de PA 6.6 não tratada e tratada por plasma

FIGURA 29 Curvas dos espectros infravermelho ATR das amostras de PA 6.6 não tratada e tratadas por irradiação com dose de 5, 10 e 20kGy, em que TX1 corresponde a taxa de dose de 11,22 kGy/s e TX2 corresponde a taxa de dose de 22,38 kGy/s. .48

FIGURA 30 Curva de composição da amostra de PA 6.6 tratada por plasma utilizando o método PIXE

FIGURA 31 Curva de composição da amostra de PA 6.6 sem tratamento utilizando o método PIXE..

FIGURA 32 Curva de RBS de comparação da amostra PA 6.6 tratada por plasma e sem tratamento.

FIGURA 33 Imagem de microscopia de força atômica da amostra de PA 6.6 sem tratamento. 
FIGURA 34 Imagem de microscopia de força atômica da amostra de PA 6.6, após tratamento por plasma.

FIGURA 35 Imagem de microscopia de força atômica da amostra de PA 6.6, após irradiação com dose de 10kGy e taxa de dose de 11,22 kGy/s. .52

FIGURA 36 Imagem de microscopia de força atômica da amostra de PA 6.6, após irradiação com dose de 20kGy e taxa de dose de 11,22 kGy/s. .52 FIGURA 37 Imagem de microscopia de força atômica da amostra de PA 6.6, após irradiação com dose de 40kGy e taxa de dose de 11,22 kGy/s........................................53 FIGURA 38 Imagem de microscopia de força atômica da amostra de PA 6.6, após irradiação com dose de 20kGy e taxa de dose de 22,38 kGy/s........................................53

FIGURA 39 Medida de ângulo de contato da amostra de PA 6.6 não tratada...................54 FIGURA 40 Medida de ângulo de contato da amostra de PA6.6, após tratamento por plasma...

FIGURA 41 Medida de ângulo de contato da amostra de PA 6.6, após tratamento por irradiação com dose de 40kGy e taxa de dose de 11,22 kGy/s. .54 


\section{LISTA DE ABREVIATURAS}

ACM - Acrilic Monomer

MEG - Metanol etanol e gasolina

SBR - Borracha estireno-butadieno

EPDM - Borracha etileno-propileno-monômero diênico

NBR - Borracha nitrílica-butadieno

SAE - SOCIETY OF AUTOMOTIVE ENGINEERS

ASTM - AMERICAN SOCIETY FOR TESTING AND MATERIALS

EDS - Espectroscopia por dispersão de energia

WDS - Espectrômetro de dispersão de comprimento

FT-IR - Infravermelho por transformada de Fourrier

PIXE - Particle Induced X-Ray Emission

RBS - Rutherford Backscattering Spectrometry

G - Ganho

AFM - Atomic Force Microscopy

SFM - Scanning Force Microscopy

$\mathrm{kHz}$ - Quilohertz

$\mathrm{MHz}$ - Megahertz

$\mathrm{N}$ - Newton

$\mathrm{g} / \mathrm{cm}^{3}$ - Grama por centímetro cúbico

${ }^{\circ} \mathrm{C}$ - Grau Celsius

$\mathrm{MPa}$ - MegaPascal

$\mathrm{kg} / \mathrm{cm}^{2}$ - Quilograma por centímetro quadrado

$\mathrm{MeV}$ - Megaeletro Volt

$\mathrm{mA}$ - Miliampere

kGy - Quilogray

kGy/s - Quiloagray por segundo

kgf - Quilograma força

$\mathrm{N} / \mathrm{mm}$ - Newton por milímetro

$\mathrm{kV}$ - QuiloVolt

cm - Centímetro 
NEC - National Eletrostatic Corporation

GFAA - Grupo de Física Aplicada com Aceleradores

LAMFI - Laboratório de Análise de Materiais por Feixes Iônicos

IFUSP - Instituto de Física da Universidade de São Paulo

mm - Milímetro

$\mathrm{Si} / \mathrm{Li}$ - Silício/lítio

V - Volt

$\mu \mathrm{m}$ - Micrometro

ATR - Refletância total atenuada

PA 6.6 - Poliamida 6.6

$\mathrm{Fe}-$ Ferro

K - Potássio

$\mathrm{S}$ - Enxofre

P - Fósforo

$\mathrm{Na}$ - Sódio 


\section{INTRODUÇÃO}

Os retentores são peças cuja função principal é reter óleos, graxas e outros tipos de fluidos, que devem ser contidos no interior de uma máquina, evitando também a entrada de impurezas do meio externo, tais como terra, areia, poeira entre outras. São constituídos por uma carcaça metálica ou plástica, revestida com borracha, estando os lábios de vedação sujeito à pressão de uma mola.

As poliamidas são polímeros que podem ser encontrados na natureza, como a lã ou a seda, e também podem ser sintéticas, como o náilon ou o "kevlar". Caracterizam-se por possuírem alta resistência à tração, elasticidade, tenacidade e resistência à abrasão. Estas propriedades mecânicas são mantidas mesmo a temperaturas altas e, por isto, as poliamidas podem ser utilizadas em diversos segmentos automotivos, como por exemplo, carcaça de retentores. Devido à energia baixa e ligações de coesão fraca, as superfícies dos polímeros possuem propriedades baixas de molhabilidade e adesão com outros materiais.

Os tratamentos superficiais são capazes de modificar a superfície dos polímeros, alterando grupos químicos e, até mesmo, a topografia do material, melhorando a adesão a outras superfícies. Neste trabalho, as técnicas utilizadas para modificar a superfície da poliamida foram plasma e radiação ionizante.

Os corpos de prova utilizados foram anéis de poliamida 6.6 revestidos com borracha poliacrílica.

A importância deste trabalho está no estudo da modificação das superfícies da poliamida 6.6 por meio do tratamento por plasma e pelo processo de radiação ionizante para substituir os processos convencionais, os quais utilizam adesivos, solventes entre outras substâncias agressivas ao meio ambiente, para aderência com a borracha poliacrílica. 


\section{REVISÃO BIBLIOGRÁFICA}

\subsection{Retentores}

Os retentores são peças cuja função principal é reter óleos, graxas e outros tipos de fluidos, que devem ser contidos no interior de uma máquina, evitando também a entrada de impurezas do meio externo, tais como terra, areia, poeira entre outras (RUBBERTEC, 2008).

Os retentores são utilizados nos mais diversos segmentos do dia-a-dia em carros, caminhões, ônibus, motocicletas, máquinas agrícolas, máquinas industriais, entre outros. Também chamados de vedadores de óleo, destinam-se a assegurar vedação entre um eixo rotativo e um elemento estacionário, trabalhando sob pressão interna baixa. São constituídos por uma carcaça metálica ou plástica, revestida com borracha, estando os lábios de vedação sujeito à pressão de uma mola (ORION S.A., 2008).

A partir da velocidade periférica, rotação e diâmetro do eixo a ser vedado, tipo de fluido e temperatura de trabalho define-se o material para o lábil de vedação (borracha poliacrílica, fluoroelastômero, entre outros). O bom desempenho do retentor está diretamente relacionado à flexibilidade da borracha e a robustez do seu perfil (ORION S.A., 2008).

\subsection{Poliamida}

As poliamidas são polímeros que podem ser encontrados na natureza, como a lã ou a seda, e também podem ser sintéticos, como o náilon ou o "kevlar". Caracterizam-se por possuírem resistência à tração alta, elasticidade, tenacidade e resistência à abrasão. Estas propriedades mecânicas são mantidas mesmo a temperaturas altas e, por isto, as poliamidas podem ser utilizadas em diversos segmentos automobilísticos (WIEBECK, HARADA, 2005). 
Os componentes estruturais e de acabamento dos automóveis há muito tempo já fazem parte da lista de aplicações da poliamida, mas hoje ela também constitui material de referência para componentes de motor. A resistência a temperaturas elevadas, resistência química a óleos, graxas e ácidos e propriedades mecânicas boas fazem da poliamida a escolha ideal em aplicações como carcaças de retentores em motores, equipamentos periféricos e sistemas de ventilação, aquecimento e ar condicionado. Ao substituir materiais tradicionais como o alumínio e o aço, a poliamida contribui para reduzir o peso do veículo, diminuindo com isto o consumo de combustível e a poluição do ar. Além disso, a flexibilidade de processamento permite aos fabricantes integrar várias peças complexas numa só, resultando em soluções de sistemas mais econômicas. O segmento do mercado de produção de peças e componentes de automóveis com a utilização da poliamida vem crescendo em média 10\% ao ano (RHODIA, 2000).

Também a poliamida reforçada com fibras de vidro com comprimento correto tem alcançado resultados significativos na substituição, com vantagem, das peças metálicas. O composto apresenta ótima resistência à tensão, ao impacto e à hidrólise, sendo atualmente também utilizada na indústria automotiva em peças sob o capô, em especial as carcaças de radiadores, pois oferecem resistência ao envelhecimento térmico em soluções de etanol, metanol e gasolina (MEG), além de melhores propriedades mecânicas (FERRO, 2001).

Em razão da energia baixa e ligações de coesão fracas, as superfícies dos polímeros possuem propriedades de molhabilidade e adesão baixas com outros materiais. Os tratamentos superficiais são capazes de modificar a superfície dos polímeros, alterando grupos químicos e, até mesmo, a topografia do material. Os polímeros podem ser modificados de diferentes formas, dependendo do tratamento utilizado, como retiradas de ligações fracas de coesão ou contaminantes presentes, introdução de novas ou aumento de funções químicas, aumento de rugosidade da superfície, entre outras. Todos estes parâmetros podem contribuir para promover a adesão da superfície. Entretanto, a eficiência do tratamento depende da natureza do substrato e do tipo de tratamento. Os métodos utilizados para tratar superfície de polímeros são vários. Eles podem ser químico, mecânico, térmico, fotoquímico e plasma (CANAL et al., 2004).

Os processos de aditivação aumentam consideravelmente o custo da poliamida 6.6. Alguns trabalhos já foram realizados pelo grupo de pesquisa utilizando radiação 
ionizante para melhorar as propriedades mecânicas da poliamida 6 e 6.6 (MOURA et al., 2002; EVORA, ANDRADE E SILVA, 2001; FERRO, SILVA, 2004). Em relação a irradiação de polímeros pode-se dizer que muitas vezes eles são irradiados para melhorar suas propriedades físico-químicas. A radiação ionizante, ao interagir com polímeros, transfere energia aos átomos da cadeia polimérica, provocando modificações que podem ser permanentes na sua estrutura físico-química (DJALMA, 2007). Tais modificações podem resultar na reticulação ou na cisão das cadeias poliméricas, que são processos simultâneos e concorrentes, e cuja preponderância de um ou de outro depende principalmente da dose de radiação com que foi tratado o material, do tipo do polímero e condições de irradiação (EVORA et al., 2002a, 2002b).

Durante as últimas décadas vem crescendo a utilização industrial da radiação ionizante para reticular termoplásticos com bons resultados para vários setores. Estes plásticos modificados por radiação ionizante não competem somente com os não modificados, mas também com os não termoplásticos, os termofixos, onde o fator custo da matéria-prima deixa de ser decisivo dando lugar à viabilidade econômica do processo como um todo, desde o custo de produção do polímero, incluindo qualidade, até armazenamento e transporte.

\subsection{Borracha}

A borracha pode ser natural ou sintética. As borrachas tradicionais são materiais poliméricos que exibem, após a vulcanização, elasticidade em longa faixa de deformação à temperatura ambiente. As borrachas comuns são borracha natural (poli-cis-isopreno), SBR (estireno-butadieno), EPDM (etileno-propileno-monômero diênico), NBR (nitrílicabutadieno) e policloropreno. As borrachas especiais são elastômeros fluorados, elastômeros de silicone, elastômeros de poliuretanos, elastômeros poliacrilatos (GORNI, 2003).

A vulcanização da borracha é o processo químico de maior importância para as borrachas tradicionais, melhorando a resistência mecânica e reduzindo a sua sensibilidade às variações de temperatura. O principal agente de vulcanização é o enxofre e, a determinação da formulação do composto de borracha é iniciada pela adequada seleção das 
matérias-primas, balanceamento correto do composto e o uso de agente de proteção (antioxidantes) que evita a degradação da borracha (GORNI, 2003).

ACM, Acrilic Monomer, é uma borracha poliacrílica utilizada em produtos que exijam excelente resistência ao calor, especialmente vedações, gaxetas e mangueiras automotivas. Compostos de poliacrilatos podem ser formulados para aplicações em faixas de temperaturas de $-40^{\circ} \mathrm{C}$ a $190^{\circ} \mathrm{C}$ e são classificados pela norma SAE J 200 e ASTM D 2000 nas seguintes categorias $\mathrm{DH}\left(150^{\circ} \mathrm{C}\right)$ e $\mathrm{EH}\left(175^{\circ} \mathrm{C}\right)$. As borrachas poliacrílicas atendem as necessidades de enorme resistência ao calor e poder de vedação, hoje necessários para aplicações em motores de alta rotação (NORMAS SAE J 200, 2005 e ASTM D 2000, 2006).

\subsection{Tratamentos de superfícies}

\subsubsection{Plasma}

Plasma é um gás ionizado. Isso quer dizer que átomos neutros de um gás se dividem ou se transformam em íons. Para isso é necessário introduzir energia por todo o gás. Esta energia se alimenta com a ajuda de campo elétrico, utilizando fonte de corrente contínua ou alternada. A aplicação de plasma é um tratamento no qual o gás é usado sob pressão para remover sujeira ou alterar a estrutura da superfície sem agredir o meio ambiente. O objetivo do tratamento é modificar a tensão superficial do substrato para aderir às tintas, borrachas ou plásticos. É feito por bombardeamento de elétrons na superfície a ser tratada. A durabilidade do tratamento varia entre os diversos tipos de polímeros podendo, em alguns casos, se manter por semanas enquanto que em outros, desaparece em alguns dias ou até horas. Isso acontece porque pode ocorrer recombinações dos grupos ativos superficiais ou migração desses grupos para o interior do material (INAGAKI et al., 1997; INAGAKI et al., 1999).

O efeito do tratamento por plasma sobre um dado material é determinado pelo tipo de reação química entre a superfície e as espécies reativas presentes no plasma. As mudanças que ocorrem na superfície do substrato dependem da composição química do polímero e dos gases usados (D’AGOSTINO, 1999). No entanto, para qualquer composição de gás, três processos superficiais competitivos ocorrem simultaneamente, 
alterando a superfície do plástico, sendo que a proporção de cada um deles depende de variáveis de processo. Esses processos são:

1) Ablação: é o bombardeamento por radicais livres, elétrons e íons, por radiação quebrando ligações covalentes do polímero gerando, portanto, polímero com menor massa mola.

2) Reticulação: é empregado gás inerte (hélio ou argônio) ocorrendo quebra das ligações do polímero, formando ligações cruzadas ou ligações dupla ou tripla, ou ainda, reagindo com subproduto e voltando ao estado inicial do plasma.

3) Ativação: ocorre quando grupos funcionais da superfíicie do polímero são substituídos por átomos ou grupos químicos provenientes do plasma. São gerados radicais livres na superfície do polímero, devido à remoção de hidrogênio ou quebra de ligações na cadeia polimérica pela exposição a espécies energéticas. Esse processo é utilizado para melhorar a adesão entre superfícies plásticas ou plástica/metálica (D’AGOSTINO, 1999).

A técnica do plasma é muito utilizada para alterar a superfície de polímeros aumentando a tensão superficial de forma a aumentar a adesão entre polímero e outra superfície. A técnica de medida de ângulo de contato pode caracterizar uma superfície tratada por plasma (CANAL et al., 2004).

A tecnologia do plasma vem sendo estudada há por pelo menos três décadas e a maior desvantagem do tratamento está no efeito do tempo. A característica hidrofílica é perdida com o tempo em função das condições ambientais, devido à reorganização dos grupos hidrofílicos durante a exposição no meio ambiente (VAN DER MAI, 1991).

\subsubsection{Radiação}

A interação da radiação ionizante com materiais poliméricos transfere energia aos materiais, provocando principalmente a excitação e a ionização das moléculas, gerando reações químicas que podem provocar modificações permanentes na estrutura físicoquímica dos polímeros (DJALMA, 2007). As modificações causadas pela radiação ionizante em polímeros dependem das condições do processo, ou seja, do tipo de radiação, 
presença de oxigênio ou diferentes atmosferas, solventes, grau de cristalinidade e homogeneidade do material polimérico que irá absorver a energia (ULLOA, 2007).

Os principais efeitos causados em polímeros pela radiação ionizante são cisão das ligações da cadeia principal e a formação de ligações químicas entre as cadeias poliméricas (reticulação) (ULLOA, 2007).

As radiações ionizantes podem ser classificadas em eletromagnéticas e partículas com cargas elétricas, tais como os elétrons. Estas radiações são emitidas por elementos com núcleos atômicos instáveis ou podem ser produzidas pelos equipamentos denominados fontes intensas de radiação, como os aceleradores de elétrons (ULLOA, 2007).

A radiação de energia alta ou ionizante inclui a eletromagnética como raios $\mathrm{X}$ e raios gama $(\gamma)$ e partículas como: alfa $(\alpha)$, partículas beta $(\beta)$, elétrons (e), prótons $(\mathrm{p})$ e nêutrons (n) e fragmentos de fissão. A principal característica da radiação de energia alta é causar ionização (ULLOA, 2007).

A ionização é a transferência de energia pela radiação ionizante à molécula, sendo suficiente para arrancar um elétron de seu orbital. Esta energia é maior que a energia de excitação, que é a energia necessária para passar um elétron de seu orbital de menor energia para um estado de maior energia (ULLOA, 2007).

A radiação de energia alta pode provocar dois efeitos principais quando interage com a matéria: mudança na estrutura nuclear com a criação de novos isótopos ou elementos, ou mudanças químicas como distúrbio da estrutura eletrônica, levando à ionização, excitação e captura de elétrons (CONCISE ENCYCLOPEDIA OF POLYMER PROCESSING AND APLICATION, 1992).

\subsubsection{Acelerador de elétrons}

A potência máxima do feixe de elétrons está diretamente relacionada com a voltagem de aceleração e a corrente de elétrons. No acelerador, os elétrons são produzidos em um cátodo de tungstênio aquecido mantido em uma região de potencia mais elevada. 
Esses elétrons são acelerados por uma diferença de potencial aplicada entre o cátodo e o ânodo.

Com a aceleração, os elétrons adquirem energia suficiente para atravessar a janela de saída, constituída por uma folha de titânio, que apresenta resistência mecânica suficiente para suportar a pressão atmosférica do exterior (DJALMA, 2007).

$\mathrm{Na}$ literatura foram encontrados alguns trabalhos sobre irradiação de diferentes tipos de náilon, mas com enfoque diferente deste trabalho (EVORA et al.,2002c; EVORA et al., 2003; GUPTA, PANDEY, 1988; SINGH, CHAUDHURI, 1979; TIMUS et al., 2000).

\subsection{Adesão}

O ensaio de adesão consiste em prender o substrato da amostra em garra fixa do dinamômetro e parte da borracha em garra móvel e submeter a uma tensão até o desprendimento da borracha. A resistência à adesão é dada em N/mm, ou seja, unidade de força por unidade da secção transversal, segundo norma (NORMA ASTM D 429, 2003). Este método de ensaio é destinado, principalmente, para amostras preparadas em laboratório, em condições padronizadas, para compostos de borracha/metal. Neste trabalho foi feito uma adaptação para borracha/poliamida.

Neste trabalho, o metal foi substituído pela poliamida 6.6. Os resultados são obtidos para medir a força necessária para separar a borracha do substrato. Os dados obtidos indicam a resistência à adesão ao longo da largura da borracha separada do metal por um ângulo de $90^{\circ} \mathrm{C}$ (ASTM D 429, 2003).

A força aplicada no corpo de prova deve ser uniforme durante a separação das garras do dinamômetro o mais perpendicular possível para permitir a formação de um ângulo de $90^{\circ} \mathrm{C}$ entre borracha e substrato. A pressão das garras deve ser tal de modo a não promover a ruptura da borracha (ASTM D 429, 2003).

O corpo de prova deve ser formado por uma parte de borracha vulcanizada por aquecimento, sob pressão e tempo definido, com 6,3 $\pm 1 \mathrm{~mm}$ de espessura, $25 \pm 0,005 \mathrm{~mm}$ 
de largura e $125 \mathrm{~mm}$ de comprimento, e uma parte metálica de 1,6 $\pm 0,1 \mathrm{~mm}$ de espessura, $25 \pm 0,005 \mathrm{~mm}$ de largura e $60 \pm 1 \mathrm{~mm}$ de comprimento (ASTM D 429, 2003).

\subsubsection{Procedimento de análise}

A parte de borracha do corpo de prova deve ser presa, simetricamente, na garra inferior do dinamômetro e a parte do substrato deve ser presa na garra superior. Aplica-se uma força com velocidade de $50 \mathrm{~mm} / \mathrm{min}$ até o desprendimento da borracha do substrato.

Os valores de resistência à adesão são expressos em unidade de força por unidade de largura, ou seja, Newton por milímetro (ASTM D 429, 2003).

\subsection{Técnicas de caracterização de superfícies}

\subsubsection{Microscopia eletrônica de varredura e espectroscopia de dispersão de energia}

A Microscopia Eletrônica de Varredura tem como principal aplicação a análise da morfologia da superfície da amostra. Além de informações estruturais de topografia, também podem ser obtidas informações sobre a composição química da superfície por meio de um equipamento de EDS, Espectroscopia por Dispersão de Energia, acoplado ao microscópio. A Microscopia Eletrônica de Varredura é uma técnica de caracterização micro estrutural versátil de aplicação em diversos campos de pesquisas. A interação de um fino feixe de elétrons focado sobre uma área ou um micro volume a ser analisado gera uma série de sinais que podem ser utilizados para caracterizar propriedades da amostra, como composição, superfície topográfica, cristalografia entre outros. Na microscopia eletrônica de varredura os sinais de maior interesse referem-se usualmente às imagens de elétrons secundários e elétrons retroespalhados, ao passo que, na micro sonda eletrônica o sinal de maior interesse corresponde aos raios $\mathrm{X}$ característicos, resultante do bombardeamento do feixe de elétrons sobre a amostra, permitindo a definição qualitativa ou quantitativa dos elementos químicos presentes em um microvolume (GOLDSTEINS et al., 2003).

A interação entre os elétrons e a amostra pode ser por meio de espalhamento elástico e espalhamento não elástico. O espalhamento elástico afeta a trajetória dos elétrons 
dentro da amostra sem, no entanto, alterar a energia cinética dos mesmos. É responsável pelo fenômeno dos elétrons retroespalhados. O espalhamento não elástico compreende as diferentes interações em que há perda de energia cinética dos elétrons para os átomos da amostra propiciando a geração de elétrons secundários, elétrons Auger, raios $\mathrm{X}$ e catodoluminescência (GOLDSTEINS et al., 2003).

Os elétrons retroespalhados correspondem ao espalhamento elástico de elétrons, cuja trajetória foi desviada em mais de $90^{\circ}$ em relação à direção do feixe incidente. Possuem dependência com o número atômico e a energia dos elétrons, $50 \mathrm{eV}$ até valores correspondentes à energia do feixe incidente. Os elétrons retroespalhados são fáceis de detectar devido a sua energia elevada, porém são difíceis de coletar em função a velocidade elevada. O detector situa-se logo abaixo da objetiva do microscópio e pode coletar tanto imagem de contraste de número atômico, composição, como de topografia, a depender de como são considerados os sinais de cada posição (GOLDSTEINS et al., 2003).

Os elétrons secundários englobam todos os elétrons de energia inferior a $50 \mathrm{eV}$. Essencialmente, compreendem os elétrons de camadas de valência perdidos que, devido a energia baixa, emergem das proximidades da superfície da amostra. Possibilitam a visualização da topografia da amostra, com elevada profundidade de foco. Os elétrons secundários são difíceis de detectar por apresentarem energia muito baixa, menor que $50 \mathrm{eV}$, porém podem ser facilmente coletados em função a sua velocidade baixa (GOLDSTEINS et al., 2003).

$\mathrm{O}$ espectro de raios $\mathrm{X}$ resultante da interação elétrons/amostra contínuo e característico é constituído por dois componentes distintos: o característico, que permite identificar e quantificar os elementos presentes, e contínuo, responsável pelo background em todos os níveis de energia. No caso dos raios-X contínuo, o feixe de elétrons incide sobre uma desaceleração resultante da colisão dos mesmos com os átomos da amostra. A energia perdida pelo feixe de elétrons no processo de desaceleração é convertida em fótons de energia eletromagnética variando desde uma fração de $\mathrm{eV}$ até a energia total correspondente ao feixe de energia incidente. Essa radiação não apresenta interesse analítico. No caso do raio $\mathrm{X}$ característico, o feixe pode interagir com as camadas de elétrons dos átomos presentes na amostra, de forma a arrancar um elétron de seu orbital, 
ocasionando uma vacância e deixando o átomo como um íon em seu estado excitado. Instantaneamente o átomo retorna ao seu estado normal com a emissão de energia característica de transição ocorrida entre os níveis de elétrons. As energias dos elétrons são bem definidas, com valores característicos para cada átomo, possibilitando a identificação e quantificação dos elementos químicos por meio de uma série de técnicas instrumentais. A profundidade da geração dos raios $\mathrm{X}$ característicos ou o microvolume da amostra analisada é dependente da energia do feixe incidente, energia crítica de excitação e da densidade do material em análise. Para detectar os raios X característicos são empregados dois tipos de espectrômetros: espectrômetro de dispersão de comprimento (WDS) e espectrômetro dispersão de energia (EDS). Além de informações sobre a composição química pontual da amostra, essas técnicas permitem realizar análise segundo uma dada direção da amostra, linha (GOLDSTEINS et al., 2003).

Um átomo excitado, quando retorna ao seu estado normal, pode tanto emitir raio $\mathrm{X}$ característico como pode perder um elétron da camada mais externa, o qual é chamado elétron Auger. Esses elétrons são característicos dos elementos presentes, visto que as transições ocorrem em níveis definidos. Tipicamente, dado as características de proporção e perda de energia, somente os elétrons Auger gerados próximos das superfícies da amostra, 1 a 2nm, podem ser detectados (GOLDSTEINS et al., 2003).

O bombardeamento da amostra por um feixe de elétrons pode dar origem a emissão de fótons de comprimento de onda elevado, situados nas regiões do espectro eletromagnético referente às radiações ultravioleta, visível e infravermelho. Esse fenômeno evidente em polímeros e em certos minerais é denominado catodoluminescêscia. Dois diferentes tipos de detectores são empregados para análise de catodoluminescência. Um coleta todo o espectro gerado em um único sinal, e o outro possibilita a discriminação de acordo com o comprimento de onda da luz emitida, mediante o emprego de filtros monocromadores (GOLDSTEINS et al., 2003).

\subsubsection{Princípio de funcionamento}

Dentro da coluna de alto vácuo, os elétrons gerados a partir de um filamento de tungstênio, por efeito termiônico, são acelerados por uma diferença de potencial entre 
cátodo e ânodo entre 0,3 e $30 \mathrm{kV}$. O feixe gerado passa por lentes condensadoras que reduzem o seu diâmetro e por uma lente objetiva que o focaliza sobre a amostra, conforme FIG. 1 (LABORATÓRIO DE FILMES FINOS, 2009; MALISKA).

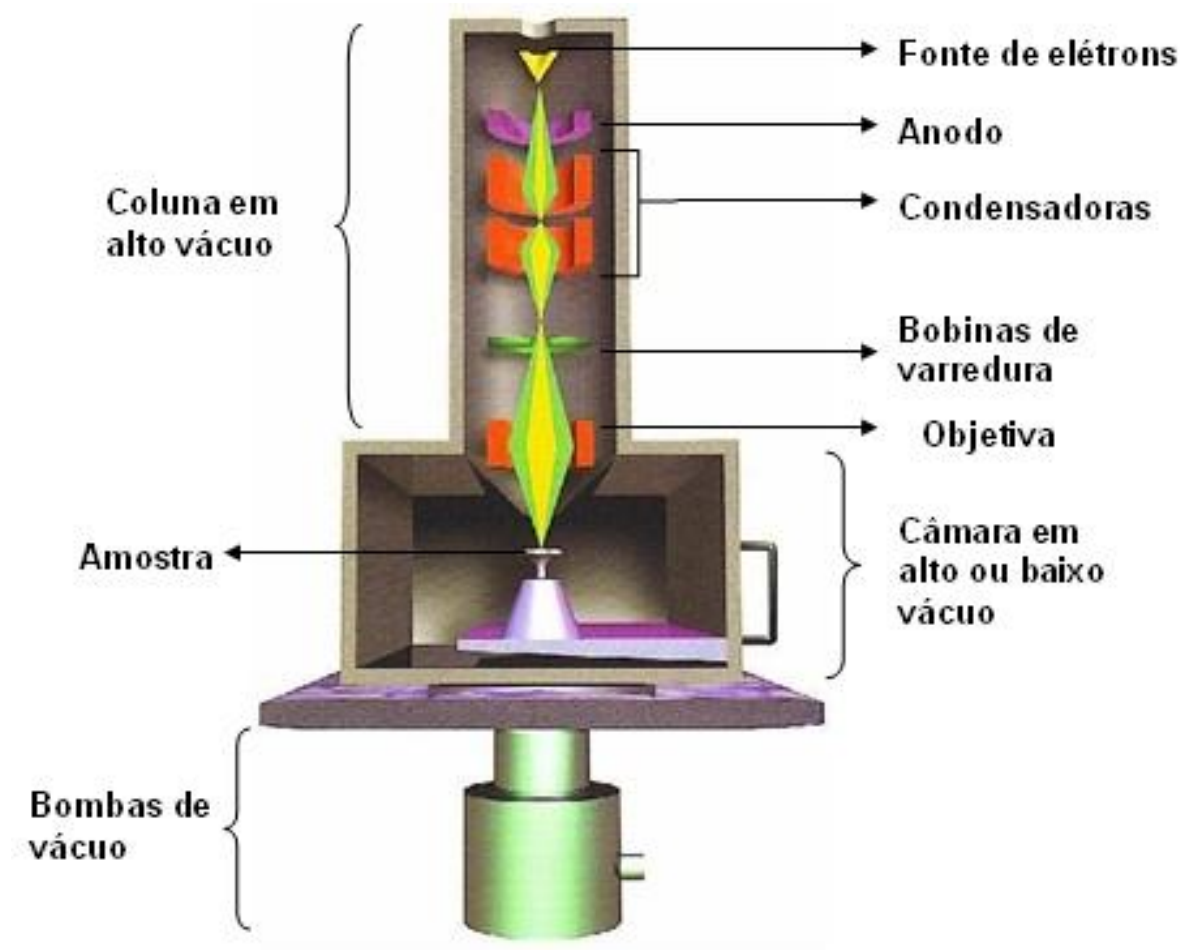

FIGURA 1- Desenho esquemático da coluna de alto vácuo do MEV

O feixe interage com a amostra até uma profundidade que depende da natureza da amostra. Essa região é chamada volume de interação, a qual gera os sinais que são detectados e utilizados para a formação da imagem e para a microanálise, conforme FIG. 2 (LABORATÓRIO DE FILMES FINOS, 2009; MALISKA). 


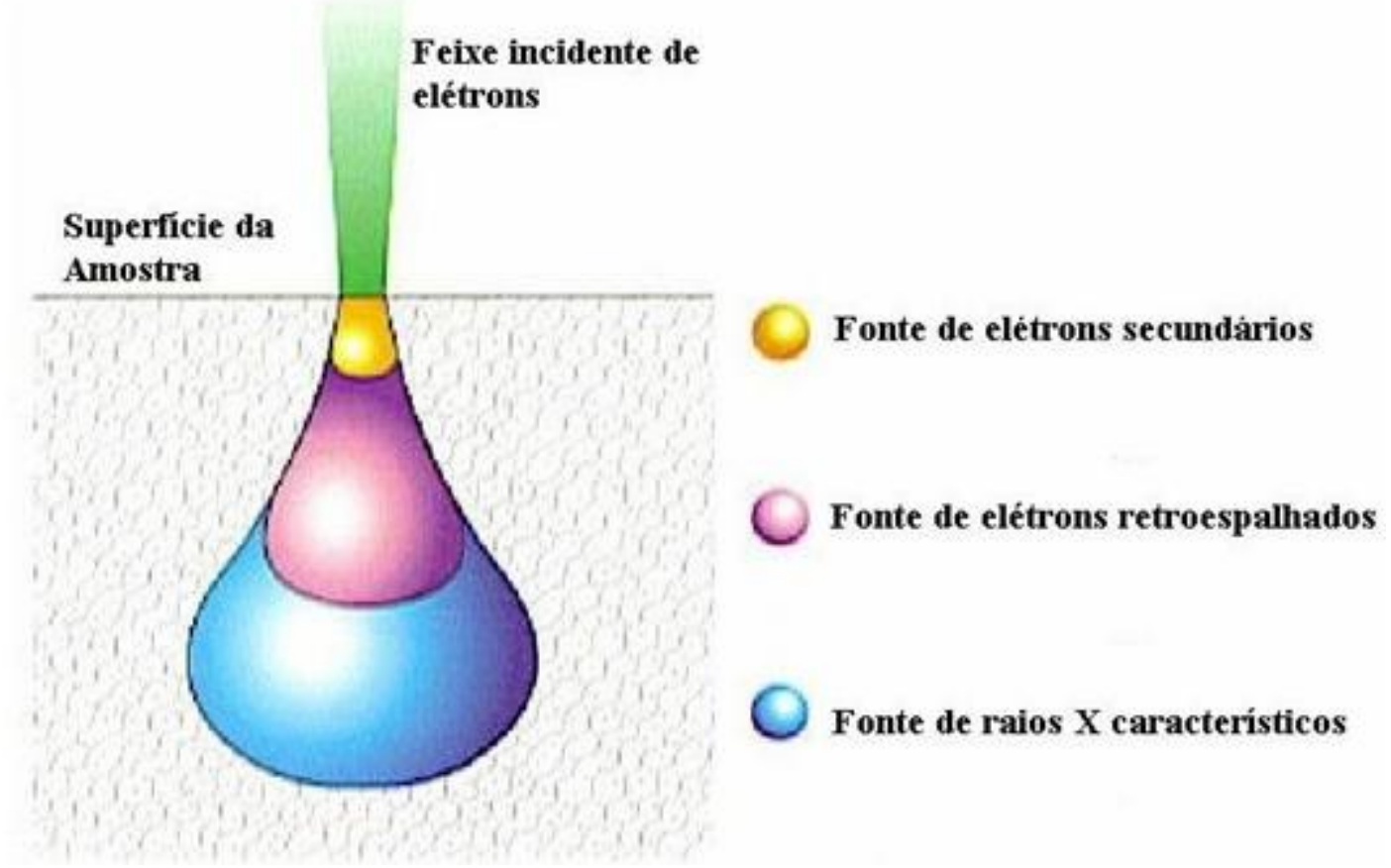

FIGURA 2 - Esquema representativo do volume da interação dos elétrons com a amostra

\subsection{Espectroscopia na região do infravermelho por transformada de Fourrier (FT-IR)}

Espectroscopia é o estudo da interação da radiação eletromagnética com a matéria. A espectroscopia de absorção na região do infravermelho por transformada de Fourrier (FT-IR) é uma ferramenta para identificação de grupos funcionais e para estudos de conformação e estrutura de macromoléculas. A radiação eletromagnética interage com a matéria em três processos distintos: absorção, emissão e espalhamento. A espectroscopia vibracional estuda a transição das vibrações normais moleculares que podem ser do tipo estiramento de ligação, deformação angular e torção. A obtenção do espectro infravermelho é o modo mais utilizado, pois é a configuração básica de maior parte dos espectrofotômetros de infravermelho do mercado, constituindo-se assim num modo universal, na medida em que pode ser aplicado em amostras sólidas, líquidas, gasosas e polímeros (CANEVAROLO JR., 2004).

A radiação infravermelha corresponde à parte do espectro eletromagnético situada entre as regiões do visível e das microondas. A região de maior utilidade para a química orgânica está situada entre 4.000 e $666 \mathrm{~cm}^{-1}$ (SILVERSTEIN et al., 1979). 
Mesmo moléculas simples podem produzir espectros extremamente complexos e, por isso, é necessário comparar o espectro de um composto desconhecido com o espectro de uma amostra conhecida. A correlação pico a pico constitui boa prova de identidade, visto ser pouco provável que dois compostos diferentes tenham o mesmo espectro no infravermelho (SILVERSTEIN et al., 1979).

Embora o espectro na região do infravermelho seja característico da molécula como um todo, certos grupos de átomos dão origem a bandas que ocorrem mais ou menos no mesmo comprimento de onda, independentemente da estrutura da molécula. $\mathrm{O}$ comprimento de onda de uma absorção depende das massas relativas dos átomos, das constantes de força de ligações e da geometria dos átomos. As posições das bandas no espectro na região do infravermelho são apresentadas em comprimento de onda $(\lambda)$ ou número de ondas. As intensidades das bandas são expressas em transmitância $(T)$ ou absorbância (A). A transmitância é a razão entre a energia radiante transmitida por uma amostra e a energia radiante que nela incide. A absorbância é o logaritmo, na base 10, do recíproco da transmitância, isto é, $A=\log _{10}(1 / T)$ (SILVERSTEIN et al., 1979).

Nas moléculas existem as vibrações angulares e os estiramentos. O estiramento é um movimento rítmico ao longo do eixo da ligação de forma em que a distância interatômica aumente e diminua alternadamente. As vibrações de deformação angular correspondem as variações de ângulo de ligação, seja internamente em um grupo de átomos, seja deste grupo de átomos em relação à molécula como um todo. Assim, por exemplo, a deformação assimétrica num plano, a deformação angular assimétrica fora do plano e as vibrações torcionais pertencem a este grupo e envolvem uma mudança nos ângulos de ligações com referência a um conjunto de coordenadas colocadas de modo arbitrário na molécula. Somente as vibrações que resultam em uma alteração rítmica do momento dipolar da molécula são observadas no infravermelho convencional. O campo elétrico alternado, produzido pela mudança de distribuição de carga que acompanha a vibração, acopla a vibração molecular com o campo elétrico oscilante da radiação eletromagnética e o resultado do processo é absorção de energia radiante (SILVERSTEIN et al., 1979). 


\subsubsection{Instrumentação}

Fonte de radiação - A radiação infravermelha é produzida por uma fonte aquecida eletricamente, usualmente um filamento de Nernst, fabricado a partir de um adesivo e óxidos de zircônio, tório e cério, ou um Globar, e um pequeno bastão de carbeto de silício, a temperatura que alcança 1.000 a $1.800^{\circ} \mathrm{C}$. A imagem da fonte deve ser mais larga do que a largura máxima das fendas. A radiação da fonte é dividida em dois feixes por dois espelhos, um de referência e um da amostra. Os feixes são focalizados na área da amostra com o auxílio de mais dois espelhos (SILVERSTEIN et al., 1979).

Área de amostras - Os feixes de referência e amostra entram na área de amostras e passam através de células, uma correspondendo à referência e outra à amostra. Obturadores opacos, montados no compartimento da fonte, permitem bloquear um ou outro feixe, independentemente (SILVERSTEIN et al., 1979).

Fotômetro - O feixe de referência atravessa o atenuador e é refletido por espelhos para um espelho hemicircular rotatório, que por sua vez, reflete o feixe de referência para fora do sistema ótico ou para outro espelho, alternadamente. O feixe de referência e o da amostra combinam-se em um feixe alternado, chegando ao detector com velocidades de energias diferentes. Quando os dois feixes são de mesma intensidade, o instrumento está no zero ótico. A pena do registrador está em 100\% de transmitância, desde que não haja amostra no feixe correspondente. $\mathrm{O}$ atenuador desloca-se para dentro e fora do feixe de referência em resposta ao sinal criado no detector pelo feixe da amostra. Assim, quando o feixe é absorvido pela amostra, o atenuador é dirigido para dentro do feixe de referência até que sua intensidade seja a mesma do feixe da amostra (SILVERSTEIN et al., 1979).

Monocromador - O feixe combinado passa através da fenda de entrada do monocromador, atinge um espelho e é desviado para a rede de difração. O feixe é disperso em várias freqüências, desviado para um espelho e subseqüentemente para outro espelho que o focaliza na fenda de saída. Filtros são inseridos automaticamente no caminho da radiação durante a varredura para eliminar toda radiação indesejável (SILVERSTEIN et al., 1979). 
Detector - Após deixar a fenda de saída do monocromador, o feixe é refletido por um espelho plano para um espelho elipsoidal, cujos focos estão na fenda de saída e no detector. $\mathrm{O}$ detector é um instrumento usado para medir a energia radiante por meio de seu efeito térmico. Como o detector recebe alternadamente os feixes de referência e o da amostra, qualquer mudança na intensidade da radiação devida à absorção de energia é detectada como um sinal fora do zero. O sinal assim obtido é amplificado e usado para posicionar o atenuador ótico de modo que a radiação dos feixes de referência e da amostra mantém a mesma intensidade. A quantidade de atenuação necessária é uma medida direta da absorção pela amostra. O movimento do atenuador é registrado pela pena do instrumento (SILVERSTEIN et al., 1979).

\subsubsection{Interpretação dos espectros}

A interpretação de um espectro de infravermelho não requer regras rígidas. Porém, deve levar em consideração certos requisitos para que a interpretação possa ser confiável. O espectro deve ser adequadamente resolvido e de razoável intensidade. O espectro deve ser de um composto razoavelmente puro e o equipamento deve ser calibrado contra padrões de maneira a que as bandas observadas estejam colocadas em seus comprimentos de ondas verdadeiros. O método de manuseio da amostra deve ser identificado e, se forem utilizados solventes é preciso indicar a concentração da solução e a espessura da célula utilizada (SILVERSTEIN et al., 1979).

\subsection{PIXE ("Particle Induced X-Ray Emission")}

PIXE, Emissão de Raios X Induzida por Partículas Carregadas, é uma técnica de análise de materiais não destrutiva e de caráter multi-elementar. O material a ser analisado é irradiado por partículas carregadas produzidas por um acelerador. A interação dessas partículas com os átomos da amostra faz com que, dentre outros efeitos, elétrons de camadas internas dos átomos da amostra sejam ejetados. Quando as vacâncias resultantes são preenchidas espontaneamente por elétrons de camadas mais externas, no processo de desexcitação são emitidos raios $\mathrm{X}$ de energias características para cada elemento constituinte da amostra, como mostrado na FIG. 3. Esses raios-X são analisados por meio de um sistema de detecção conveniente. A técnica PIXE permite medir quantitativamente concentrações de elementos até o limite de algumas partes por milhão, chegando em alguns 
casos, a partes por bilhão. Em razão desse limite de detecção extrasensível, a técnica PIXE é aplicada em vários campos de pesquisas como medicina, física, arqueologia, biologia, geologia entre outros (ABURAYA, 2005).

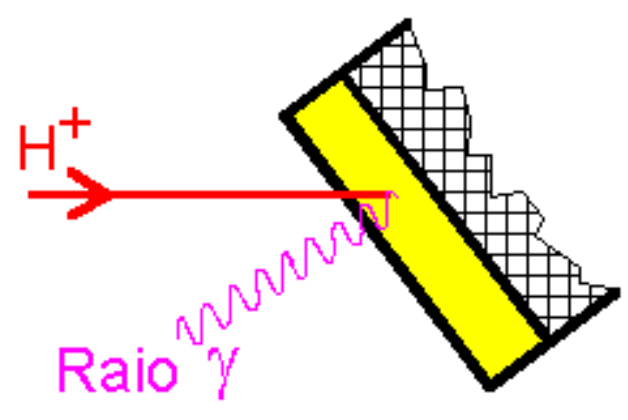

FIGURA 3 - Esquema representativo da emissão de raios X induzidos por partículas

\subsubsection{Espectro característico de raios $X$}

A emissão de radiação eletromagnética característica de um átomo excitado, ocorre quando um átomo desexcitado por meio de transições eletrônicas a partir de camadas mais externas preenchendo a vacância em outra mais externa (ABURAYA, 2005).

A energia do quantum de radiação é característica do elemento químico, cujo valor é a diferença da energia das camadas envolvidas na transição. Para as transições de dipolo existem regras de seleção determinadas por:

$$
\begin{gathered}
\Delta \ell \neq 0 \\
\Delta j=0, \pm 1 \text { e } j=\ell \pm|s|
\end{gathered}
$$

Em que: $\ell$ é o momento angular orbital, $s$ é o momento angular de spin e $j$ é o momento angular total.

As transições de interesse na análise PIXE são aquelas que têm como base a camada $\mathrm{K}$ identificadas pelos seus números quânticos $n=1, \ell=0, s= \pm 1 / 2, j=1 / 2$, que envolvem as camadas L e M, cujas energias são determinadas pela lei de Moseley, de ordem $1 \mathrm{keV}$ a 30keV, região sensível ao detector de $\mathrm{Si}(\mathrm{Li})$ utilizado (ABURAYA, 2005). 


\subsubsection{Detecção das linhas de raios $\mathrm{X}$}

A detecção dos raios X emitidos pode se por meio de detector de cristal de $\mathrm{Si}(\mathrm{Li})$, dispersivo em energia sensível na região de $1 \mathrm{keV}$ e $30 \mathrm{keV}$, medindo principalmente linhas $\mathrm{K}$ para elementos com $11 \leq \mathrm{Z} \leq 40$ e linhas $\mathrm{L}$ para $\mathrm{Z} \geq 30$.

A identificação das linhas é feita pela simples leitura da energia, devidamente calibradas por meio de amostras conhecidas, considerando possíveis interferências de pico soma, pico escape e superposição de linhas.

Picos soma são resultados da detecção simultânea de dois ou mais raios X com energia resultante da combinação linear das energias dos raios $\mathrm{X}$ envolvidos. Picos escape são resultados da detecção parcial do raio $\mathrm{X}$ incidente no detector, devido a fluorescência do cristal de Si que emite um fóton com energia média de $1780 \mathrm{eV}$ que "escapa" sem gerar sinal (ionização) no cristal detector. A superposição de picos (linhas) ocorre devido a falta de resolução do detector para linhas com energias muito próximas. É comum a superposição entre $\mathrm{k}_{\beta}$ e $\mathrm{k}_{\alpha}$ para os elementos $18 \leq \mathrm{Z} \leq 30$ (ABURAYA, 2005).

\subsection{RBS ("Rutherford Backscattering Spectrometry")}

RBS é um método analítico que utiliza o espalhamento do íon incidente ou da partícula da amostra para análise. A técnica RBS consiste em medir a energia de partículas de um feixe monoenergético que sofrem colisões com os átomos do alvo que se quer analisar e que foram retroespalhados, conforme mostrado na FIG. 4

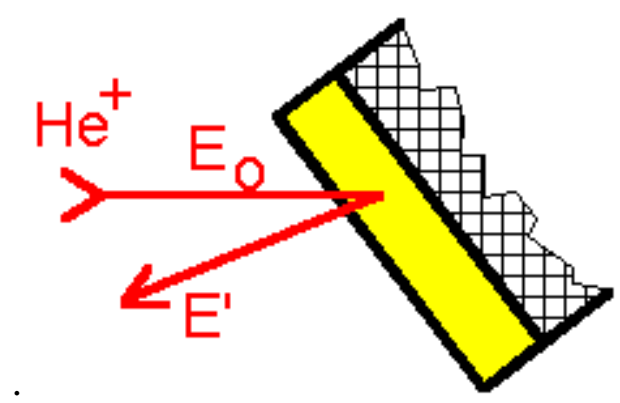

FIGURA 4 - Esquema representativo do processo de espectrometria por retroespalhamento de Rutherford. 
A espectrometria por retroespalhamento Rutherford é um método de análise de materiais que empregam íons energéticos, tipicamente entre 0,5 e $3 \mathrm{MeV} / \mathrm{u}$ para a determinação da composição atômica de materiais. Baseado nas propriedades de espalhamento de íons no campo coulombiano de núcleos atômicos, mede-se as energias das partículas de um feixe de íons monoenergéticos, após serem espalhados pelos núcleos atômicos no alvo. A razão da redução de energia, $\mathrm{E}_{1} / \mathrm{E}_{0}$ da partícula espalhada, depende da razão entre as massas do projétil do núcleo alvo e permite determinar a massa atômica. Identificado o átomo alvo, sua densidade em átomos $/ \mathrm{cm}^{2}$ na amostra pode ser determinada a partir da intensidade do sinal medido. Finalmente, uma vez que o íon perde energia ao longo de seu percurso no interior da amostra, a distância à superfície do local onde ocorreu a colisão também pode ser determinada. Dessa forma, a espectroscopia RBS pode ser usada para determinar a composição atômica e o seu perfil em profundidade numa amostra (TABACNIKS, 2005).

No arranjo experimental, um feixe de elétrons monoenergético colimado por um conjunto de fendas é dirigido sobre uma amostra a ser analisada. As partículas do feixe espalhadas pela amostra são detectadas em um ângulo traseiro, $\theta$. Além do ângulo de espalhamento, os principais parâmetros experimentais são a energia das partículas num feixe, sua intensidade, a inclinação da amostra $\varphi$ e o ângulo sólido de detecção $\Omega$. Seguindo a notação usual, será convencionado o índice " 1 " para as partículas do feixe e “2” para os átomos alvo (TABACNIKS, 2005).

Nas condições das análises por RBS, a colisão entre partículas do feixe e átomos alvo pode ser descrito como um espalhamento clássico em um campo de forças central entre duas massas puntiformes com cargas positivas. A cinética da colisão é independente de ligações eletrônicas e, portanto, insensível ao estado químico da amostra. Numa colisão elástica, as conservações de energia e do momento linear permitem calcular a razão entre a energia da partícula espalhada, $\mathrm{E}_{1}$ e sua inicial $\mathrm{E}_{0}$ denominada fator cinético $\mathrm{K}_{1}$ (TABACNIKS, 2005).

\subsubsection{Interpretação e processamento de um espectro de RBS}

Um espectro RBS é um gráfico da intensidade (taxa de contagem) em função da energia das partículas detectadas. Um espectro é, na realidade, um histograma em que o 
eixo das energias (abscissa) é dividido em canais de 512 a 1025. Cada canal corresponde a um pequeno intervalo de energia, por exemplo, $5 \mathrm{keV} / \mathrm{canal}$ (TABACNIKS, 2005).

\subsubsection{Altura de picos e patamares}

A altura da borda de espalhamento de cada pico de superfície (elementarmente puro) é o número de eventos que ocorre em 1 canal, cuja largura (em energia) é dada pelo ganho, G. Existe uma equação que define a escala de alturas de pico que pode ser usada para determinar a fração elementar no pico experimental (TABACNIKS, 2005).

\subsection{MFA (Microscopia de Força Atômica)}

Binnig, Quate e Gerber inventaram, em 1986, o microscópio de força atômica, ("Atomic Force Microscopy" - AFM), também conhecido como SFM ("Scanning Force Microscopy"), que pode produzir imagens de superfícies condutoras e não condutoras. Esta técnica baseia-se na varredura da superfície estudada por meio de sondas de dimensões muito reduzidas à distância muito pequena, da ordem de alguns ângstrons, proporcionando alta resolução espacial tanto lateral como vertical na visualização de superfícies em nível atômico de diferentes naturezas, metais, películas orgânicas, polímeros, amostras biológicas em sistemas condutores e isolantes, e em diversos meios como vácuo, pressão atmosférica e meio líquido (BERNARDES FILHO, MATTOSO, 2003; PAQUIM, BRETT, 2003). A técnica de microscopia de força atômica permite medir a força de adesão na superfície de amostras tratadas e não tratadas (YIP et al., 2003).

O princípio de funcionamento do AFM baseia-se na varredura da superfície e da amostra por meio de uma ponta piramidal, ponteira, de alguns micrômetros de comprimento, 100 a $200 \mu \mathrm{m}$, e geralmente com menos de 20 nanômetros de diâmetro, integrada em um cantilever flexível. A sonda, ponteira + cantilever, é sempre o componente básico do AFM. A força entre a ponta e a superfície da amostra faz com que o cantilever se aproxime ou se afaste e essa deflexão é proporcional à força de interação. Na parte superior da haste há um espelho que reflete a luz de um feixe de laser. Após a deflexão, o feixe de laser passa por uma lente e incide sobre um fotodetector, fotodiodo, de quatro quadrantes que mede as variações de posição e da intensidade da luz produzidas pelas deflexões do cantilever. À medida que a ponta varre a amostra ou a amostra é 
deslocada sob a ponta, os diferentes tipos de "acidentes geográficos" encontrados sobre a superfície fazem com que a interação mude. As variações das interações são os fatores que provocam diferentes deflexões. Essas diferenças são captadas no detector, são armazenadas e processadas por um computador que as transformam em imagens topográficas da superfície bi e tridimensionais. A força mais comumente associada ao AFM na deflexão do cantilever é a força de Van der Waals (FERREIRA; YAMANARA, 2006; OLIVEIRA, 2007).

A técnica de AFM pode ser operada em três modos diferentes: contato, não-contato e contato intermitente. No modo contato, o cantilever é mantido a poucos ângstrons da superfície da amostra e a força interatômica entre a ponta e a amostra é repulsiva. Neste modo de operação, a ponta faz um leve "contato físico" com a amostra produzindo imagens com alta resolução, mas a compressão e as forças geradas entre a ponta e a superfície, podem causar danos à amostra. Amostras biológicas não podem ser analisadas por meio de modo contato. No modo não contato, o cantilever é mantido de dezenas a centenas de ângstrons da superfície da amostra e a força interatômica entre a ponta e a amostra é atrativa. Neste caso, a ponta oscila em alta frequiência, $100 \mathrm{kHz}$ a $1 \mathrm{MHz}$, a poucos nanômetros acima da superfície e a força total entre a ponta e a amostra é muito baixa, geralmente em torno de $10^{-12} \mathrm{~N}$. Esta oscilação aumenta consideravelmente a sensibilidade do microscópio, o que faz com que as forças de Van der Waals e as forças eletrostáticas possam ser detectadas. O modo contato intermitente é similar ao não contato, exceto pelo fato que a ponta vibrante fica mais próxima da amostra, de forma que tenha um contato intermitente e é utilizado para contornar as limitações impostas pelo modo contato (FERREIRA; YAMANARA, 2006).

\subsection{1 Ângulo de contato}

O estudo de problemas que envolvem fenômenos de superfície, nos quais diferentes fluídos podem interagir com substratos sólidos, sempre foi assunto de grande interesse científico e econômico. Uma das propriedades físicas que tem sido intensamente estudada é a molhabilidade sobre superfícies sólidas. Esta propriedade é devido à ação de forças de interação de longa distância entre as moléculas do fluído e do sólido, e leva à observação macroscópica do ângulo de contato, geralmente definido por meio da equação de Young. Para que a molhabilidade seja modelada corretamente, a utilização de potenciais de 
interação fisicamente consistentes para a representação das interações entre diferentes tipos de moléculas é de grande importância, uma vez que tal propriedade é de fato apenas resultado estatístico de interações intermoleculares que ocorrem na escala macroscópica. $\mathrm{O}$ papel das forças de longa distância tem se mostrado fundamental na explicação de fenômenos envolvendo a interação de líquido e sólido (WOLF et al., 2004).

A interação entre uma superfície e um determinado líquido pode ser estudada por meio da medida do chamado ângulo de contato $\theta$. Este é definido como o ângulo entre um plano tangente a uma gota do líquido e um plano contendo a superfície onde o líquido se encontra depositado, conforme FIG. 5.

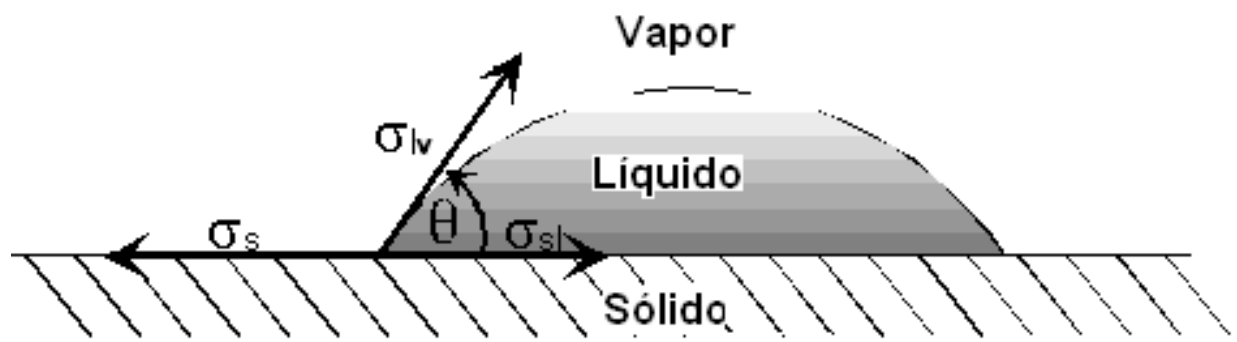

FIGURA 5 - Desenho esquemático da interação entre uma superfície e um determinado líquido.

O conceito de energia de superfície pode ser mais facilmente compreendido usando um líquido como exemplo. Átomos e moléculas do líquido podem se mover livremente procurando ocupar uma posição de menor energia potencial, ou seja, um lugar onde as forças atrativas e repulsivas, agindo em todas as direções, estejam em equilíbrio (WOLF et al., 2004).

Uma gota de água apresenta um formato diferente para cada superfície que se espalha, pois o modo como o volume de água de uma gota se acomoda depende das interações entre a água e a superfície do material em que foi depositado. É, portanto, possível medir o ângulo com que uma gota fica na superfície e, com isso, caracterizar a superfície. O ângulo de contato de uma gota de água numa folha, num vidro, no azulejo, entre outras coisas, são diferentes. O ângulo de contato influencia na forma como a água fica numa superfície determinando assim o molhamento da mesma (NETO, 2006). 
$\mathrm{O}$ ângulo de contato igual a $0^{\circ}$ é um caso extremo de máxima afinidade química entre a superfície e o líquido e, portanto, haverá espalhamento completo do líquido no sólido. O ângulo de contato igual a $90^{\circ}$ é o outro caso extremo onde o líquido não apresenta qualquer interação com a superfície. Quando o ângulo de contato é menor que $90^{\circ}$ pode-se considerar que a superfície é molhada pelo líquido. Uma modificação química na superfície, por reação ou adsorção, pode ser usada para aumentar ou diminuir o ângulo de contato quando houver necessidade, influenciando, assim, no molhamento do sólido pelo líquido (NETO, 2006).

O método direto mais utilizado para medidas de ângulo de contato consta na medida do perfil da gota de líquido ou de uma bolha posicionada sobre uma superfície sólida. A amostra é colocada em um goniômetro, posteriormente, uma gota de água deionizada é então depositada, por meio de uma micro seringa, sobre a área da amostra. A gota é observada com uma lente de baixo aumento e o ângulo de contato é medido. Esse tipo de medida é chamado de estático. O valor do ângulo de contato de uma gota de líquido depende da energia de superfície da amostra e da tensão superficial do líquido (BUZETO; CAMPOS, 2004). 


\section{OBJETIVO}

O objetivo deste trabalho é comparar as propriedades superficiais da poliamida 6.6 tratada por plasma e por radiação ionizante, assim como determinar qual a melhor técnica e condição para ativação da superfície, visando à adesão da mesma com a borracha poliacrílica utilizada na fabricação de retentores para automóveis. 


\section{MATERIAIS E MÉTODOS}

\subsection{Matérias-primas utilizadas}

Para execução deste trabalho foram utilizados corpos de prova de poliamida 6.6 fornecidos na forma de anéis pela empresa Rhodia, cujas características principais são: densidade de 1,18 a $1,30 \mathrm{~g} / \mathrm{cm}^{3}$ e ponto de fusão entre 250 e $270^{\circ} \mathrm{C}$. A borracha poliacrílica foi fornecida pela empresa Sabó, cujas propriedades são: densidade 1,55 a $1,58 \mathrm{~g} / \mathrm{cm}^{3}$; tensão de ruptura 7MPa (mínimo); alongamento 100\% (mínimo) e dureza Shore A 70 de acordo com a norma ASTM D 2000, 2006.

\subsection{Tratamento da poliamida 6.6 por plasma}

As amostras de poliamida 6.6 foram tratadas por plasma a baixa pressão. $\mathrm{O}$ equipamento de plasma utilizado foi o "Electronic DIENER - Plasma - SurfaceTechnology LFG40", com gás nitrogênio à pressão de $1,40 \mathrm{~kg} / \mathrm{cm}^{2}$, da empresa Sabó, mostrado na FIG. 6. Posteriormente, estas amostras de poliamida 6.6 foram caracterizadas e em seguida incorporadas a borracha poliacrílica, conforme mostrado na FIG.7. 


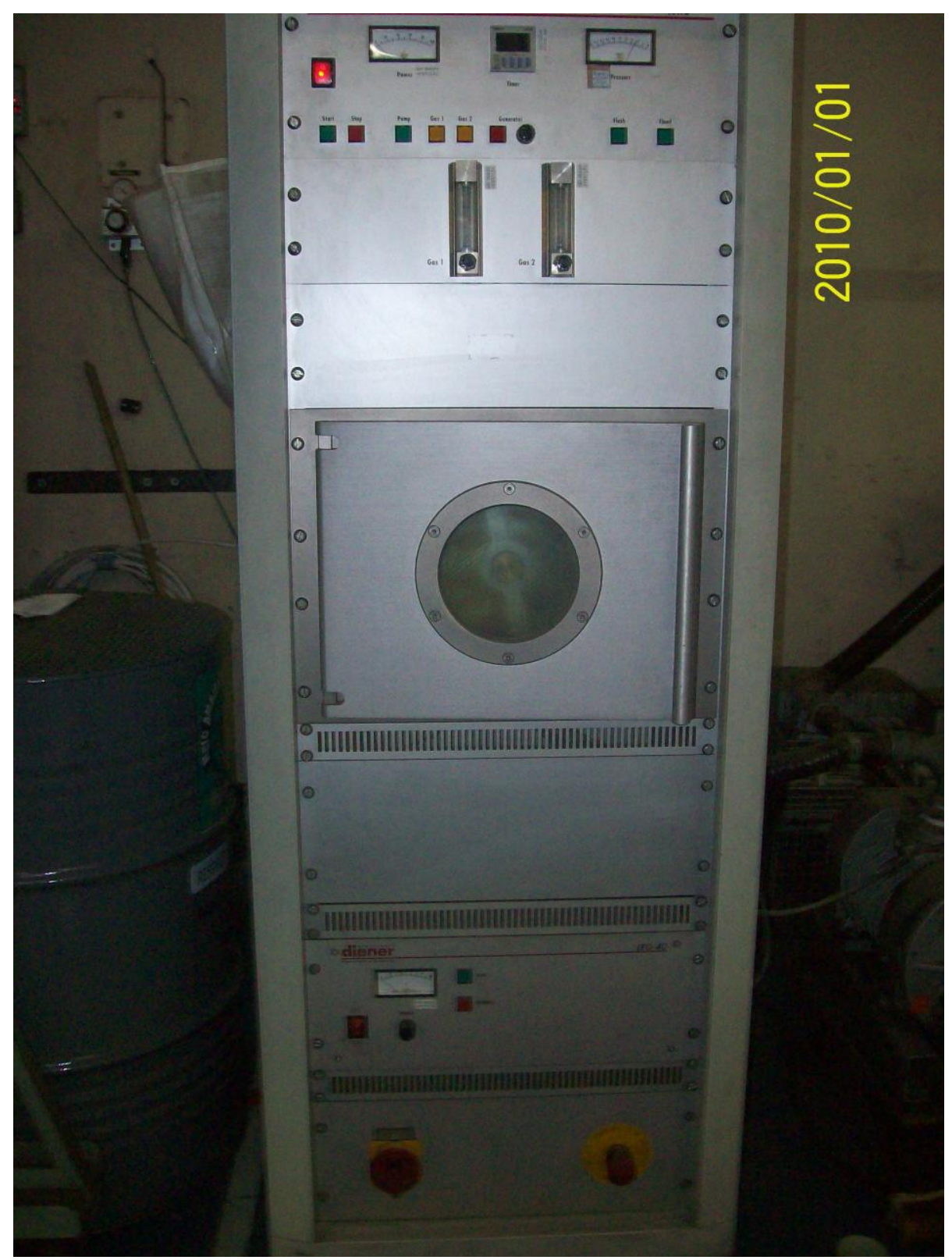

FIGURA 6 - Fotografia do equipamento de plasma "Electronic DIENER - Plasma Surface- Technology LFG40" 


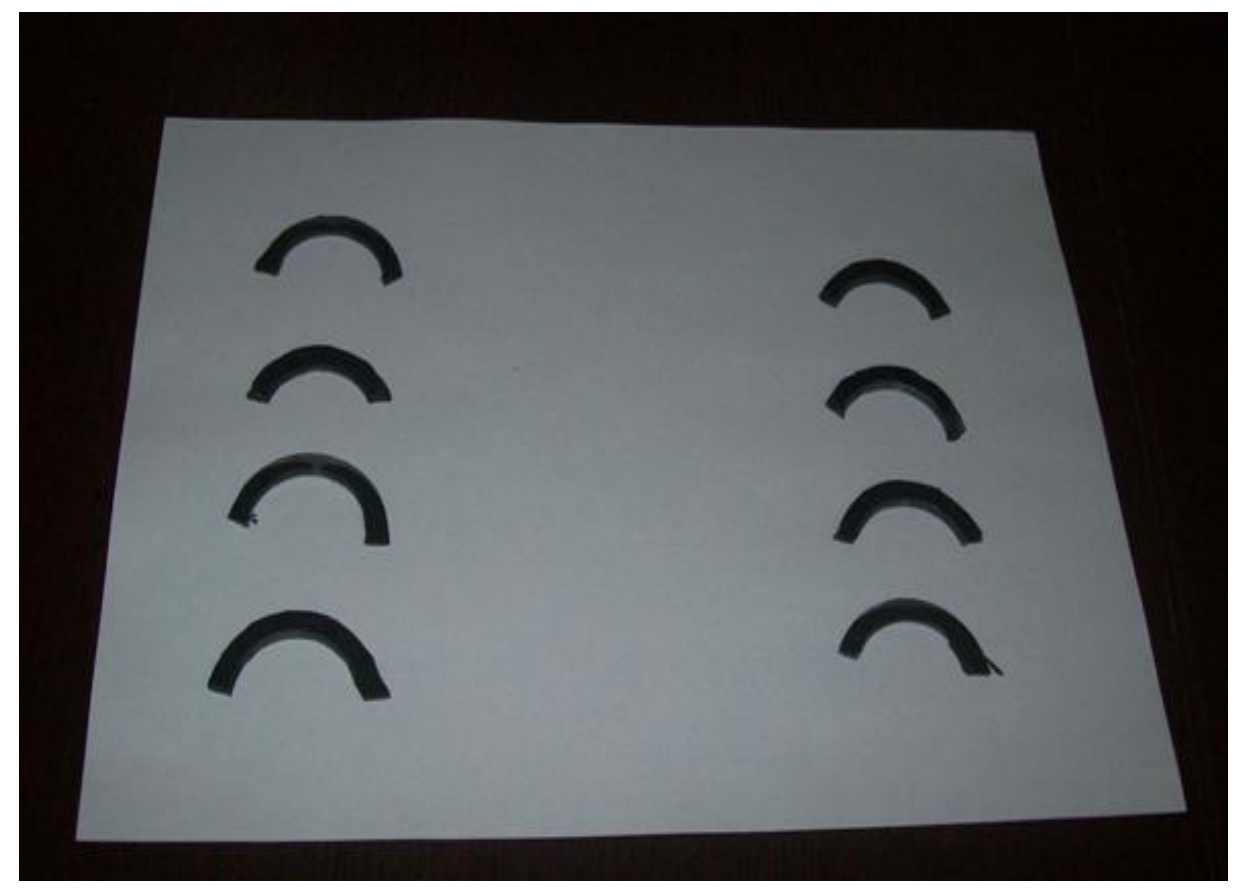

FIGURA 7 - Fotografia das amostras de PA 6.6 incorporadas à borracha poliacrílica após tratamento por plasma

\subsection{Tratamento da poliamida 6.6 por radiação ionizante}

As amostras de poliamida 6.6 foram irradiadas com feixe de elétrons utilizando um acelerador industrial de elétrons Dynamitron JOB 188, energia de 0,5 a $1,5 \mathrm{MeV}$ e corrente de 0,3 a 25mA, do Centro de Tecnologia das Radiações, no IPEN - CNEN/SP, mostrado na FIG. 8. 


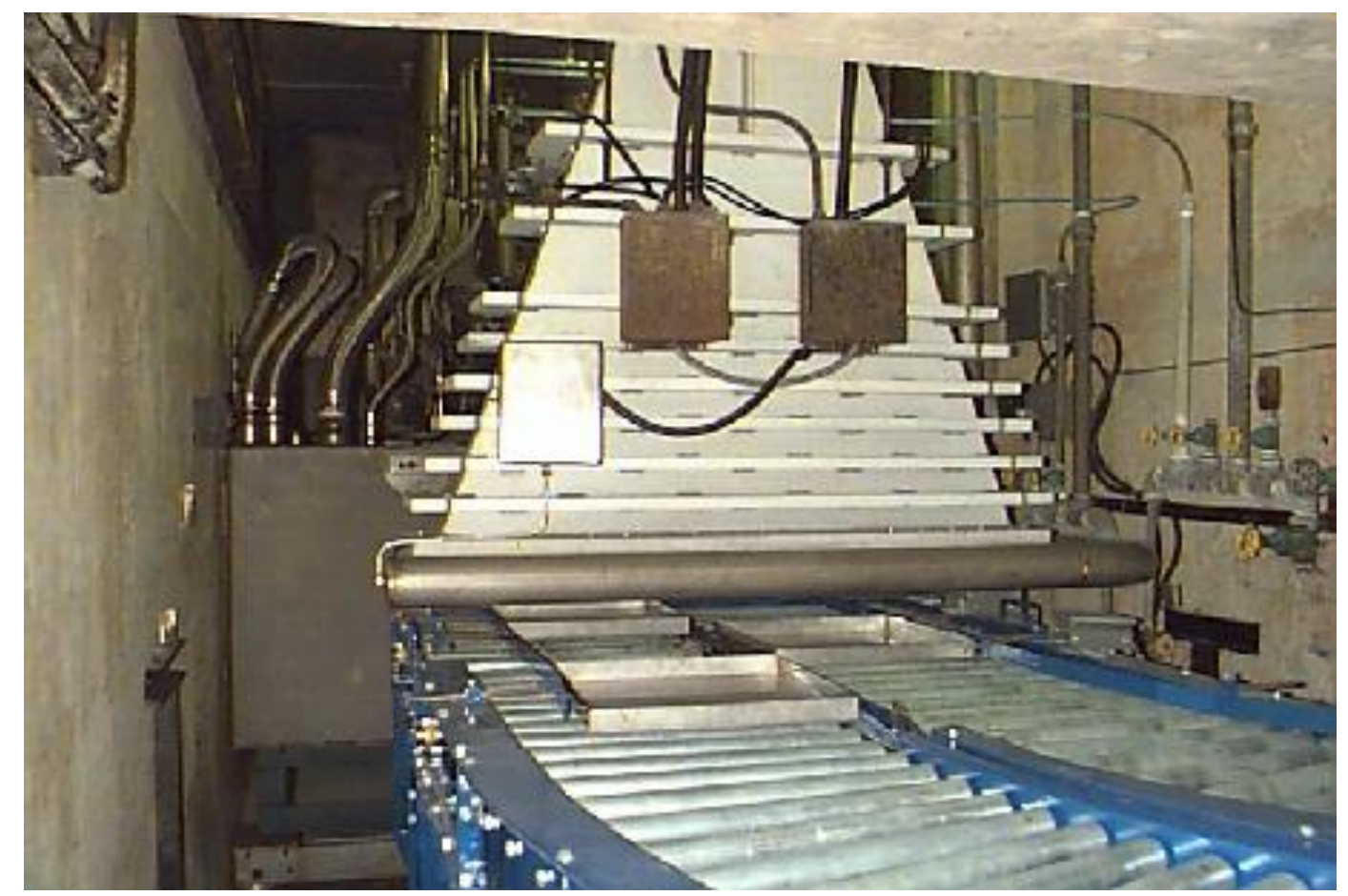

FIGURA 8 - Fotografia do acelerador industrial de elétrons Dynamitron II, modelo DC 1500 JOB 188

Estas amostras foram submetidas a diferentes doses de radiação, 5, 10, 20 e 40kGy, utilizando vácuo, e 50, 100, 200, 300, 400 e 500kGy, utilizando pressão atmosférica. A taxa de dose foi 11,22 kGy/s para todas as doses e 11,22 kGy/s e 22,38 $\mathrm{kGy} / \mathrm{s}$ para a dose de 20kGy. Parte das amostras irradiadas foi separada para a caracterização da superfície. Outra parte das amostras irradiadas foi incorporada à borracha poliacrílica, conforme mostrado na FIG. 9. 


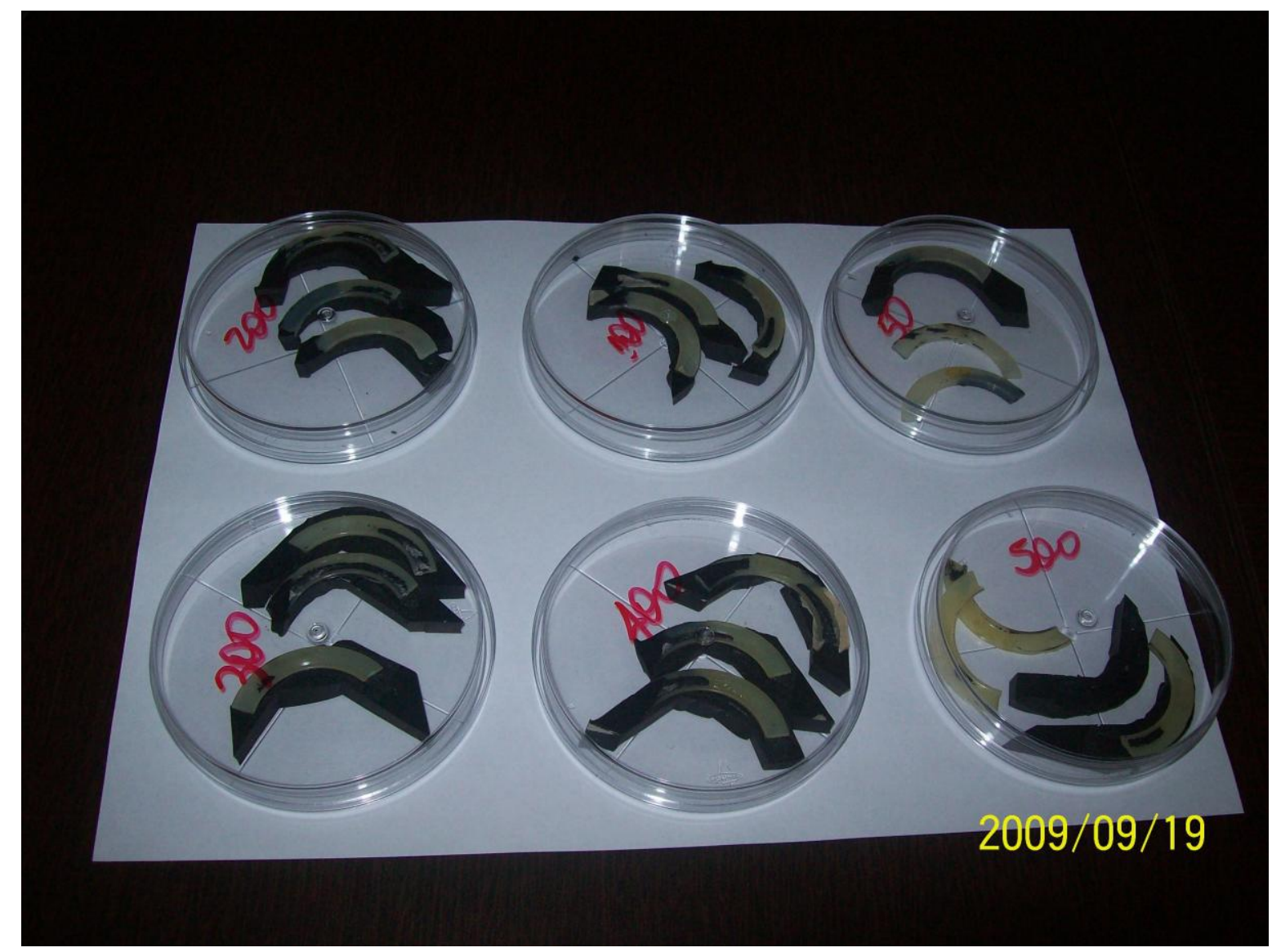

FIGURA 9 - Fotografia das amostras de PA 6.6 irradiadas e incorporadas à borracha poliacríllica

\subsection{Incorporação da poliamida 6.6 à borracha poliacrílica}

As amostras de PA 6.6 não tratadas, tratadas por plasma e irradiadas foram incorporadas a borracha poliacrílica utilizando uma prensa hidráulica, da empresa Sabó, sob pressão de $140,62 \mathrm{~kg} / \mathrm{cm}^{2}$, temperatura de $180^{\circ} \mathrm{C}$, durante cinco minutos. Nas FIG. 10 , 11 e 12 são mostrados os equipamentos utilizados neste processo. 


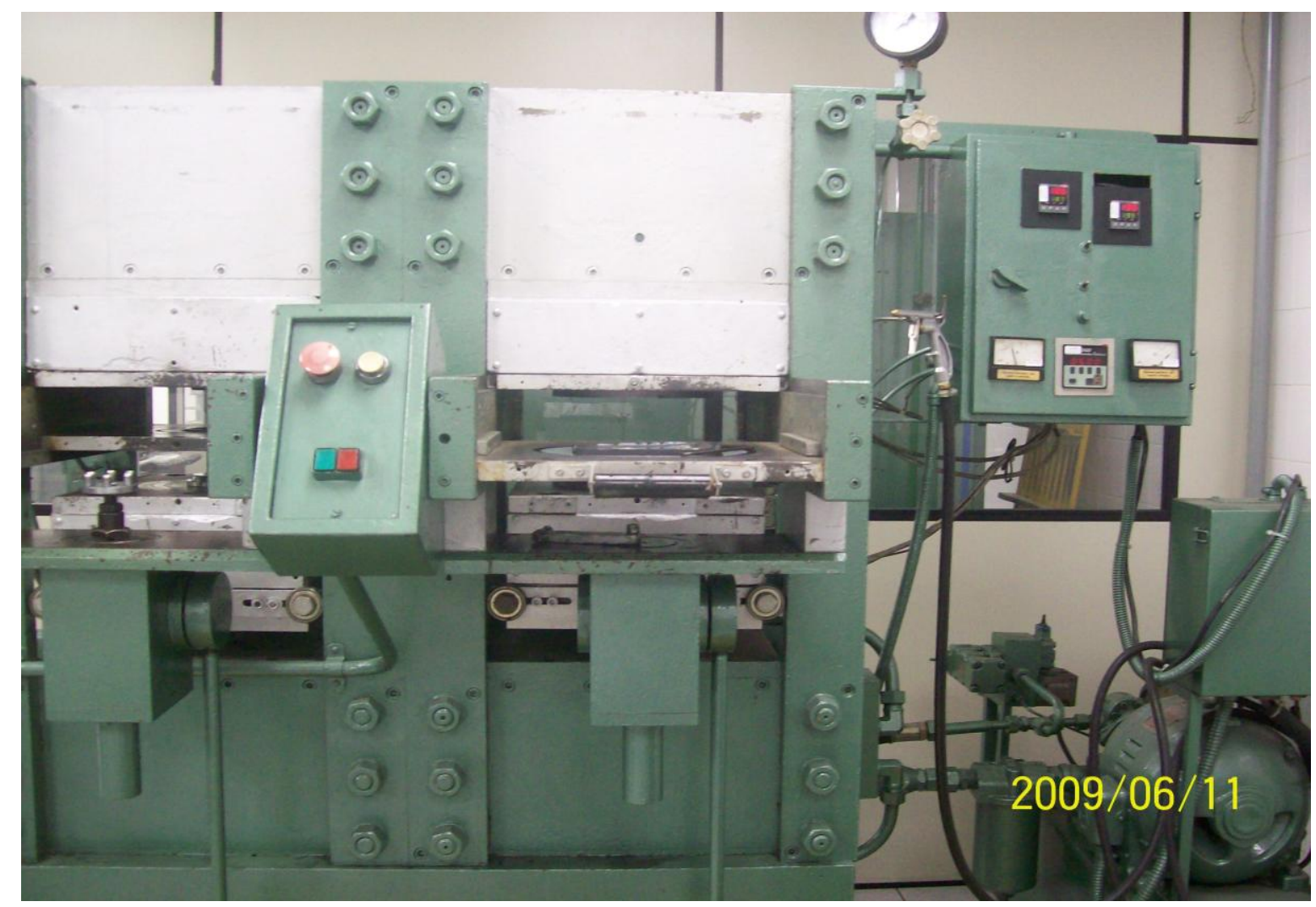

FIGURA 10 - Fotografia da prensa hidráulica utilizada para a incorporação da poliamida 6.6 à borracha poliacrílica

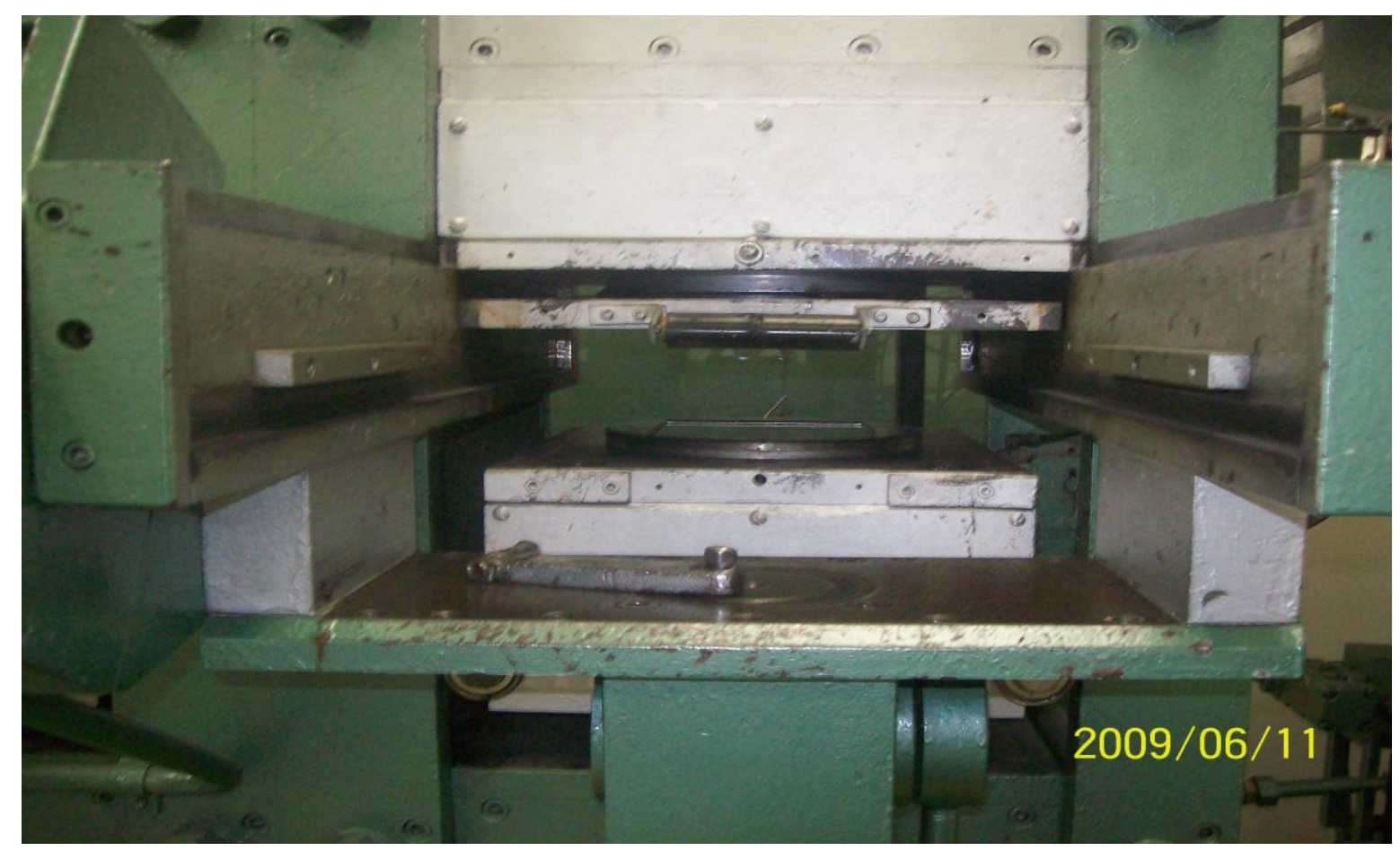

FIGURA 11 - Fotografia do molde utilizado para a incorporação da poliamida 6.6 à borracha poliacrílica 


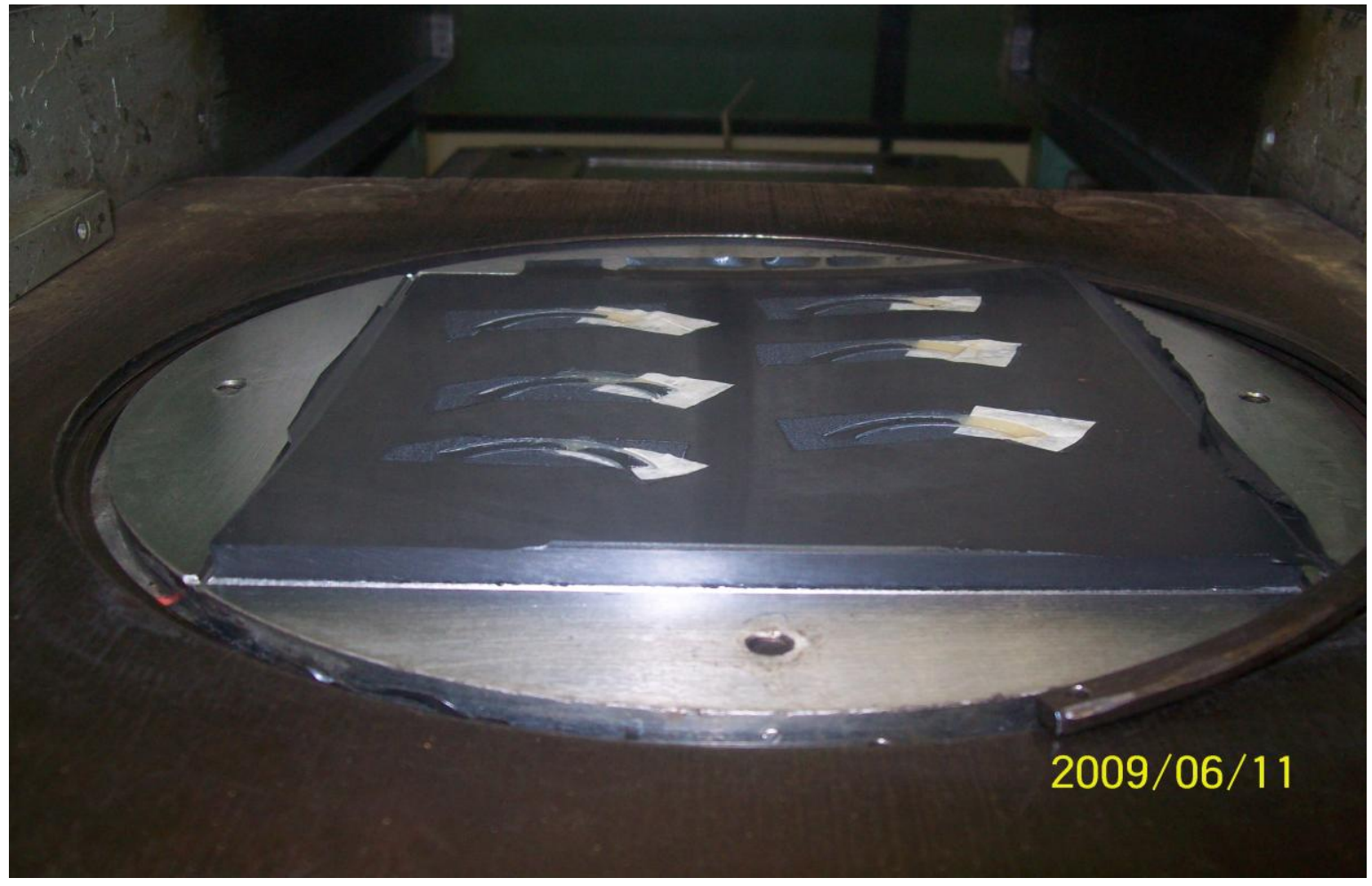

FIGURA 12 - Fotografia das amostras de poliamida 6.6 incorporadas à borracha poliacrílica

\subsection{Ensaio de adesão da poliamida 6.6 com a borracha poliacrílica}

As amostras de poliamida 6.6 não tratadas, tratadas por plasma e por radiação ionizante foram analisadas em relação à adesão com a borracha poliacrílica. A resistência à adesão entre a poliamida 6.6 e a borracha poliacrílida foi feita de acordo com a norma ASTM D 429, 2003, utilizando o dinamômetro da marca Emic dl 2000, da empresa Sabó, com célula de carga de 50kgf, da empresa Sabó mostrado na FIG. 13. 


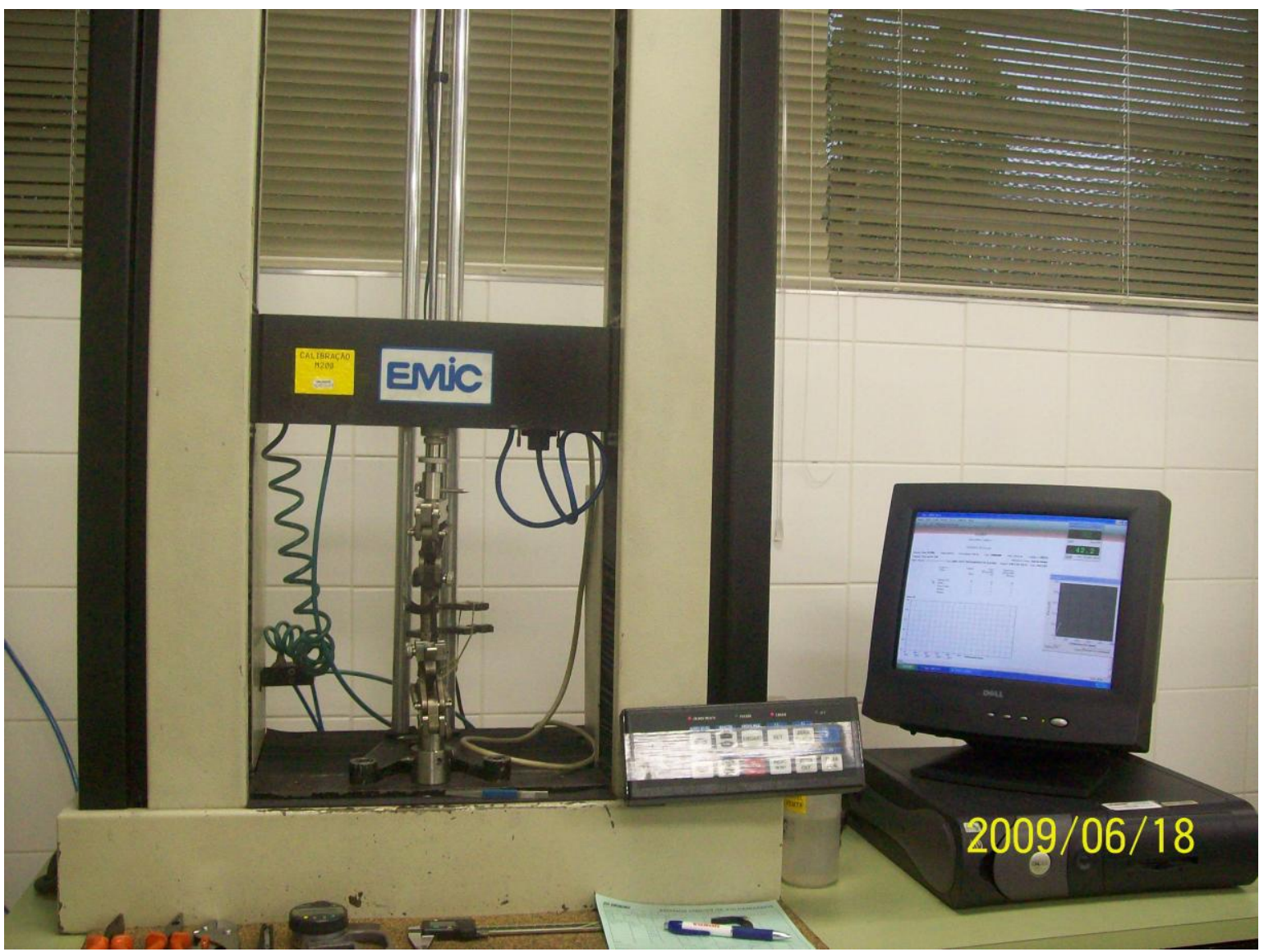

FIGURA 13 - Fotografia da máquina universal de ensaio Emic dl2000, com célula de carga de $50 \mathrm{kgf}$

O ensaio de adesão consiste em prender o substrato da amostra na garra fixa do dinamômetro e parte da borracha na garra móvel, e submeter a uma tensão até o desprendimento da borracha, conforme mostrado na FIG. 14.

A resistência à adesão é dada por N/mm, ou seja, força por unidade da secção transversal. 


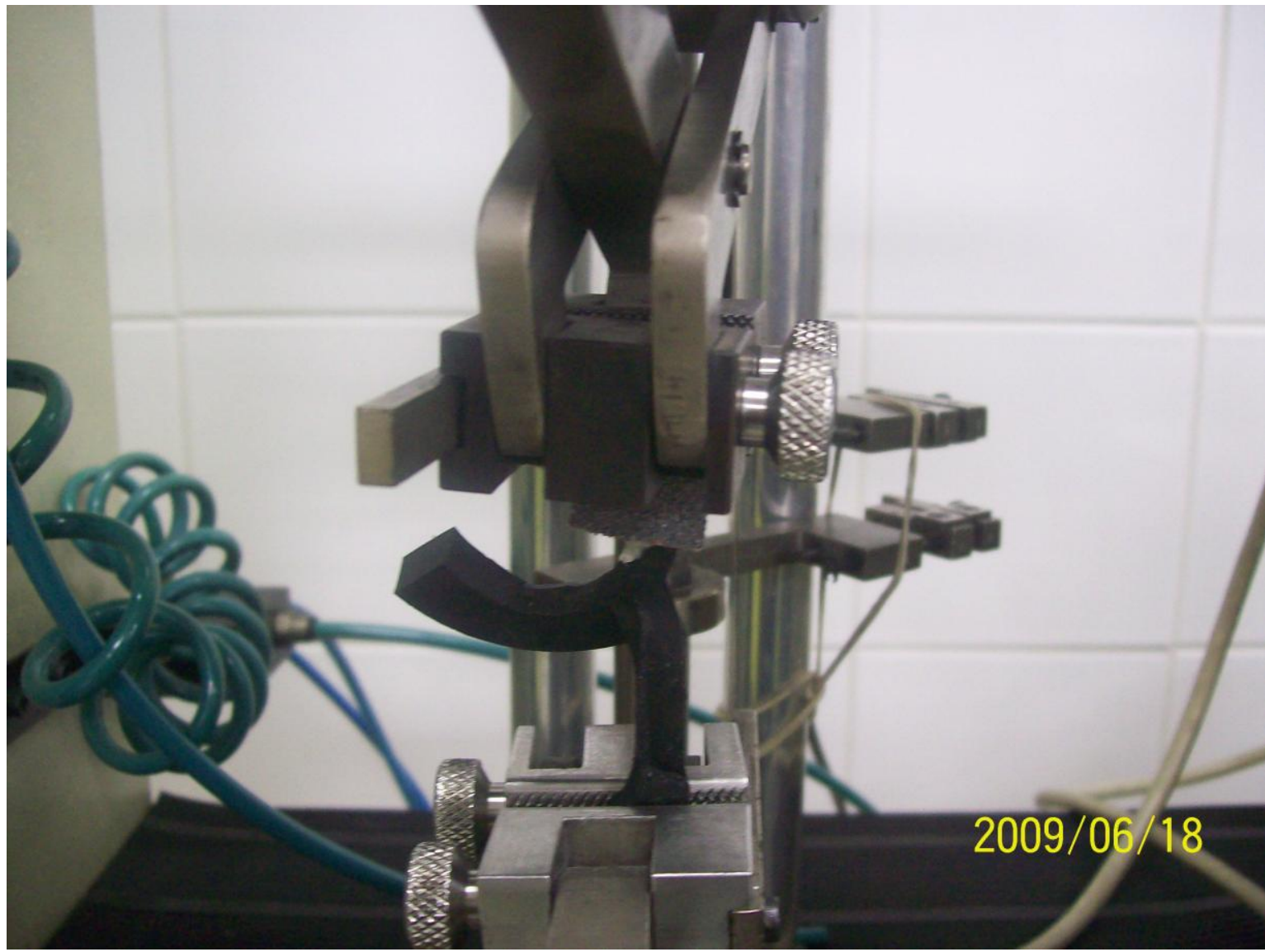

FIGURA 14 - Fotografia do instrumento utilizado para realizar o ensaio de aderência da amostra de PA 6.6/borracha poliacrílica

\subsection{Caracterização das amostras de poliamida 6.6}

A caracterização das amostras de poliamida 6.6 foi realizada utilizando diferentes técnicas que serão descritas a continuação.

\subsubsection{Microscopia Eletrônica de Varredura}

As análises foram realizadas utilizando-se um Microscópio Eletrônico de Varredura, da marca Joel, modelo 6460 LV, do IFUSP, mostrado na FIG. 15, com detector de elétrons retroespalhados, detector de elétrons secundários (alto e baixo vácuo) e sistema de EDS (Energy Dispersive Spectroscopy), sob um feixe eletrônico de 10,0kV e ampliações variáveis. 


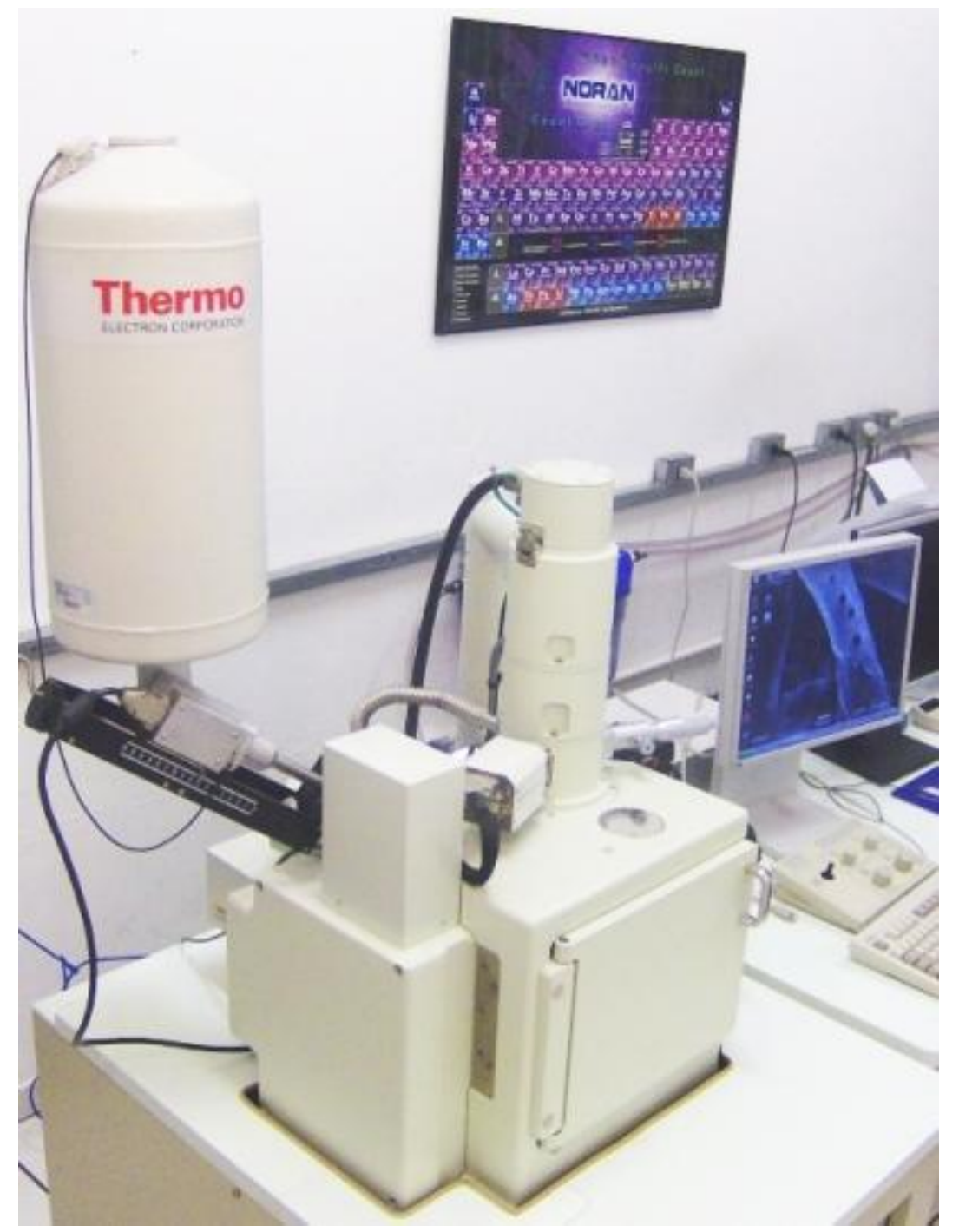

FIGURA 15 - Microscópio Eletrônico de Varredura, modelo 6460LV da marca Jeol

\subsubsection{Espectroscopia na região do infravermelho por transformada de Fourrier (FT-} IR)

Os ensaios de espectroscopia na região do infravermelho por transformada de Fourrier (FT-IR) foram realizados no espectrômetro marca Perkin Elmer, modelo Spectrun One, acoplado com dispositivo Universal ATR (“Sampling Acessory”), refletância total atenuada, do CTR, IPEN-CNEN/SP, conforme mostrado na FIG. 16. O equipamento possui um programa de comparação que permite correlacionar as diferenças espectrais ocorridas entre as amostras analisadas. A análise da amostra foi efetuada com radiação de número de onda variando entre 400 e $10.000 \mathrm{~cm}^{-1}$, a resolução utilizada foi de $2 \mathrm{~cm}^{-1}$ e os dados correspondem a uma média de 32 medidas, que é adquirida automaticamente pelo equipamento. Antes de posicionar a amostra para análise, obteve-se um espectro da 
radiação incidente transmitida por meio do porta amostra vazio. Esse espectro é utilizado para efetuar o cálculo da porcentagem da radiação, a qual foi transmitida.

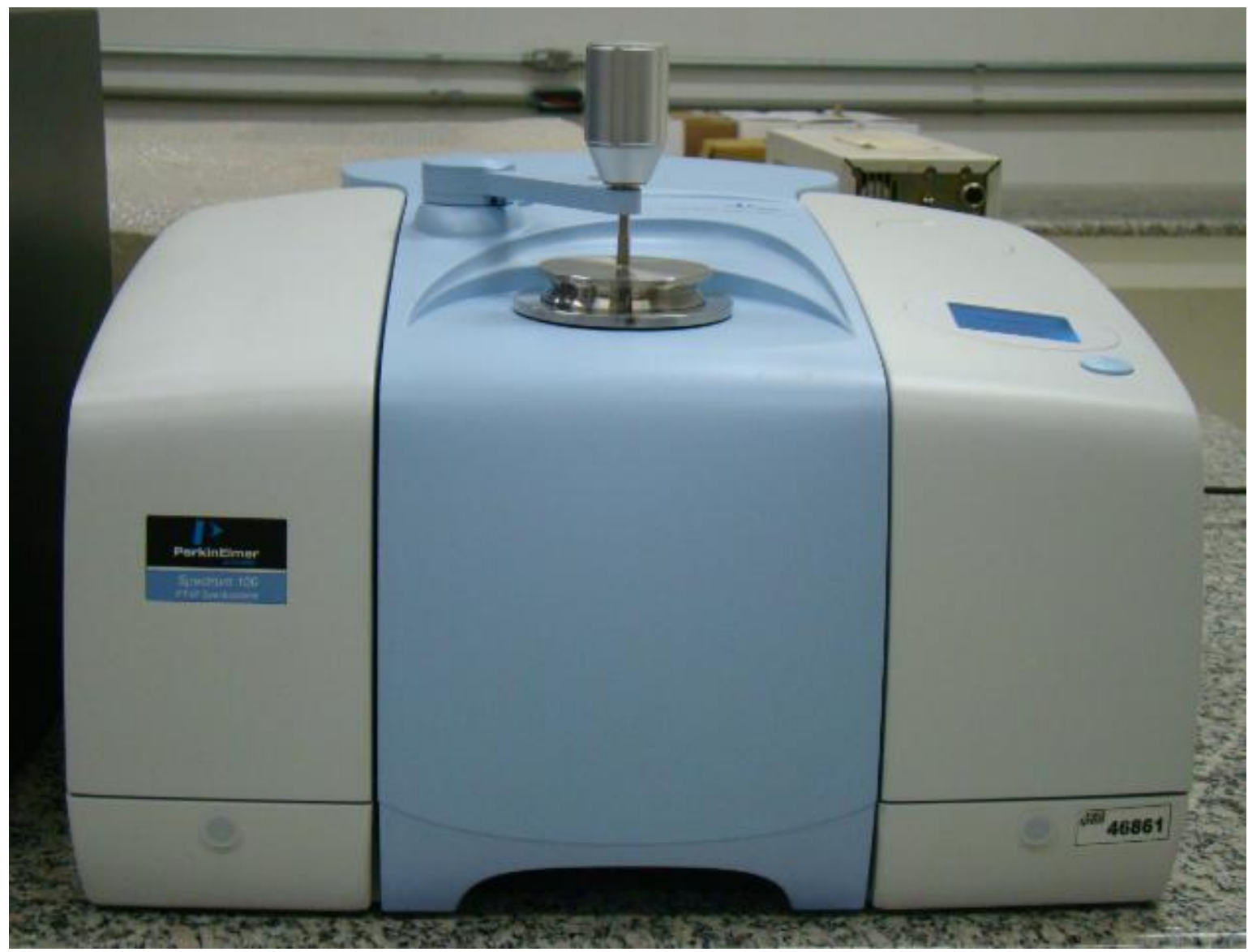

FIGURA 16 - Fotografia do espectrômetro Perkin Elmer, modelo Spectrun One, acoplado com dispositivo Universal ATR (“Sampling Acessory”)

\subsubsection{PIXE ("Particle Induced X-Ray Emission")}

PIXE é um método físico de análise quantitativa multielementar. Esta análise foi realizada no acelerador do tipo Pelletron-Tandem com stripper gasoso $\left(\mathrm{N}_{2}\right)$, modelo 5SDH, construído pela NEC ("National Eletrostatic Corporaation”), mostrado na FIG. 17, com a colaboração do Grupo de Física Aplicada com Aceleradores (GFAA), no LAMFI do Instituto de Física da USP. 


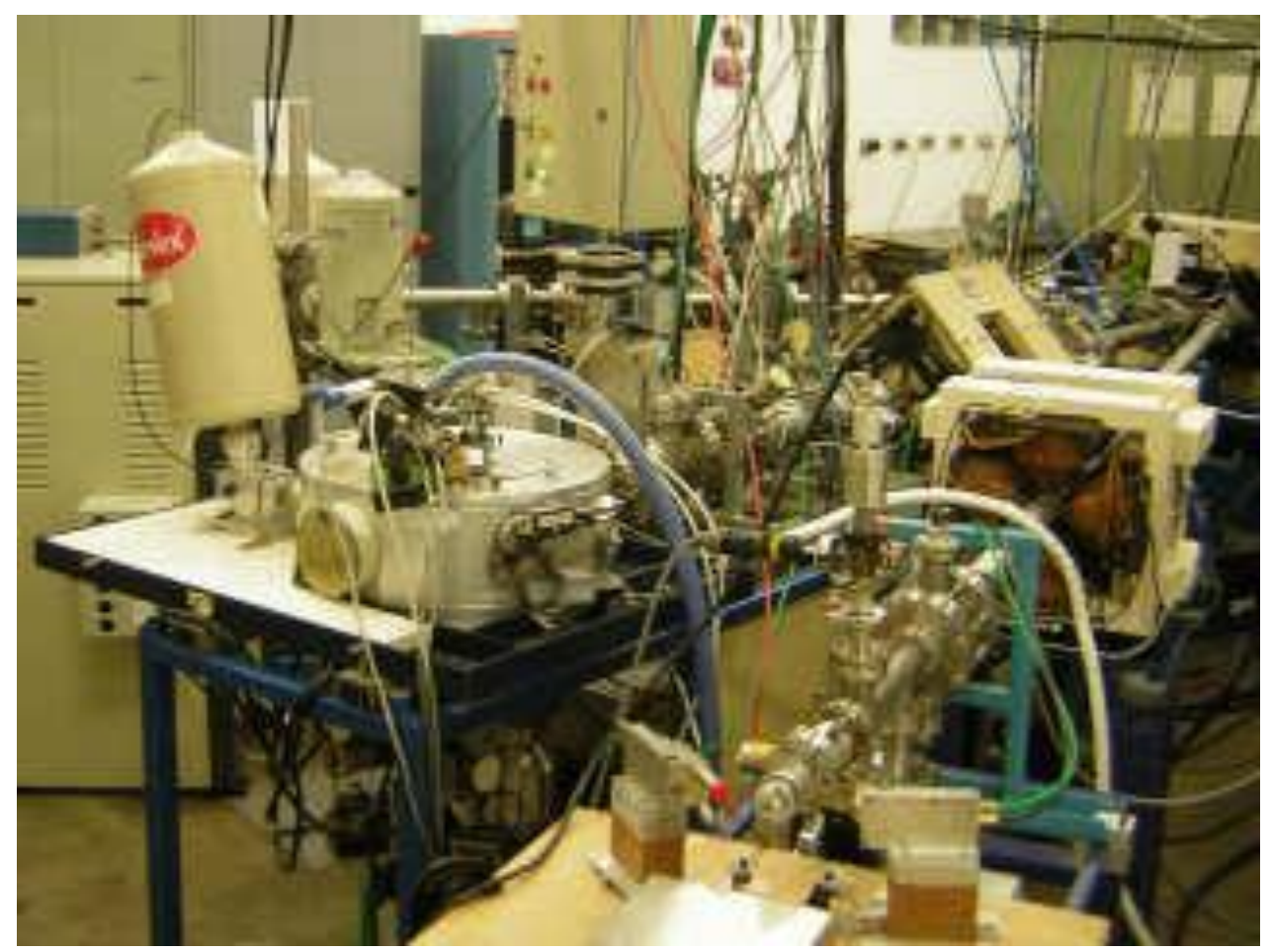

FIGURA 17 - Fotografia do acelerador do tipo Pelletron-Tandem com stripper gasoso $\left(\mathrm{N}_{2}\right)$, modelo 5SDH, construído pela NEC ("National Eletrostatic Corporation”)

A estação de análises PIXE, mostrada na FIG. 18 consta de uma câmara de alto vácuo projetada e construída no IFUSP. Contém um porta amostra linear parcialmente automatizado com capacidade para 18 discos de $25 \mathrm{~mm}$ de diâmetro, com controles-XY manuais e externos. Dispõe de dois detectores de raios-X tipo $\mathrm{Si}(\mathrm{Li})$, de eletrônica de controle e aquisição de espectros e de integração de carga. Os espectros são acumulados em buffer-multicanal conectado a um microcomputador pessoal tipo PC.

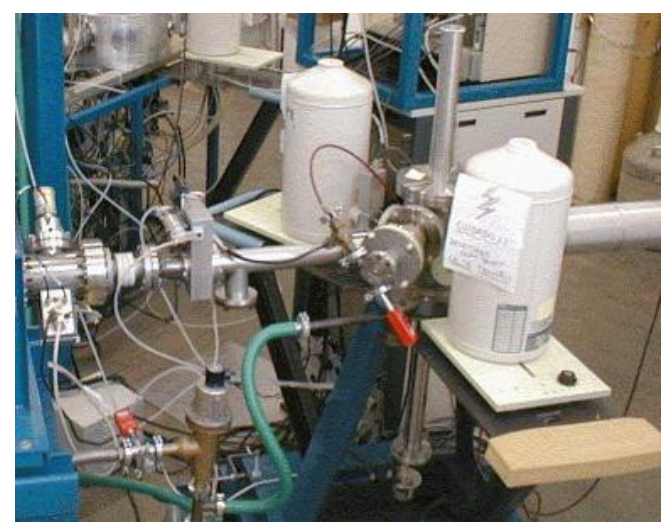

FIGURA 18 - Fotografia da estação de análises PIXE com dois detectores de Si(Li) 


\subsubsection{RBS ("Rutherford Backscattering Spectrometry")}

RBS é um método analítico que utiliza o espalhamento do íon incidente ou da partícula. Para a análise desta técnica foi utilizado um acelerador do tipo Pelletron-Tandem com stripper gasoso $\left(\mathrm{N}_{2}\right)$, modelo 5SDH, construído pela NEC ("National Eletrostatic Corporation"), mostrado na FIG. 17, com a colaboração do Grupo de Física Aplicada com Aceleradores (GFAA), no LAMFI do Instituto de Física da USP. A estação de análise por RBS mostrada na FIG. 19, consta de uma câmara de espalhamento, com $43 \mathrm{~cm}$ de diâmetro interno e $15 \mathrm{~cm}$ de altura que permite análises por espalhamento elástico, canalização de feixe e reações nucleares. Contém uma plataforma para vários detectores de barreira de superfície, os quais podem ser montados em qualquer ângulo em torno da amostra. As amostras são montadas num suporte móvel com cinco graus de liberdade semi automatizado e podem ser carregadas sem quebra de vácuo da câmara. A aquisição de dados é feita por um buffer-multicanal acoplado a um microcomputador pessoal tipo PC.

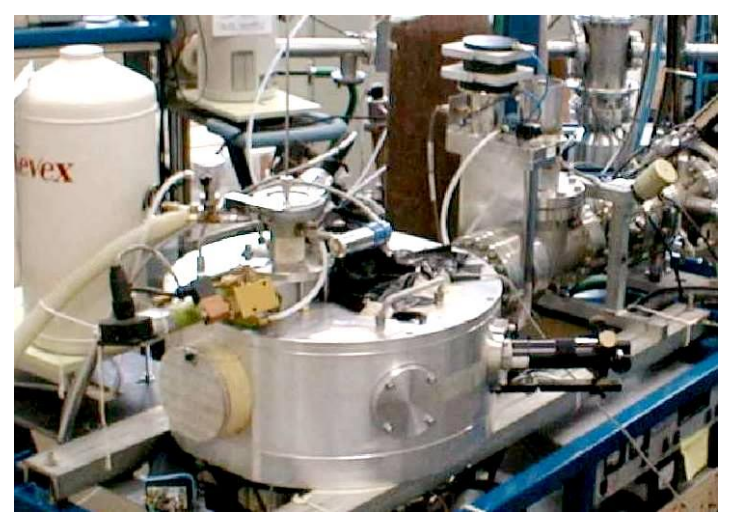

FIGURA 19 - Fotografia da câmara multiuso para análise RBS

\subsubsection{MFA (Microscopia de força atômica)}

As análises de microscopia de força atômica foram realizadas utilizando-se um Microscópio de Varredura por Sonda, da marca Joel, modelo JSPM 5200 utilizando modo contato de força, referência de $-1,50 \mathrm{~V}$ e tamanho de imagem de $10 \times 10 \mu \mathrm{m}$, do Centro de Ciência e Tecnologia de Materiais (CCTM), no IPEN - CNEN/SP, conforme FIG. 20. 


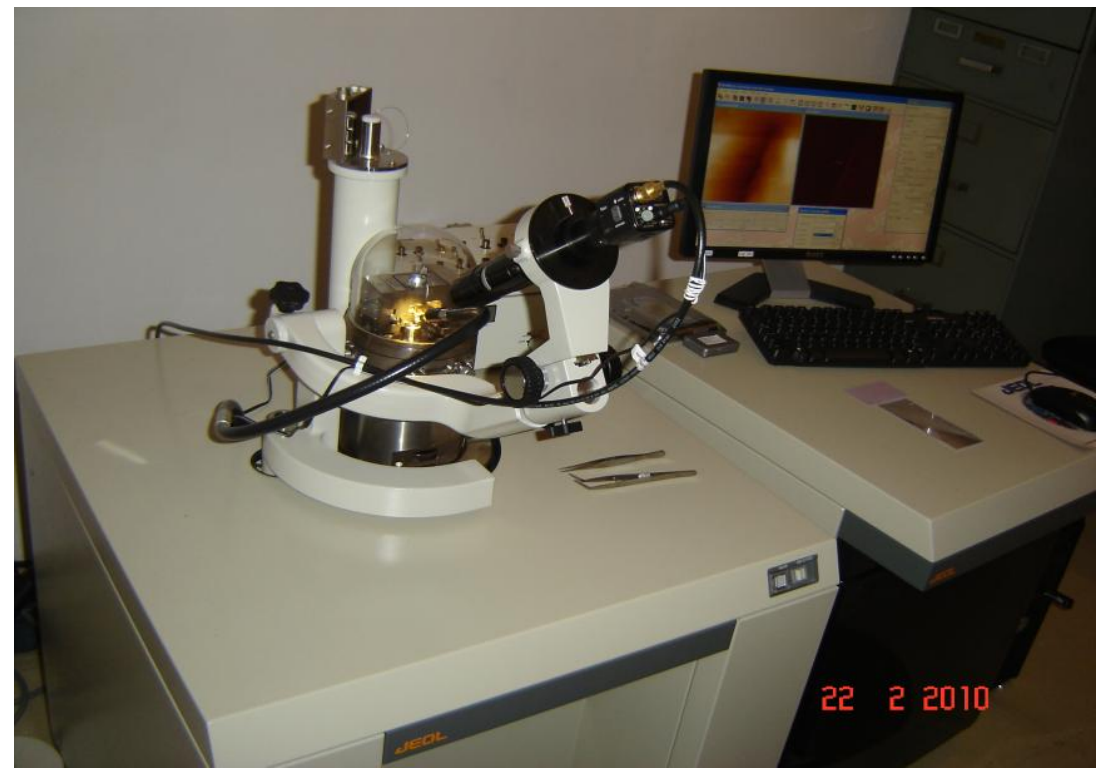

FIGURA 20 - Fotografia do equipamento de microscopia de força atômica

\subsection{6 Ângulo de contato}

As análises de ângulo de contato foram realizadas no LAMFI do Instituto de Física da USP, utilizando um orgoniômetro constituído de micropitetador, resistência de aquecimento, porta-amostra, ponteira plástica, câmera digital, nível de bolha e dispersador, conforme FIG. 21.

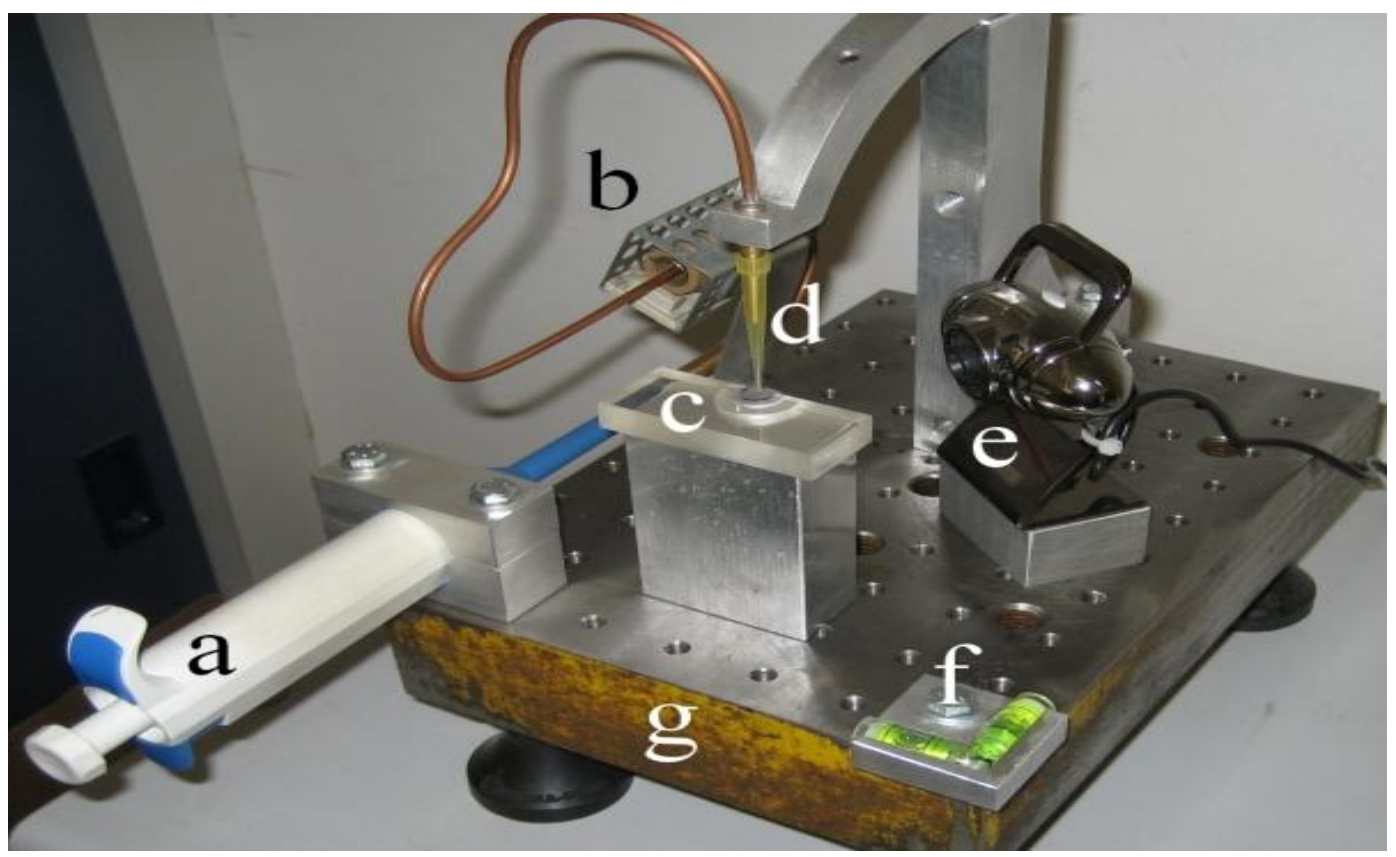

FIGURA 21 - Fotografia do equipamento de medição de ângulo de contato 


\section{DISCUSSÃO DOS RESULTADOS}

\subsection{Ensaios de adesão}

As amostras de PA 6.6 não tratadas, tratadas por plasma e por radiação ionizante foram incorporadas a borracha poliacrílica. Posteriormente, foi analisada a qualidade da adesão entre a poliamida 6.6 e a borracha poliacrílica. As amostras de PA 6.6 não tratadas, em número de três, não apresentaram aderência com a borracha poliacrílica.

As amostras de PA 6.6 tratadas por plasma apresentaram boa aderência com a borracha poliacrílica, após oito horas do tratamento. Porém, em função da espessura de 1 $\mathrm{mm}$ da borracha, a mesma rompeu antes do térmico do ensaio. Os resultados dos ensaios de adesão entre a PA 6.6 e a borracha poliacrílica estão apresentados na TAB.1.

TABELA 1 - Resultados dos ensaios de adesão $(\mathrm{N} / \mathrm{mm})$ entre a poliamida 6.6 e a borracha poliacrílica para amostras sem tratamento e após 8 horas do tratamento

\begin{tabular}{ccc}
\hline Corpo de prova & Sem tratamento & $\begin{array}{c}\text { 8h após } \\
\text { tratamento }\end{array}$ \\
\hline Amostra 01 & 0,2 & 1,55 \\
Amostra 02 & 0,1 & 0,80 \\
Amostra 03 & 0,2 & --- \\
\hline
\end{tabular}

Após $72 \mathrm{~h}$ e $168 \mathrm{~h}$ do tratamento por plasma foram feitas novas incorporações com amostras de PA-6.6 e borracha poliacrílica, aumentando a espessura da borracha para 4 mm. Os resultados dos ensaios de adesão entre a PA 6.6 e a borracha poliacrílica são apresentados na TAB. 2. 
TABELA 2 - Resultados dos ensaios de adesão $(\mathrm{N} / \mathrm{mm})$ entre a poliamida 6.6 e a borracha poliacrílica para amostras sem tratamento e após 72 e 168 horas do tratamento

\begin{tabular}{ccccc}
\hline Corpos de prova & Sem tratamento & $\begin{array}{c}\text { Após } \\
\text { tratamento }\end{array}$ & $\begin{array}{c}72 \mathrm{~h} \\
\text { do Após } \\
\text { tratamento }\end{array}$ & $\begin{array}{c}\text { do8h } \\
\text { Amostra 01 }\end{array}$ \\
\hline Amostra 02 & 0,52 & 6,21 & 9,87 \\
Amostra 03 & 0,79 & 5,79 & 9,70 \\
\hline
\end{tabular}

Após 504h e 1008h do tratamento por plasma foram feitas novas incorporações com amostras de PA 6.6 e borracha poliacrílica, para avaliar possíveis alterações na superfície da PA 6.6 tratada. A qualidade da adesão entre a PA 6.6 e a borracha poliacrílica continuou muito boa conforme resultados apresentados na TAB 3.

TABELA 3 - Resultados dos ensaios de adesão (N/mm) entre a poliamida 6.6 e a borracha poliacrílica para amostras sem tratamento e após 504 e 1008 horas do tratamento

\begin{tabular}{cccc}
\hline Corpos de prova & Sem tratamento & $\begin{array}{c}\text { Após } 504 \mathrm{~h} \text { do } \\
\text { tratamento }\end{array}$ & $\begin{array}{c}\text { Após } 1008 \mathrm{~h} \mathrm{do} \\
\text { tratamento }\end{array}$ \\
\hline Amostra 01 & 1,18 & 7,36 & 5,23 \\
Amostra 02 & 0,52 & 9,95 & 8,39 \\
Amostra 03 & 0,79 & 9,52 & 9,83 \\
\hline
\end{tabular}

As amostras de poliamida 6.6 irradiadas com doses de radiação de 5, 10, 20, e 40kGy, a vácuo, utilizando taxa de dose de 11,22 kGy/s, não aderiram a borracha poliacrílica. Para a dose de 20kGy e taxa de dose de 22,38 kGy/s também não houve aderência da poliamida com a borracha poliacrílica, assim como, as amostras não irradiadas. Foi observado mudança na coloração das amostras.

As amostras de poliamida 6.6 irradiadas com feixe de elétrons, submetidas a diferentes doses de radiação de 50,100, 200, 300, 400 e 500kGy, à pressão atmosférica, tiveram mudanças na coloração e não aderiram à borracha poliacrílica. 
Posteriormente, foram comparados os resultados destes ensaios de tratamento por plasma e por radiação ionizante da poliamida 6.6, para verificar qual seria o melhor para a adesão entre a poliamida 6.6 e a borracha poliacrílica e assim, poder usar estes materiais na fabricação de retentores para automóveis.

\subsection{Caracterização da superfície da poliamida 6.6}

As análises das superfícies das amostras de PA 6.6 não tratadas e tratadas por plasma, utilizando a técnica de $\mathrm{MEV}$, apresentaram pequenas diferenças de relevo nas imagens topográficas, como mostradas nas FIG. 22 e 23.

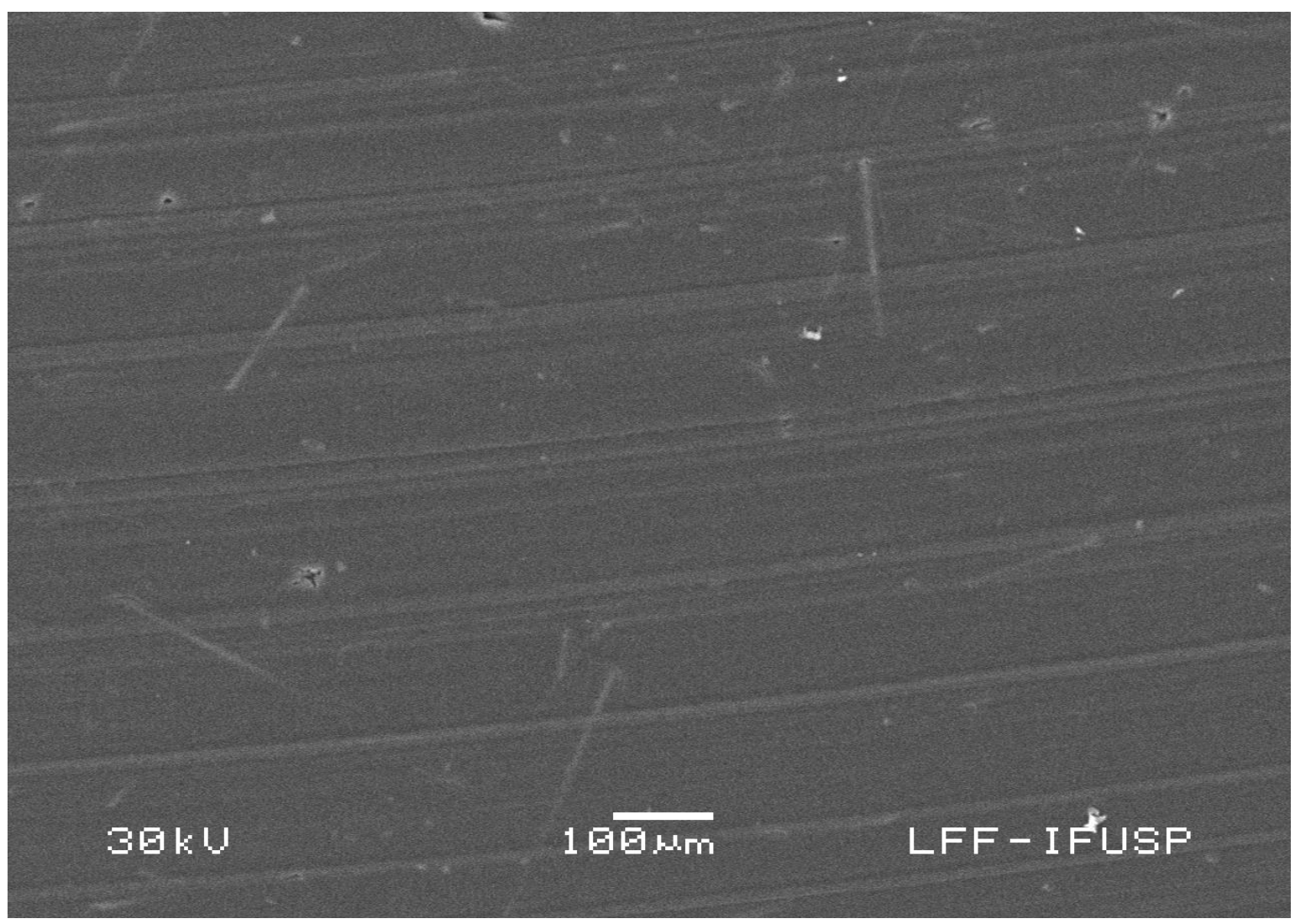

FIGURA 22 - Imagem topográfica da amostra de PA 6.6 sem tratamento, magnitude $1000 \mathrm{X}$ e $30 \mathrm{kV}$ 


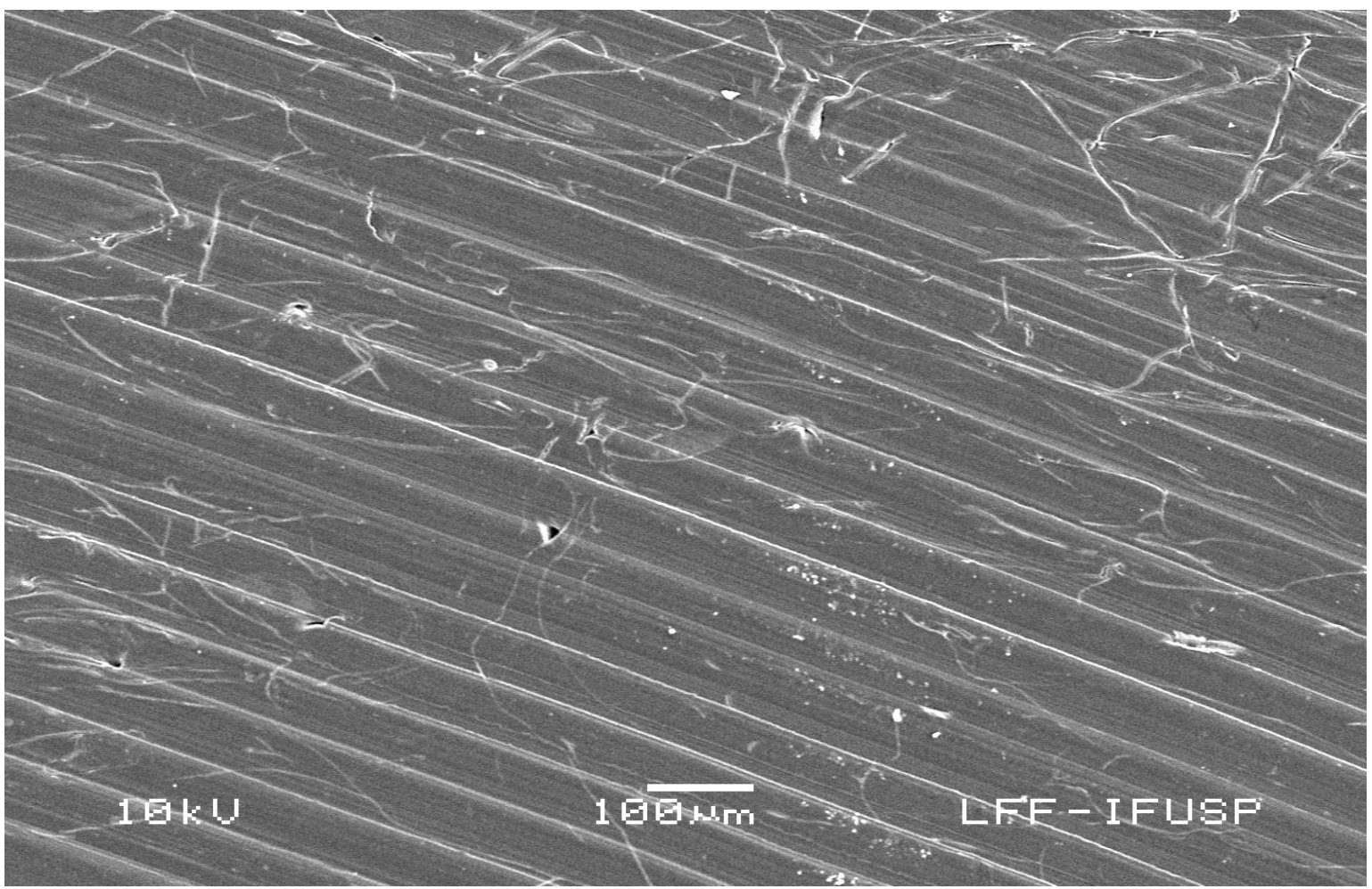

FIGURA 23 - Imagem topográfica da amostra de PA 6.6 após tratamento por plasma, magnitude 1000X e 10kV

As superfícies das amostras não tratadas e tratadas por plasma, analisadas pela técnica de EDS, acoplado ao microscópio eletrônico de varredura, não apresentaram diferenças de composição, conforme os resultados apresentados nas TAB. 4 e 5 e mostradas nas FIG. 24 e 25.

TABELA 4 - Análise de composição da amostra de PA 6.6 sem tratamento

\begin{tabular}{cccc}
\hline Elemento & Massa (\%) & Erro (\%) & Átomo (\%) \\
\hline $\mathrm{C}$ & 70,98 & $+/-0,36$ & 80,64 \\
$\mathrm{~N}$ & 13,71 & $+/-1,61$ & 13,36 \\
$\mathrm{O}$ & 6,30 & $+/-0,33$ & 5,38 \\
$\mathrm{Au}$ & 9,01 & $+/-1,53$ & 0,62 \\
Total & 100,00 & & 100,00 \\
\hline
\end{tabular}


TABELA 5 - Análise de composição da amostra de PA 6.6 após tratamento por plasma

\begin{tabular}{cccc}
\hline Elemento & Massa $(\%)$ & Erro $(\%)$ & Átomo $(\%)$ \\
\hline $\mathrm{C}$ & 69,68 & $+/-0,38$ & 80,63 \\
$\mathrm{~N}$ & 13,11 & $+/-1,69$ & 13,01 \\
$\mathrm{O}$ & 6,45 & $+/-0,36$ & 5,60 \\
$\mathrm{Au}$ & 10,77 & $+/-1,82$ & 0,76 \\
Total & 100,00 & & 100,00 \\
\hline
\end{tabular}

O elemento ouro, Au, o qual aparece na análise de composição das amostras de PA 6.6 é proveniente do processo de metalização das mesmas. O processo de metalização da PA 6.6 é necessário para torná-la condutora e ser possível realizar a análise no MEV.

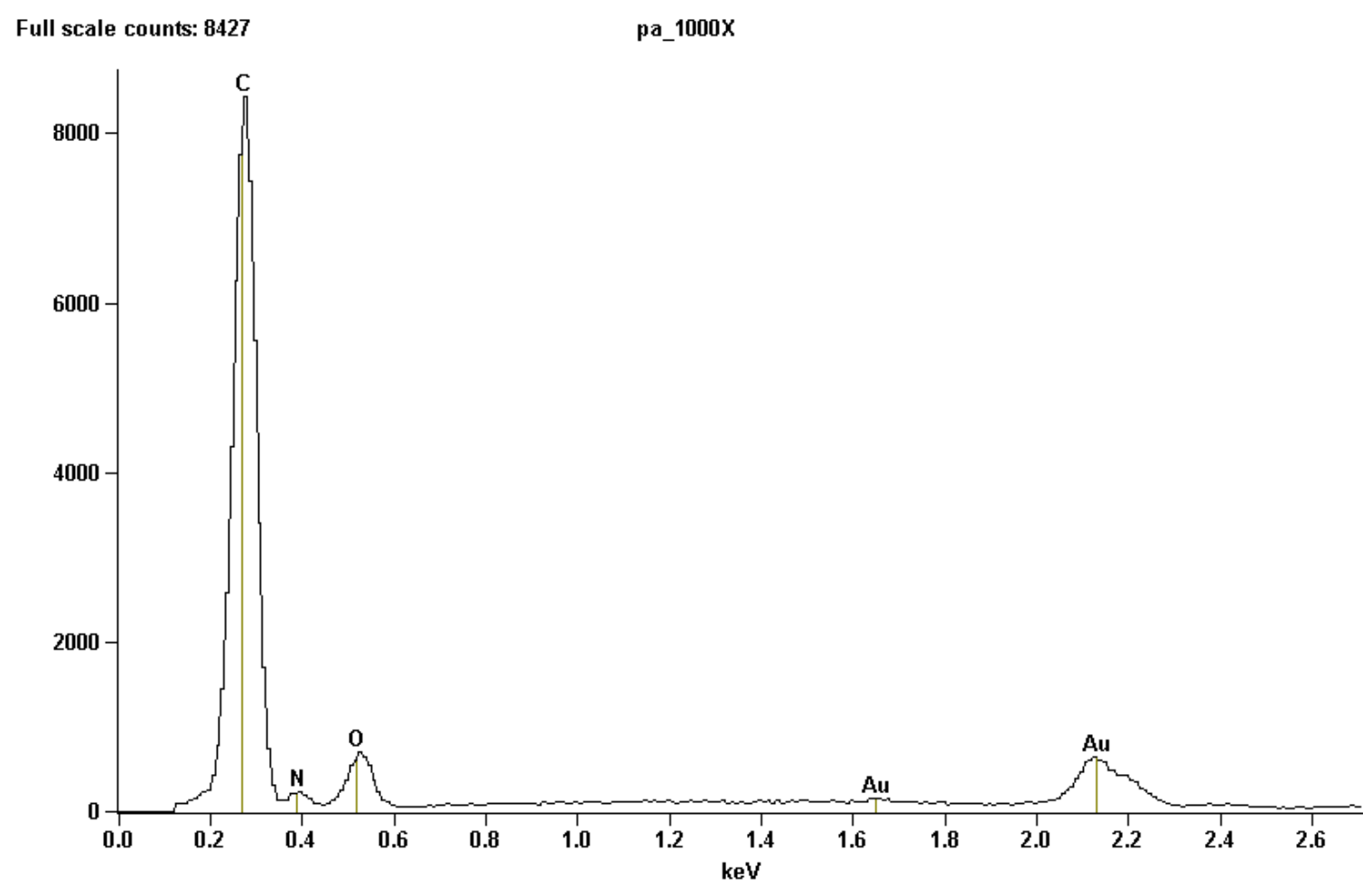

FIGURA 24 - Curva de composição da amostra de PA 6.6 sem tratamento 


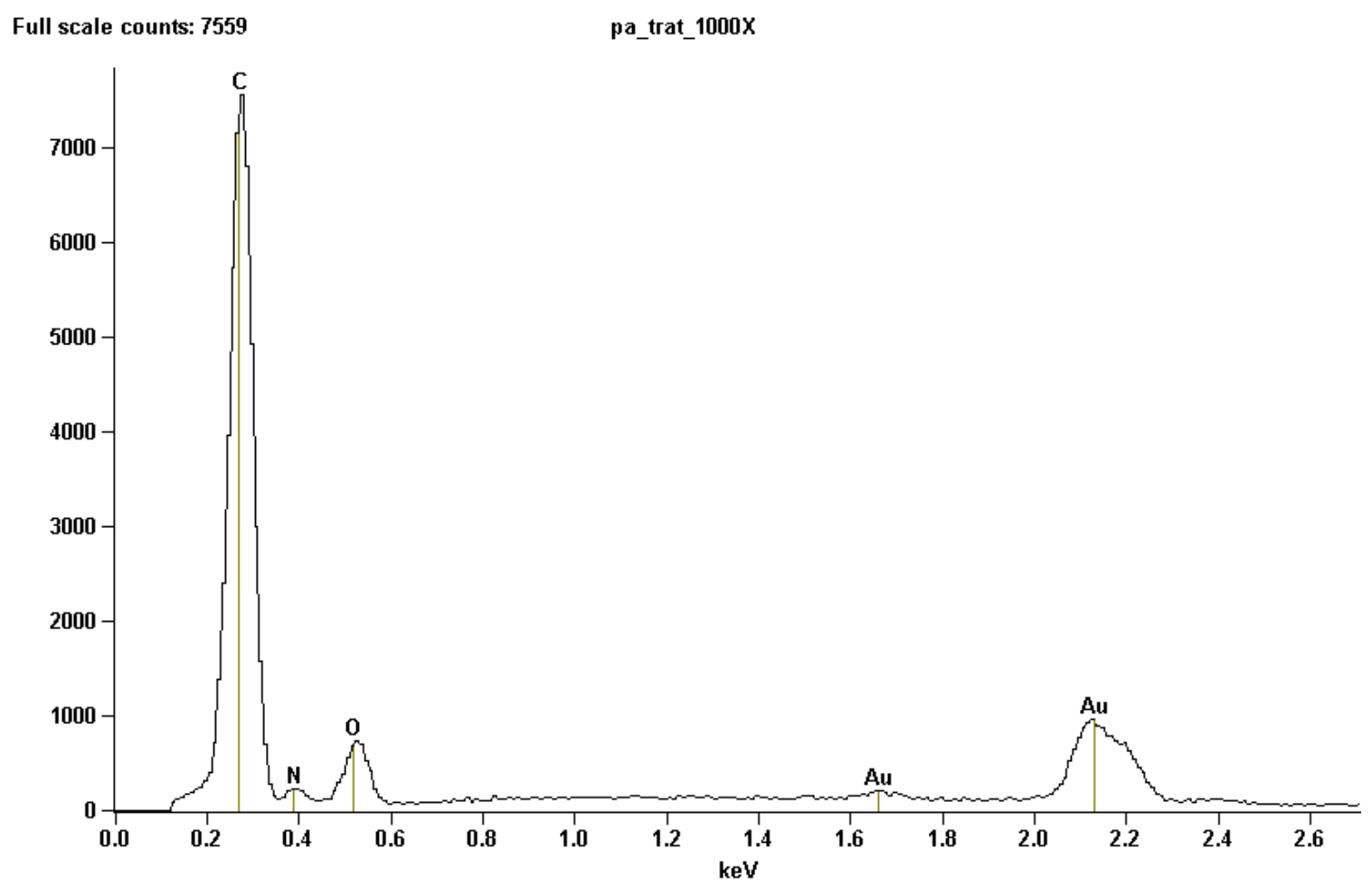

FIGURA 25 - Curva de composição da amostra de PA 6.6 após tratamento por plasma

As amostras não tratadas e as amostras tratadas por plasma foram caracterizadas utilizando a técnica de FTIR, que consistiu na análise das bandas de absorção da radiação infravermelho pelo material estudado. As regiões de comprimento de onda que apresentaram menores valores de transmitância são regiões onde ocorrem absorções da radiação. Essa absorção está relacionada com os grupos químicos existentes no material.

Nas FIG. 26 e 27 são mostrados os espectros de transmissão da radiação de IR para duas regiões de comprimento de onda. A região de 8.000 a $10.000 \mathrm{~cm}^{-1}$ foi omitida por não apresentar nenhuma informação. 


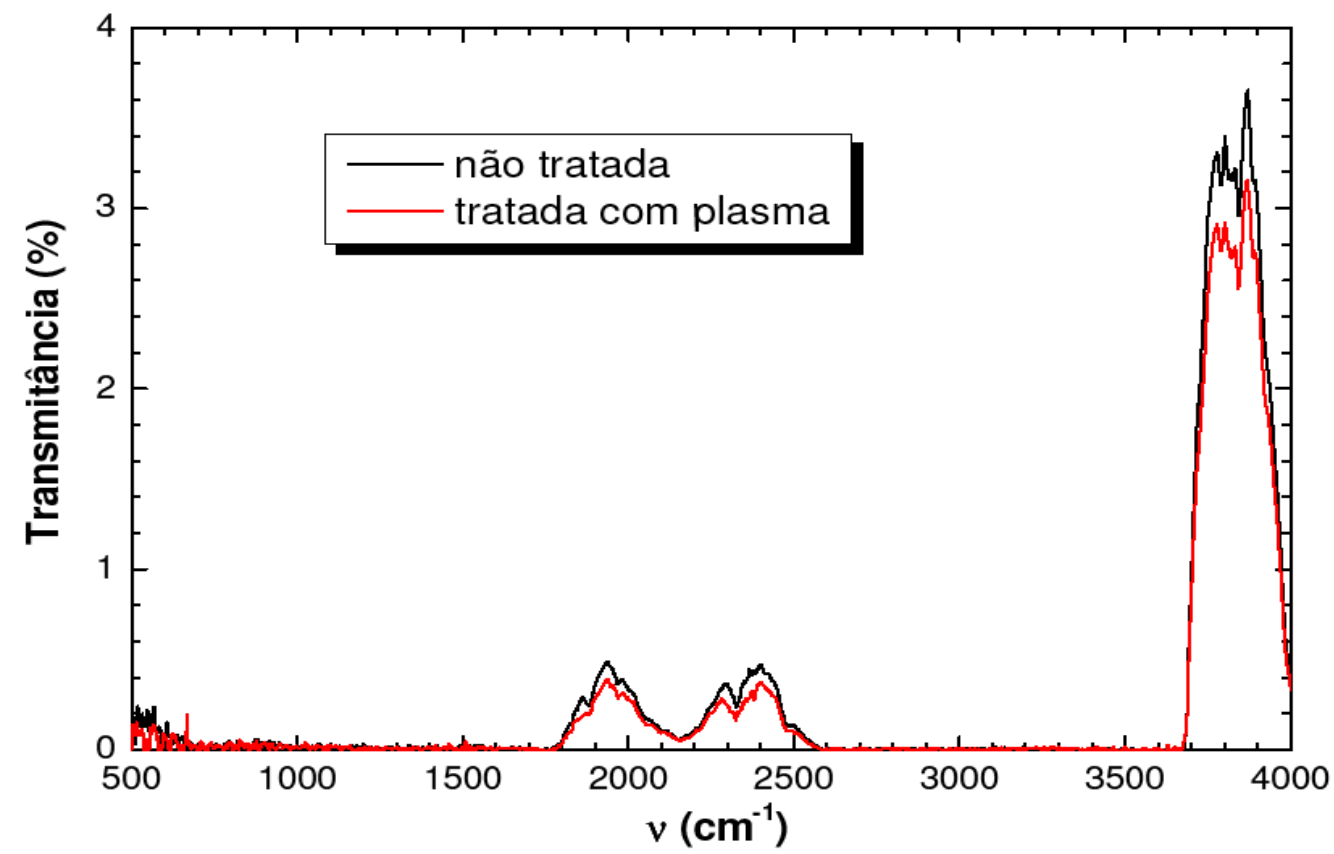

FIGURA 26 - Espectro de transmissão de IR de uma amostra de PA 6.6 não tratada e uma tratada por plasma na região de 500 a $4000 \mathrm{~cm}^{-1}$

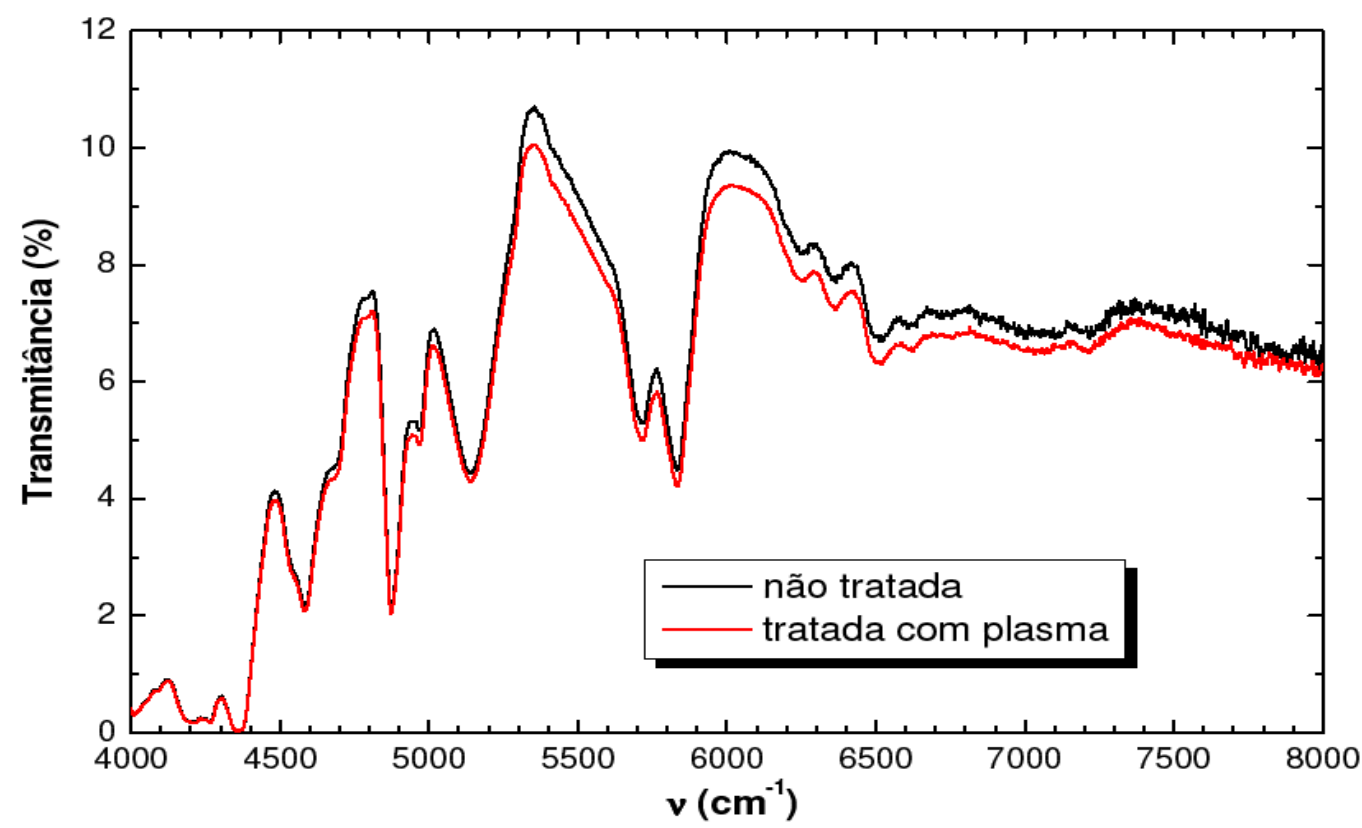

FIGURA 27 - Espectro de transmissão de IR de uma amostra de PA 6.6 não tratada e uma tratada por plasma na região de 4000 a $8000 \mathrm{~cm}^{-1}$ 
Nas FIG. 26 e 27 pode-se observar que, após o tratamento por plasma, a amostra de PA 6.6 passou a apresentar menores valores de transmitância em todo o espectro, o que indica que as modificações induzidas não correspondem às mudanças nas ligações ou grupos químicos existentes no material, mas sim em alguma propriedade do material que é independente do comprimento de onda. A diminuição da transmitância pode ser associada ao aumento de espessura do material, após o depósito de outro material durante o tratamento. Esse depósito pode ser revelado por meio da técnica de RBS.

Também é possível verificar nas FIG. 26 e 27 que a porcentagem de transmitância foi baixa, fato que se deve à espessura da amostra. Essa elevada espessura dificulta a análise nas regiões de 500 a 1800 e 2600 a $3700 \mathrm{~cm}^{-1}$, em que a intensidade da absorção encontra-se saturada.

As amostras não tratadas, as amostras tratadas por plasma e as amostras irradiadas também foram analisadas utilizando o método de refletânica (ATR) pela técnica de FT-IR.

De acordo com os resultados mostrados nas FIG. 28 e 29 observou-se que a amostra tratada por plasma, as amostras irradiadas e a amostra não tratada de PA 6.6 não apresentaram diferenças de transmitância, confirmando a ausência de formação de novos grupamentos ou ligações químicas, após os tratamentos das amostras. 


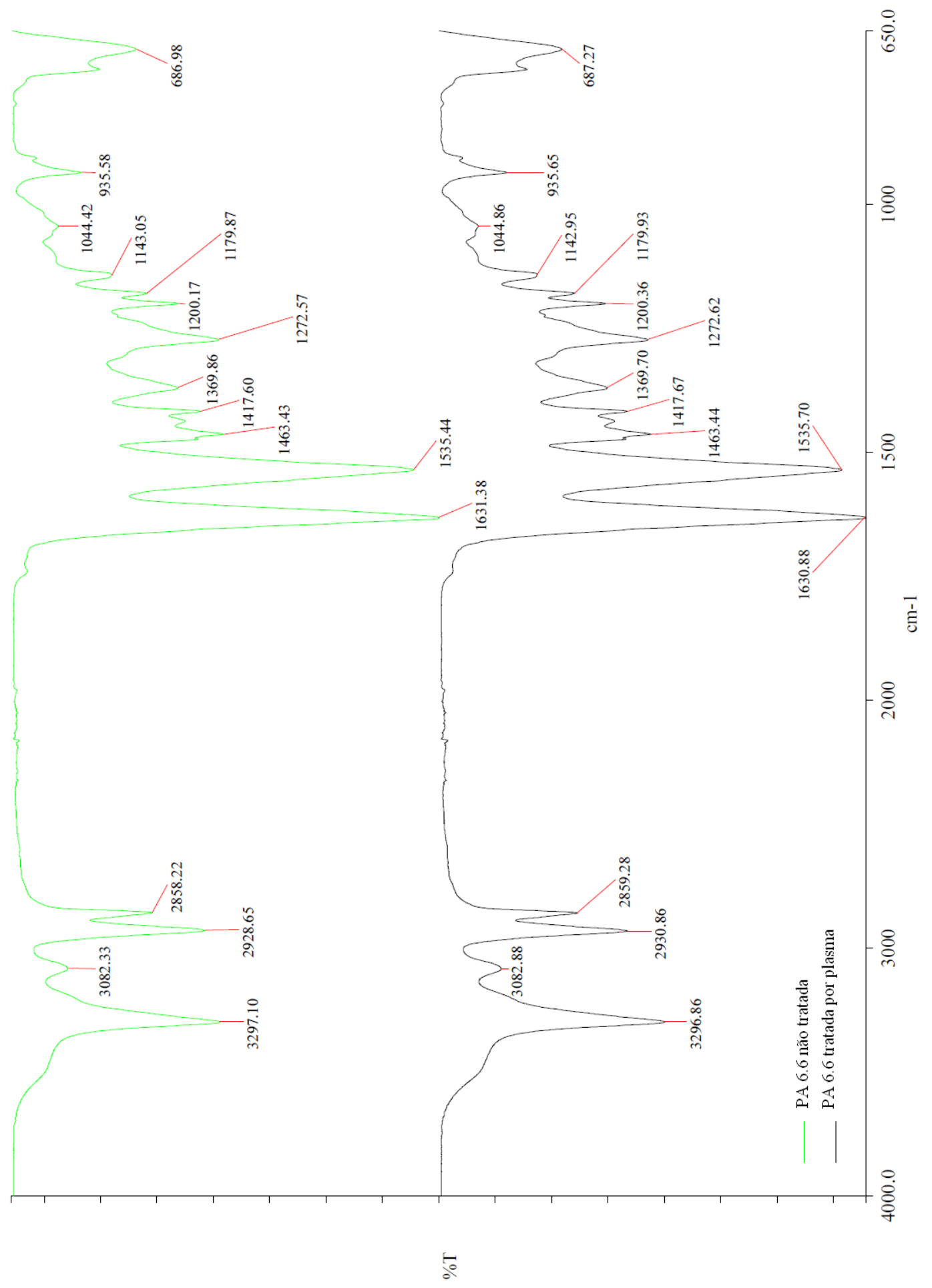

FIGURA 28 - Curvas dos espectros de infravermelho ATR das amostras de PA 6.6 não tratada e tratada por plasma 


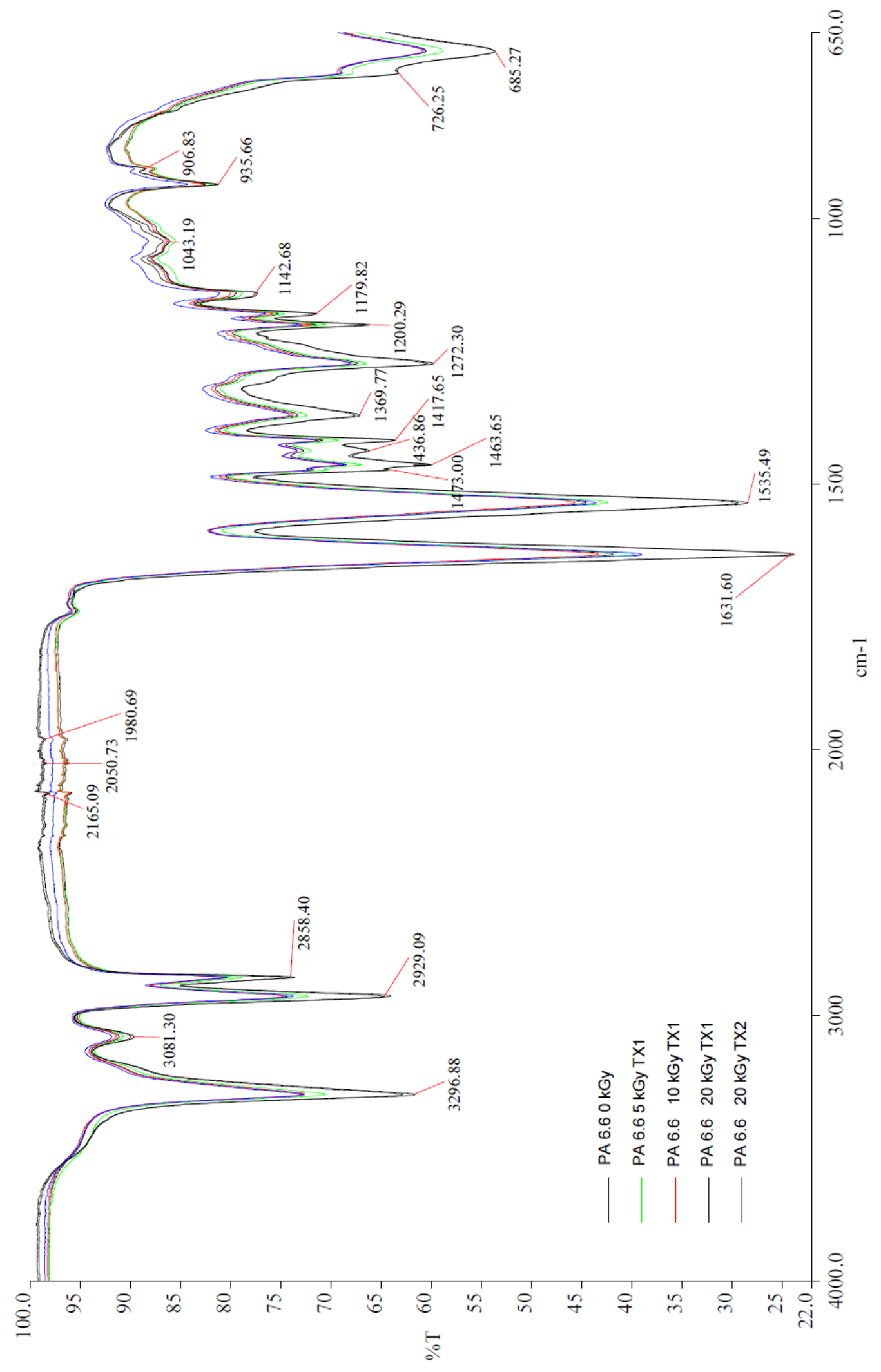

FIGURA 29 - Curvas dos espectros de infravermelho ATR das amostras de PA 6.6 não tratadas e tratadas por irradiação com dose de 5, 10 e 20kGy, em que TX1 corresponde a taxa de dose de 11,22 kGy/s e TX2 corresponde a taxa de dose de 22,38 kGy/s 
As amostras não tratadas e as amostras tratadas por plasma foram analisadas utilizando-se as técnicas de PIXE e RBS.

Por meio da técnica de PIXE nota-se, conforme mostrados nas FIG. 30 e 31, os elementos Fe, K, S e P presentes na amostra de PA 6.6 tratada. Fato não observado nas amostras de PA 6.6 sem tratamento.

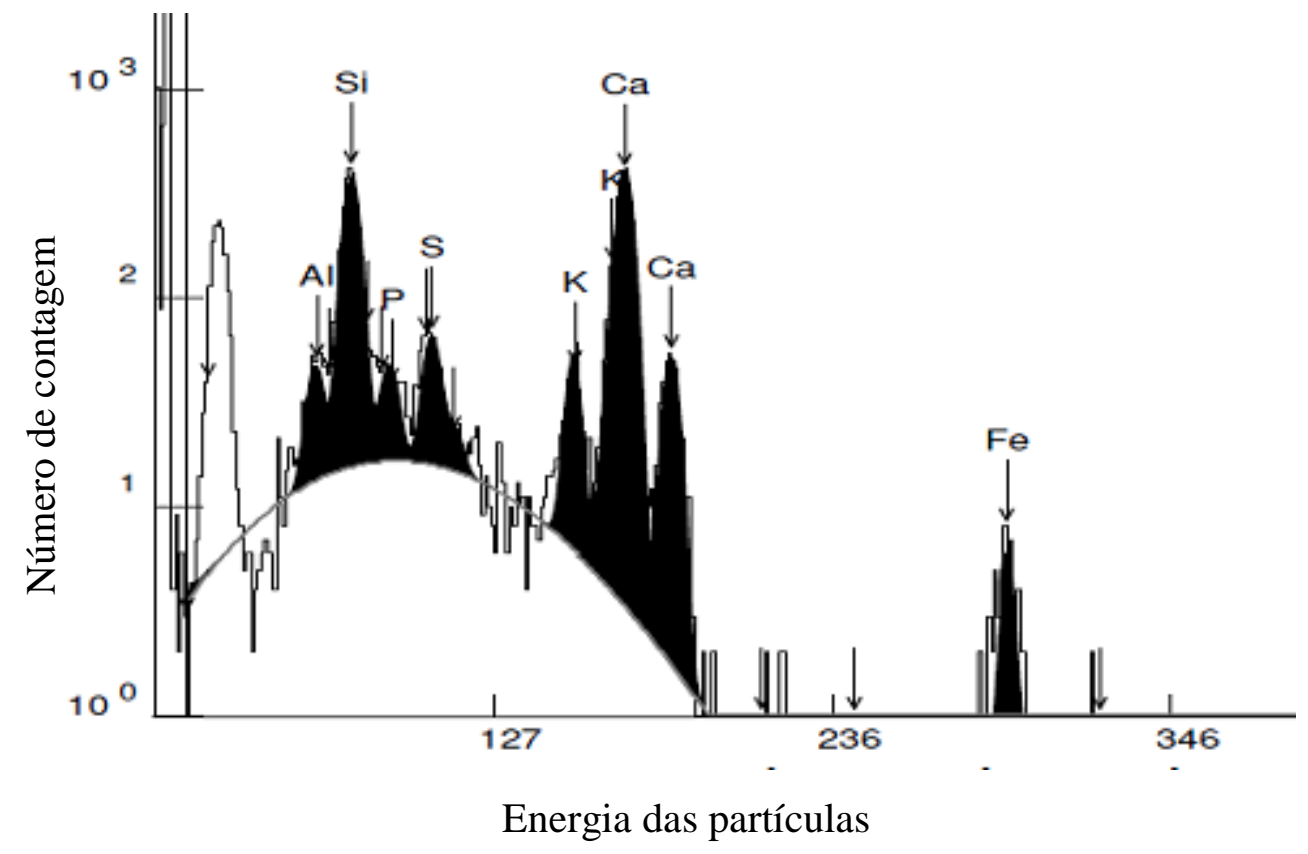

FIGURA 30 - Curva de composição da amostra de PA 6.6 tratada por plasma utilizando o método PIXE 


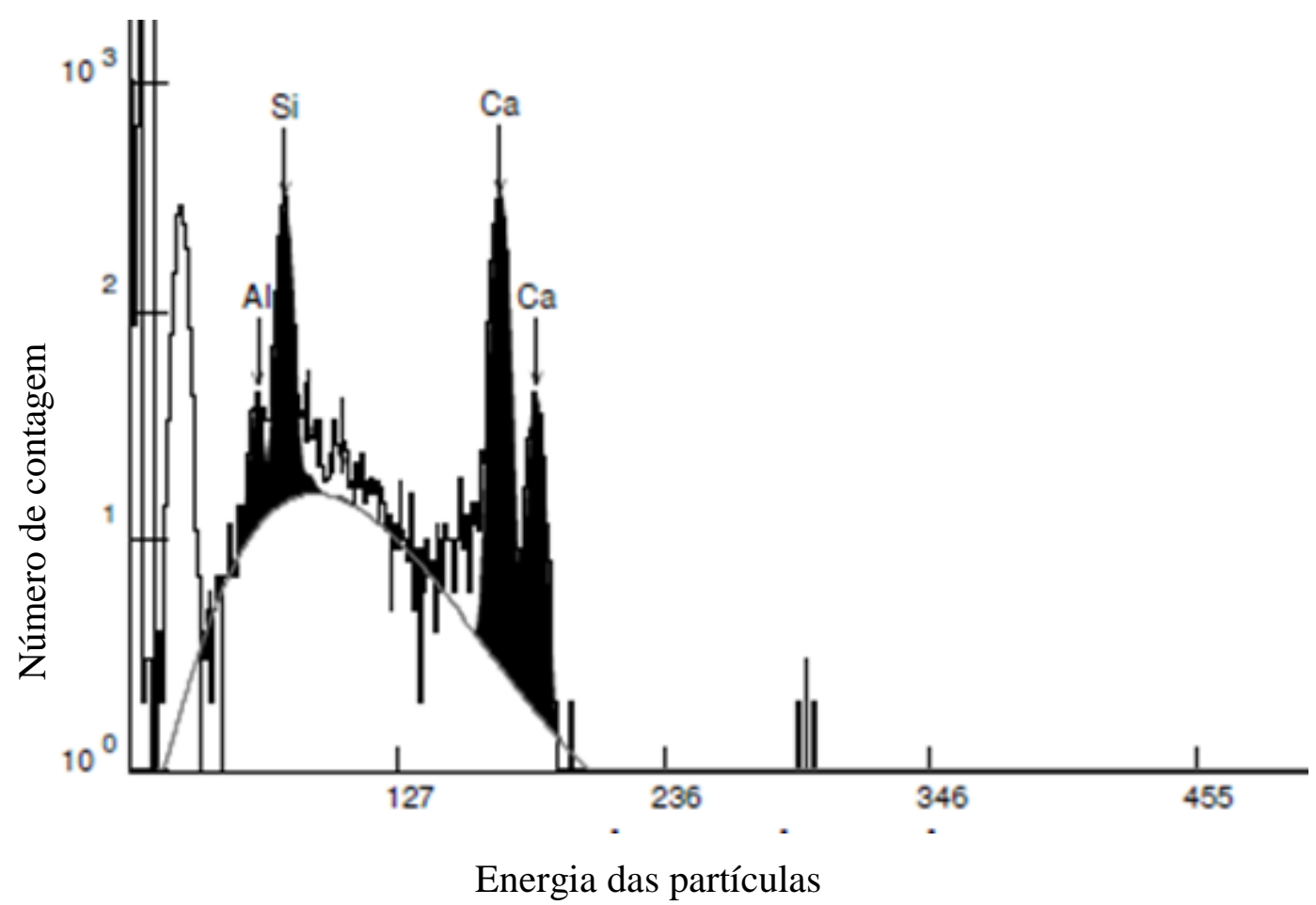

FIGURA 31 - Curva de composição da amostra de PA 6.6 sem tratamento utilizando o método PIXE

Na FIG. 32 são mostrados os resultados da análise por RBS, da amostra de PA 6.6 tratada por plasma e da amostra não tratada, na qual se observa os elementos $\mathrm{Fe}, \mathrm{K}, \mathrm{S}$ e Na. $\mathrm{Na}$ amostra não tratada não foram observados tais elementos.

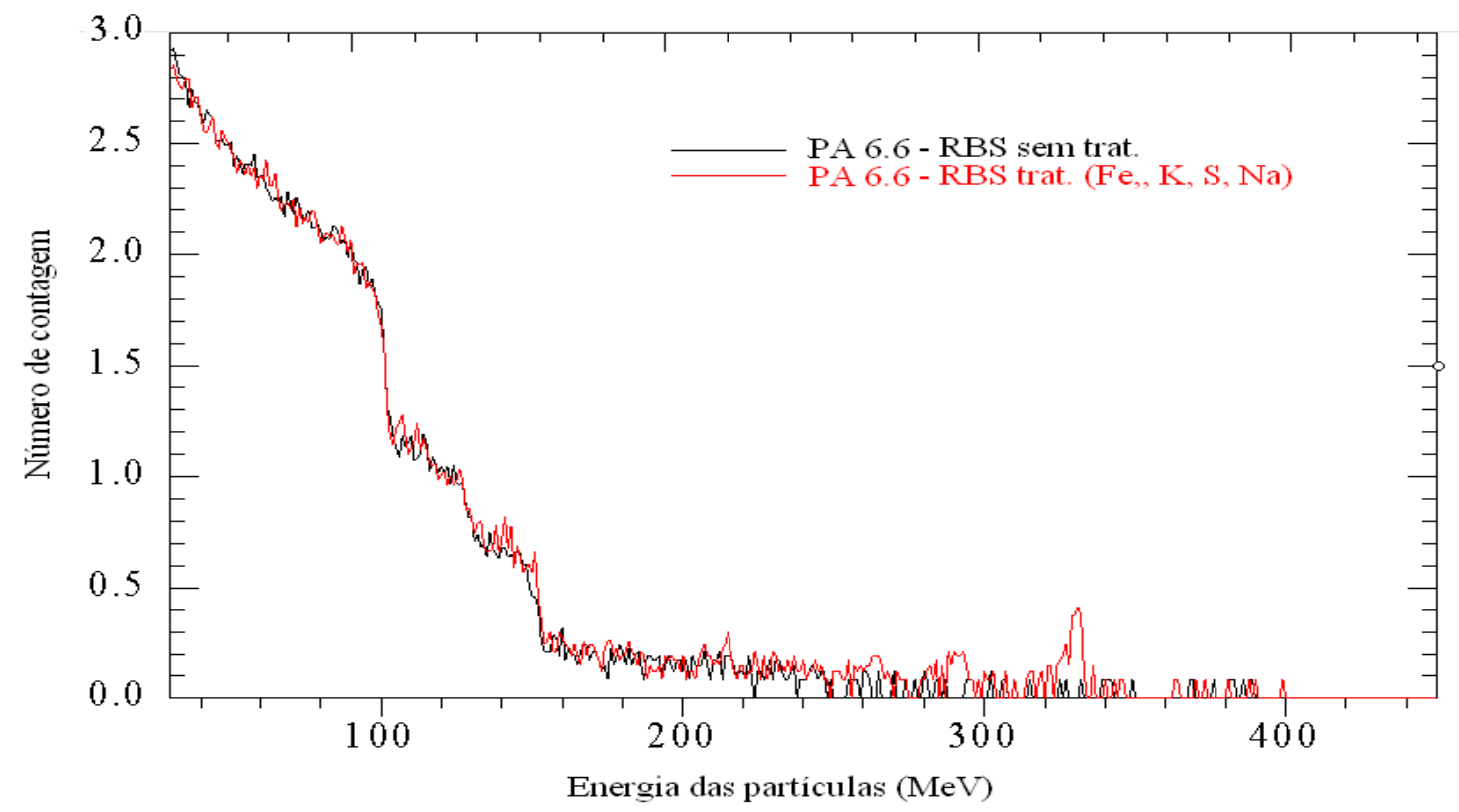

FIGURA 32 - Curva de RBS de comparação da amostra de PA 6.6 tratada por plasma e sem tratamento 
As amostras de PA 6.6 não tratadas, tratadas por plasma e por irradiação foram caracterizadas por meio da técnica de AFM.

As amostras tratadas por plasma apresentaram diferenças de topografia, como relevo e rugosidade em comparação às amostras não tratadas, conforme mostrado nas FIG. 33 e 34 .

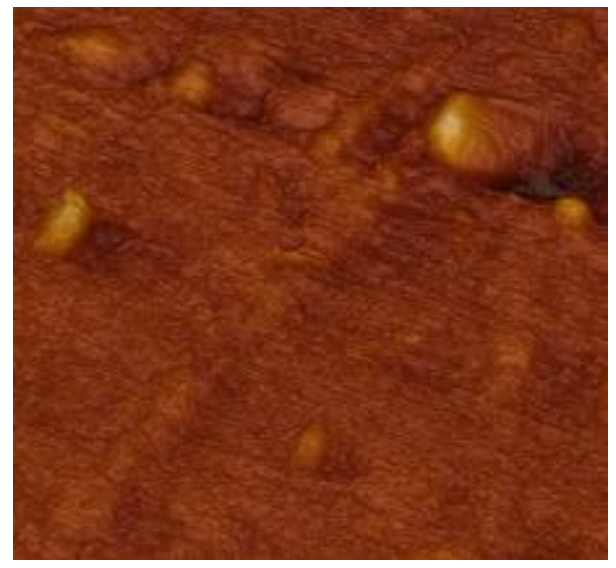

FIGURA 33 - Imagem de microscopia de força atômica da amostra de PA 6.6 sem tratamento

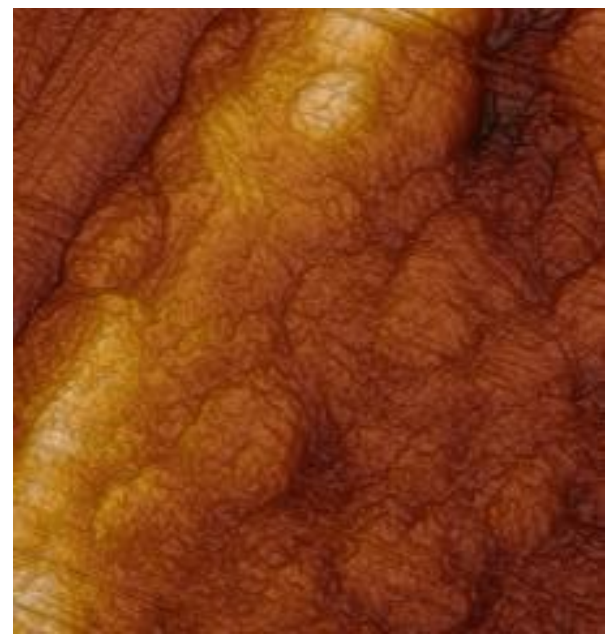

FIGURA 34 - Imagem de microscopia de força atômica da amostra de PA 6.6, após tratamento por plasma

As amostras irradiadas apresentaram discretas diferenças de topografia, no relevo e na rugosidade, dependendo da dose de radiação utilizada, comparadas às amostras não tratadas. A amostra irradiada com 10kGy e taxa de dose de 11,22 kGy/s tem a sua superfície muito parecida com a amostra não irradiada. As amostras irradiadas com 20 e 
40kGy e taxa de dose de 11,22 kGy/s apresentaram diferenças de relevo conforme mostrado nas FIG. 35, 36 e 37.

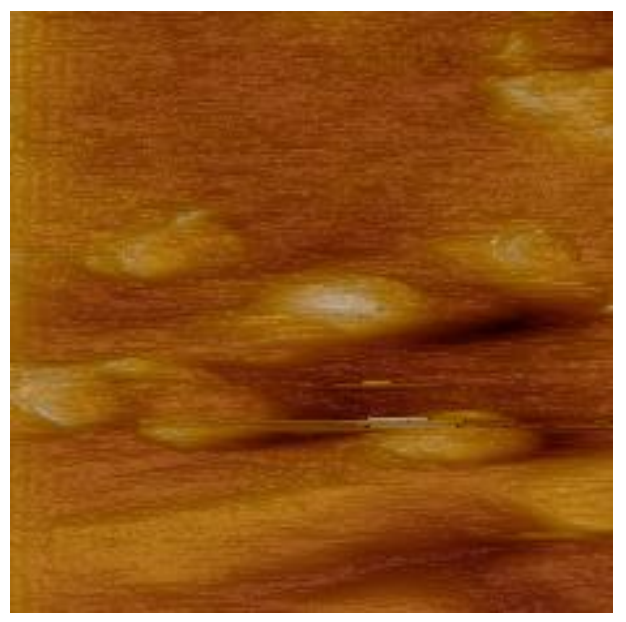

FIGURA 35 - Imagem de microscopia de força atômica da amostra de PA 6.6, após irradiação com dose de 10kGy e taxa de dose de 11,22 kGy/s

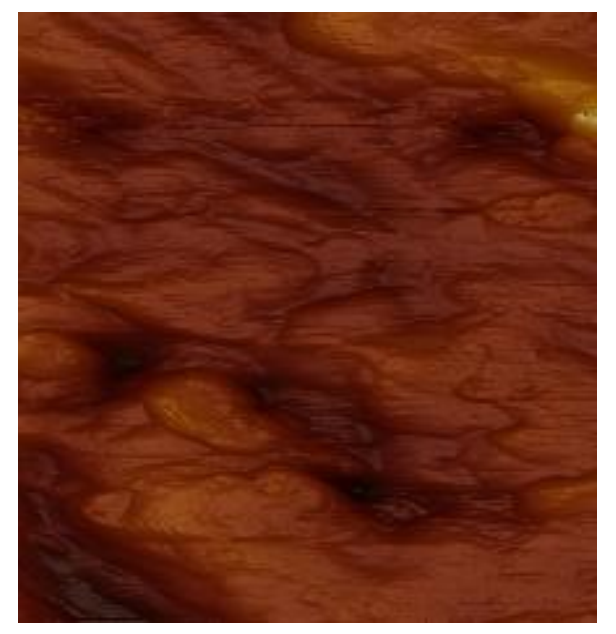

FIGURA 36 - Imagem de microscopia de força atômica da amostra de PA 6.6, após irradiação com dose de 20kGy e taxa de dose de 11,22 kGy/s 


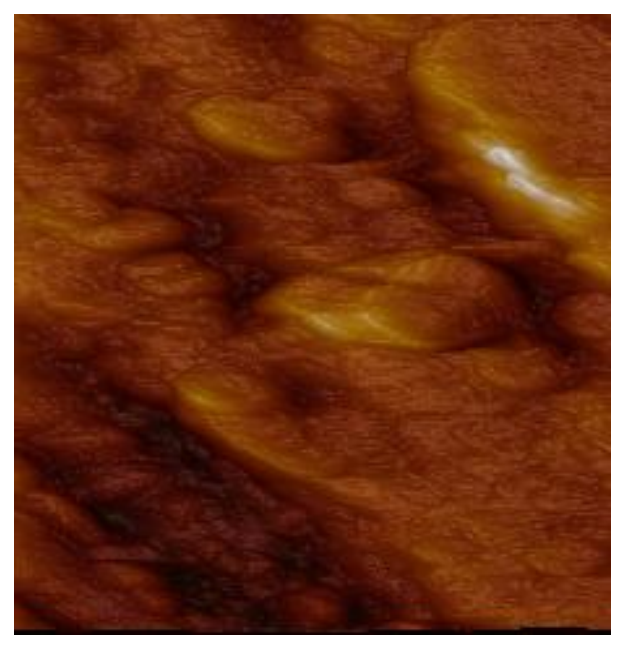

FIGURA 37 - Imagem de microscopia de força atômica da amostra de PA 6.6, após irradiação com dose de 40kGy e taxa de dose de 11,22 kGy/s

Ao aumentar a taxa de dose para 22,38 kGy/s aumentou-se, também, a rugosidade da amostra como mostrado na FIG. 38.

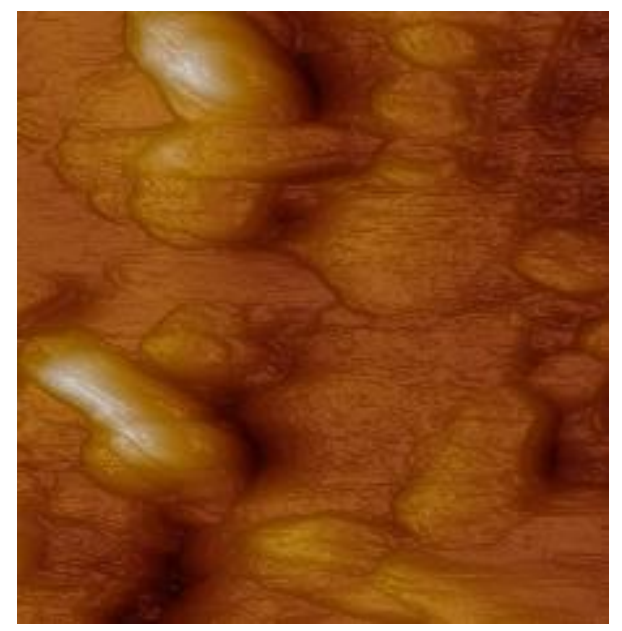

FIGURA 38 - Imagem de microscopia de força atômica da amostra de PA 6.6, após irradiação com dose de 20kGy e taxa de dose de $22,38 \mathrm{kGy} / \mathrm{s}$

As amostras de PA 6.6 não tratada, tratadas por plasma e por irradiação foram analisadas em um goniômetro, utilizando a técnica de medida de ângulo de contato. A amostra tratada por plasma, por ser mais hidrofílica, apresentou maior ângulo de contato quando comparada à amostra não tratada. A amostra irradiada também apresentou ângulo de contato maior que à amostra não irradiada, mostrando, desta forma, característica hidrofílica, conforme mostrado nas FIG. 39, 40 e 41. 


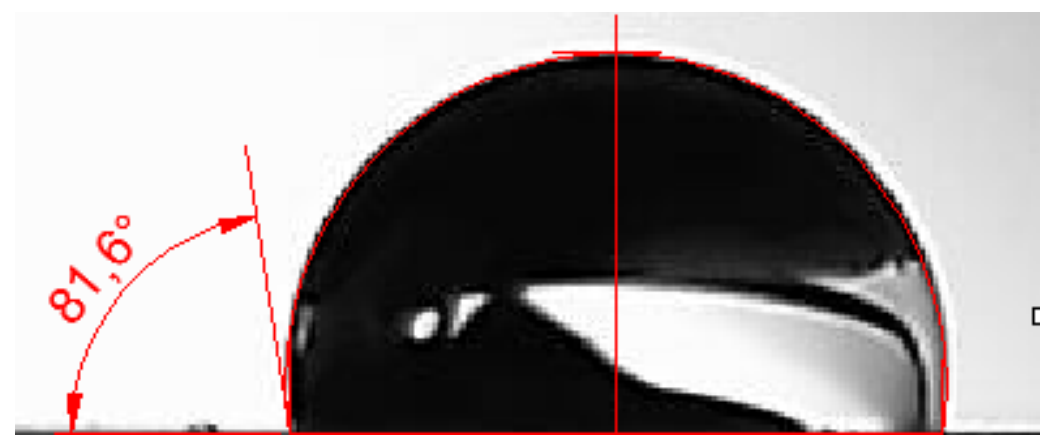

FIGURA 39 - Medida de ângulo de contato da amostra de PA 6.6 não tratada

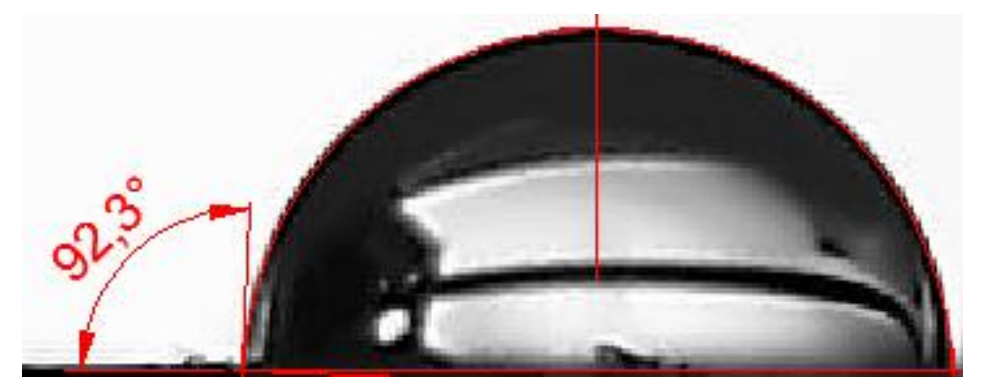

FIGURA 40 - Medida de ângulo de contato da amostra de PA 6.6, após tratamento por plasma

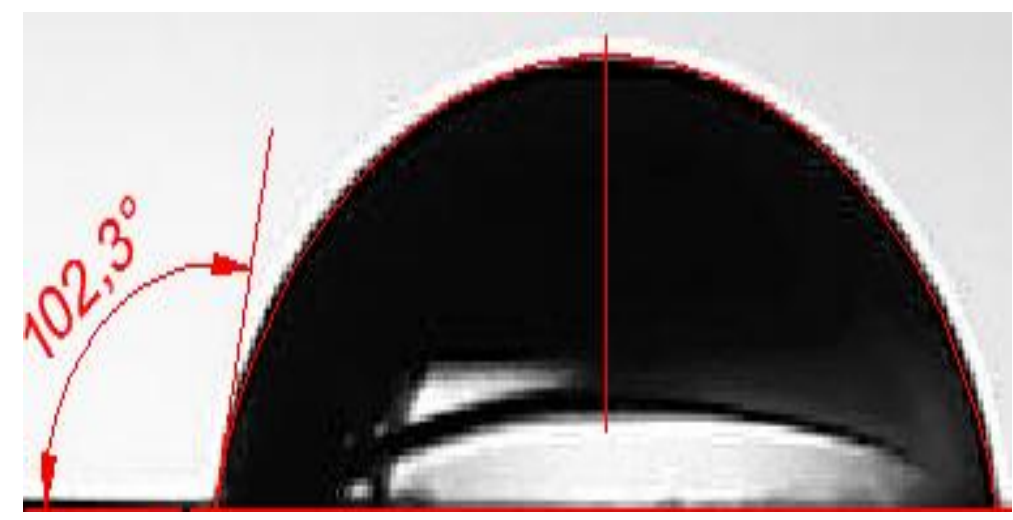

FIGURA 41 - Medida de ângulo de contato da amostra de PA 6.6, após tratamento por irradiação com dose de 40kGy e taxa de dose de 11,22 kGy/s 


\section{CONCLUSÃO}

O tratamento da poliamida PA 6.6 por plasma foi eficiente para aderência com a borracha poliacrílica. Porém, não se consegue identificar, por meio das técnicas de MEV, EDS, PIXE e RBS, a ocorrência de diferenças significativas que ocorrem na superfície da poliamida, após o tratamento que justifique a aderência, apenas pequenas alterações de rugosidade mostradas nas imagens de MEV. Os elementos novos que aparecem incorporados na amostra tratada identificados por meio das técnicas de PIXE e RBS estão associados à contaminação da amostra durante o manuseio dos processos.

Na técnica de FT-IR por absorção não observou-se alteração nos grupos e ligações químicas específicas após o tratamento por plasma, mas ocorreu diminuição de transmitância em todo o espectro resultado do depósito de material, após o tratamento por plasma.

Por outro lado, é possível observar mudanças de topografia, relevo e rugosidade nas amostras tratadas por plasma, utilizando a técnica MFA, indicando que o tratamento por plasma modifica a superfície do substrato, alterando sua rugosidade e melhorando a ancoragem com outras superfícies.

A superfície da PA 6.6 tornou-se hidrofílica, após o tratamento por plasma, característica confirmada por meio dos resultados das medidas de ângulo de contato. Essa característica também pode confirmar o aumento da resistência à adesão entre a poliamida 6.6 e a borracha poliacrílica.

Quanto às amostras de poliamida tratadas pelo processo de irradiação com feixe de elétrons não foram eficientes para que ocorresse a adesão entre a PA 6.6 e a borracha poliacrílica, embora, em algumas amostras observou-se alterações semelhantes às amostras tratadas por plasma, como por exemplo, aumento de rugosidade e aumento de ângulo de contato, com o aumento da taxa de dose. 
O tratamento das amostras de PA 6.6 pelo processo de irradiação com feixe de elétrons não foi eficiente na modificação da superfície para possibilitar a adesão entre a PA 6.6 e a borracha poliacrílica.

Para trabalhos futuros podem ser feitos estudos com doses de radiação diferentes das doses utilizadas nesse trabalho, assim como, condições diferentes de irradiação. Técnicas diferentes de caracterização de superfícies também poderão ser utilizadas para identificar possíveis mudanças nas superfícies, após os tratamentos. 


\section{REFERÊNCIAS BIBLIOGRÁFICAS}

ABURAYA, J. H. Padronização de análises PIXE de amostras sólidas em alvos espessos. 2005. Dissertação (Mestrado) - Instituto de Física, Universidade de São Paulo, São Paulo.

AMERICAN SOCIETY FOR TESTING AND MATERIALS, Standard Test Methods for Rubber Property - Adhesion to Rigid Substrates, 2003 (ASTM D 429).

AMERICAN SOCIETY FOR TESTING AND MATERIALS, Classification System for Rubber Materials for Automotive Applications, 2006 (ASTM D 2000).

BERNARDES FILHO, R.; MATTOSO, L.H.C. Estudo de polímeros por microscopia de força atômica. COMUNICADO TÉCNICO 53, ISSN 1517-4786, SÃO CARLOS, SP, Set., 2003.

BUZETO, F.A.; CAMPOS, J.S.C. Modificação do ângulo de contato de amostras de borracha natural submetida a tratamento por descarga corona. In: CONGRESSO CONAMET/SAM, 2004. Departamento de tecnologia de polímeros, FEQ, UNICAMP, Campinas, SP, Brasil. Proceedings... Campinas. CD-ROM.

CANAL, C.; MOLINA, R.; BERTRAN, E.; ERRA, P. Wettability, ageing and recovery process of plasma-treated polyamide 6. J. Adhesion Sci. Technol., v. 18, p. 1077-1089, 2004.

CANeVholo JR., S.V. Técnicas de Caracterização de Polímeros. 1. ed. São Paulo, S.P.: Artliber Editora, 2004.

PAQUIM, A.M.C.; BRETT, A.M.O. Microscopia de força atômica de moléculas de DNA adsorvida na superfície de HOPG. ARTIGO 57, Departamento de Química, Faculdade de Ciências e Tecnologia de Coimbra, Coimbra, Portugal, 2003. 
CONCISE ENCYCLOPEDIA OF POLYMER PROCESSING AND APLICATION; Radiations diffects on polymers. New York, N.Y.: Pergamom Press. p.581-588. 1992.

D’AGOSTINO, R. Plasma Deposition, Treatment, and Etching of Polymers. Itália, Bari: Academic Press, Inc., 1999.

DJALMA, B.D. Estudo da caracterização de espumas de polietileno reticulado pelo processo de irradiação com feixe de elétrons . 2007. Dissertação (Mestrado) - Instituto de Pesquisas Energéticas e Nucleares, São Paulo.

EVORA, M.C.C.; ANDRADE E SILVA, L.G. Electron beam radiation effects on recycled polyamide-6. In: INTERNATIONAL SYMPOSIUM ON UTILIZATION OF ACCELERATORS, November 26-30, 2001, São Paulo, SP, Brazil. IAEA-SM366...Viena: IAEA, 2001. p.111-112.

EVORA, M.C.C.; ROSSINI, E.L.; WIEBECK, H.; ANDRADE E SILVA, L.G. Estudo da degradação por envelhecimento artificial da poliamida 6 reciclada irradiada com feixe de elétrons. In : XV CONGRESSO BRASILEIRO DE ENGENHARIA E CIÊNCIA DOS MATERIAIS, November 9-13, 2002, Natal, RGN, Brasil. Proceedings... Natal: ABM, 2002a. 1 CD-ROM.

EVORA, M.C.C.; MACHADO, L.D.B.; LOURENÇO, V.L.; LOPÉRGOLO, L.C.; WIEBECK, H.; ANDRADE E SILVA, L.G. Caracterização da poliamida 6 reciclada irradiada por feixe de elétrons. Revista Brasileira de Pesquisa e Desenvolvimento, v. 4, n. 3, p. 703-708, 2002 b.

EVORA, M. C. C.; GONÇALEZ, O.L.; DUTRA, R.C.L.; DINIZ, M.F.; WIEBECK, H.; ANDRADE E SILVA, L.G. Comparação de Técnicas FTIR de Transmissão, Reflexão e Fotoacústica na Análise de Poliamida-6, Reciclada e Irradiada, Polímeros: Ciência e Tecnologia, v. 12, n. 1, p. 60-68, 2002c.

EVORA, M.C.C.; MACHADO, L.D.B.; LOURENÇO, V.L.; GONÇALEZ, O.L.; WIEBECK, H.; ANDRADE E SILVA, L.G. Thermal analysis of ionizing radiation effects on recycled polyamide 6. Therm. Anal. Cal., v. 67, n. 1-6, p. 327-333, 2003. 
FERREIRA, A.A.P.; YAMANARA, H. Microscopia de força atômica aplicada em imunoensaios. Química Nova, v. 29, n. 1, 2006.

FERRO, S. Nova fibra de vidro reforça poliamidas, Plástico Moderno, n. 323, Agosto de 2001.

FERRO, W.P.; SILVA, L.G.A. Ionizing radiation effect studies on polyamide 6.6 properties. Radiat. Phys. Chem., v. 71, p. 269-271, 2004.

GOLDSTEINS, J.; NEWBURY, D.; JOY, D.; ECHLIN, P.; JYMAN, C.; SAUYER, L.; MICHAEL, J. Scanning electron microscopy and X-ray microanalysis. 3. ed., Springer, 2003.

GORNI, A.A.A evolução dos materiais poliméricos ao longo do tempo. Revista Plástico Industrial, 2003.

GUPTA, M. C.; PANDEY, R.R. $\gamma$-Irradiation of Nylon 6, J. Polym. Sci., v. 26, p. 491-502, 1988.

INAGAKI, N.; TASAKA, S.; UMEHARA, T. Effects of surface modification by remote hydrogen plasma on adhesion in poly(tetrafluoroethylene)/copper composites. J. Appl. Polym. Sci., v. 71, n. 13, p. 2191-2200, 1999.

INAGAKI, N.; TASAKA, S.; INOUE, T. Surface modification of aromatic polyamide film by plasma graft copolymerization of glycidylmethacrylate for epoxy adhesion. Laboratory of Polymer Chemistry, Faculty of Engineering, Shizuoka University, 3-5 Johoku, Hamamatsu, 432 Japan, Nov., 1997.

LABORATÓRIO DE FILMES FINOS. Microscopia eletrônica de varredura com EDS e sistema de nonolitografia. Instituto de Física, Universidade de São Paulo, 2009. 
MALISKA, A.M. Microscopia eletrônica de varredura. Departamento de Engenharia mecânica, Universidade Federal de Santa Catarina.

MOURA, E.A.B.; ORTIZ, A.V.; WIEBECK, H.; ANDRADE E SILVA, L.G. Efeito da radiação gama sobre as propriedades mecânicas de materiais de embalagens plásticas flexíveis. In: XV CONGRESSO BRASILEIRO DE ENGENHARIA E CIÊNCIA DOS MATERIAIS, November 9-13, 2002. Natal, RGN, Brasil. Proceedings... Natal: ABM, 2002. 1 CD-ROM.

NETO, J.M.M. Molhamento e ângulo de contato. Fundação de Amparo à Pesquisa do Estado de Piauí - Governo do Estado do Piauí, 2004. Disponível em: <http://www.fapepi.pi.gov.br/ciencia > . Acesso em: 12 ago. 2010.

OLIVEIRA, C.S. Caracterização por microscopia de força atômica de camadas de lipídicas imobilizadas em superfície. 2007. Dissertação (Mestrado) - Universidade Federal de Santa Catarina, Santa Catarina.

ORION S.A. Tecnologia em borracha - retentores. Disponível em: <http://www.orionsa.com.br/produtos/index $>$. Acesso em: 10 mar. 2008.

RHODIA lança nova geração de poliamida ( nylon ) revolucionária. Jornal de Plásticos. junho de 2000, Disponível em: <http://www.jorplast.com.br/jpjun00/jun008.htm. > . Acesso em: 10 mar. 2008.

RUBBERTEC. Solução em vedação hidráulica e pneumática. Disponível em: <http://www.rubbertec.com.br/retentores.htm >. Acesso em: 10 mar. 2008.

SILVERSTEIN, R.M.; BASSLLER, G.C.; MORRILL, T.C. Identificação espectrométrica de compostos orgânicos. 3. ed. Rio de Janeiro, RJ: Editora Guanabara, 1979.

SINGH, L.P.; CHAUDHURI, N.K. Effect of gamma irradiation on nylon 6 films. In: SYMPOSIUM ON INDUSTRIAL POLYMERS AND RADIATION, February 12-14, 1979, Proceedings... Sardar Patel University, Vallabh Vidyanagar, Gujarat, 1979. 
SOCIETY OF AUTOMOTIVE ENGINEERS, Classification System for Rubber Materials for Automotive Applications, 2005 (SAE J 200).

TABACNIKS, M.H. Os elementos na matéria. 2005. Tese de Livre Docência - Instituto de Física, Universidade de São Paulo, São Paulo.

TIMUS, D.M.; CINCU, C.; BRANDLEY, D.A.; CRACIUN, G.; MATEESCU, E. Modification of some properties of polyamide 6 by electron beam induced grafting. Appl. Rad. Isot., v. 53, p. 937-944, 2000.

ULLOA, M.E.P. Estudo do efeito da radiação ionizante em compósitos de polipropileno/pó de madeira usando titanato de bário como agente de acoplagem. 2007. Dissertação (Mestrado) - Instituto de Pesquisas Energéticas e Nucleares, São Paulo.

VAN DER MAI, H.C.; STOKROOS, I.; SCHAKENRAAD, J.M.; BUSSCHER, H.J. Aging effects of repeatedly glow-discharged polyethylene: influence on contact angle, infrared absorption, elemental surface composition and surface topography. J. Adhesion Sci. Technol. v. 5, n. 9, p. 757-769, 1991.

WIEBECK H.; HARADA, J. Plásticos de Engenharia, São Paulo, SP.: Artiber Editora, 2005.

WOLF, F.G.; SANTOS, L.O.E.; FHILIPPI, P.C. Modelagem da molhabilidade sobre superfícies sólidas pelo método Lattice-Boltzmann baseado em medidores de campo. In: $3^{\circ}$ CONGRESSO BRASILEIRO DE P\&D EM PETRÓLEO E GÁS, 2004. Proceedings... 2004. CD ROM.

YIP, J.; CHAN, K.; SIN, K.M.; LAU, K.S. Study on the surface chemical properties of UV excimer laser irradiated polyamide by XPS, ToF-SIMS and CFM. Appl. Surf. Sci., v. 205, p. 151-159, 2003. 